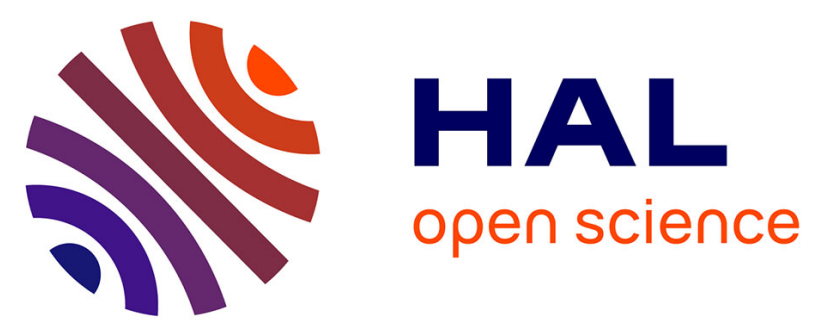

\title{
Organic Rankine Cycle based waste heat recovery modeling and control of the low pressure side using direct condensation and dedicated fans
}

Francesco Galuppo, Thomas Reiche, Vincent Lemort, P Dufour, Madiha Nadri

\section{- To cite this version:}

Francesco Galuppo, Thomas Reiche, Vincent Lemort, P Dufour, Madiha Nadri. Organic Rankine Cycle based waste heat recovery modeling and control of the low pressure side using direct condensation and dedicated fans. Energy, 2021, 216, pp.119074. 10.1016/j.energy.2020.119074 . hal-03401098

\section{HAL Id: hal-03401098 \\ https://hal.science/hal-03401098}

Submitted on 25 Oct 2021

HAL is a multi-disciplinary open access archive for the deposit and dissemination of scientific research documents, whether they are published or not. The documents may come from teaching and research institutions in France or abroad, or from public or private research centers.
L'archive ouverte pluridisciplinaire HAL, est destinée au dépôt et à la diffusion de documents scientifiques de niveau recherche, publiés ou non, émanant des établissements d'enseignement et de recherche français ou étrangers, des laboratoires publics ou privés. 
This document must be cited according to its final version which is published in a journal as:

F. Galuppo, T. Reiche, V. Lemort, P. Dufour, \& M. Nadri.

Organic Rankine Cycle based waste

heat recovery modeling and control of the low pressure side using direct condensation and dedicated fans,

Energy, 2021, 216, 119074. DOI : 10.1016/j.energy.2020.119074

You downloaded this document from the

CNRS open archives server, on the webpages of Pascal Dufour: http://hal.archives-ouvertes.fr/DUFOUR-PASCAL-C-3926-2008 


\section{Energy}

\section{Organic Rankine cycle based waste heat recovery modeling and control of the low pressure side using direct condensation and dedicated fans

\author{
--Manuscript Draft--
}

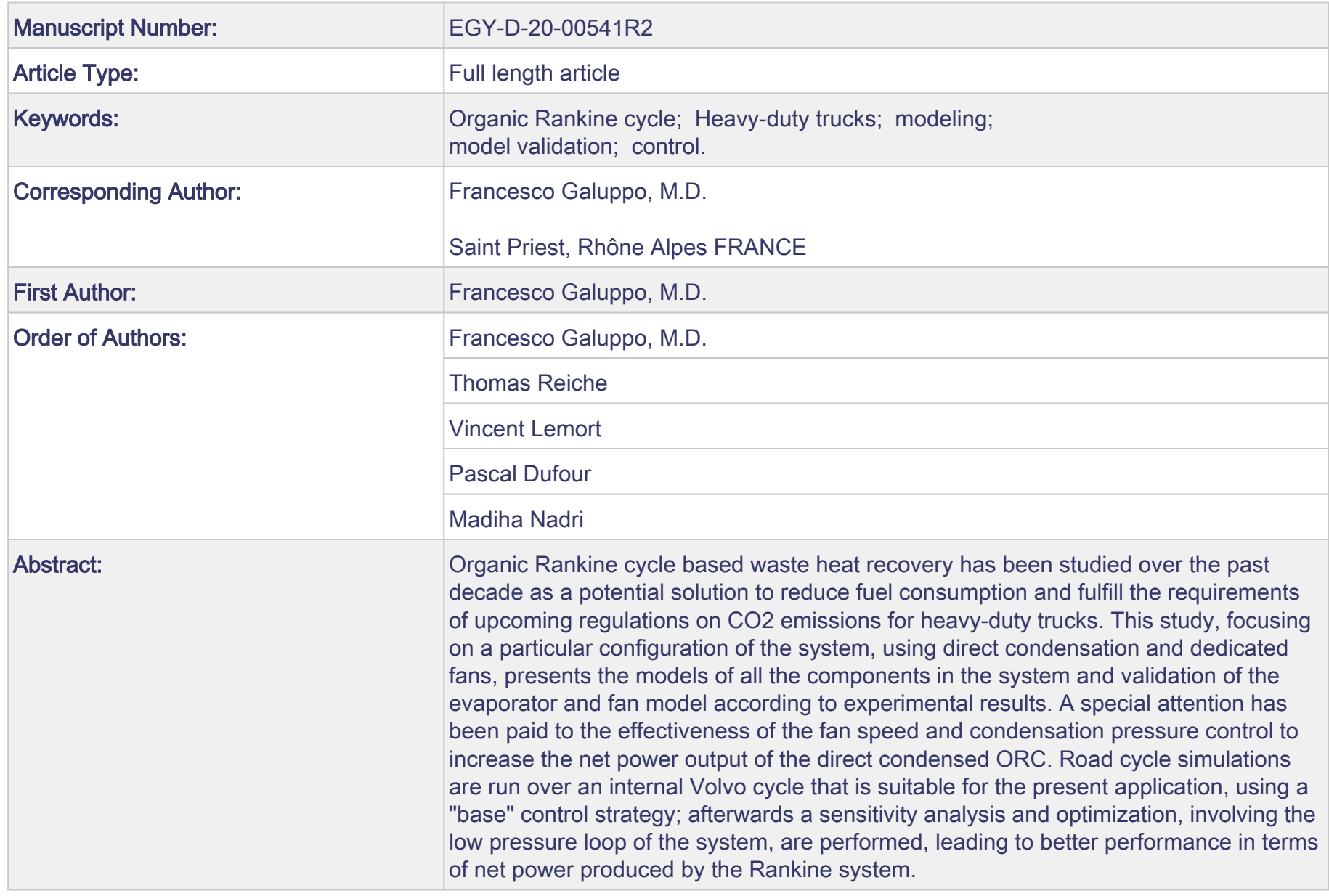


Dear Editor-in-Chief,

I am happy to submit our paper entitled "Organic Rankine cycle based waste heat recovery modeling and control of the low pressure side using direct condensation and dedicated fans".

This work is the result of our effort on modeling, control and design of the waste heat recovery architecture and it underlines the necessity to act on the control of the low pressure side in order to ensure the complete condensation and optimize performance. This topic, despite its big importance, is not sufficiently studied in the field of waste heat recovery in heavy-duty trucks.

With my best regards, Sincerely yours,

Francesco Galuppo, PhD Candidate 


\section{Declaration of interests}

$\bigotimes$ The authors declare that they have no known competing financial interests or personal relationships that could have appeared to influence the work reported in this paper.

$\square$ The authors declare the following financial interests/personal relationships which may be considered as potential competing interests:

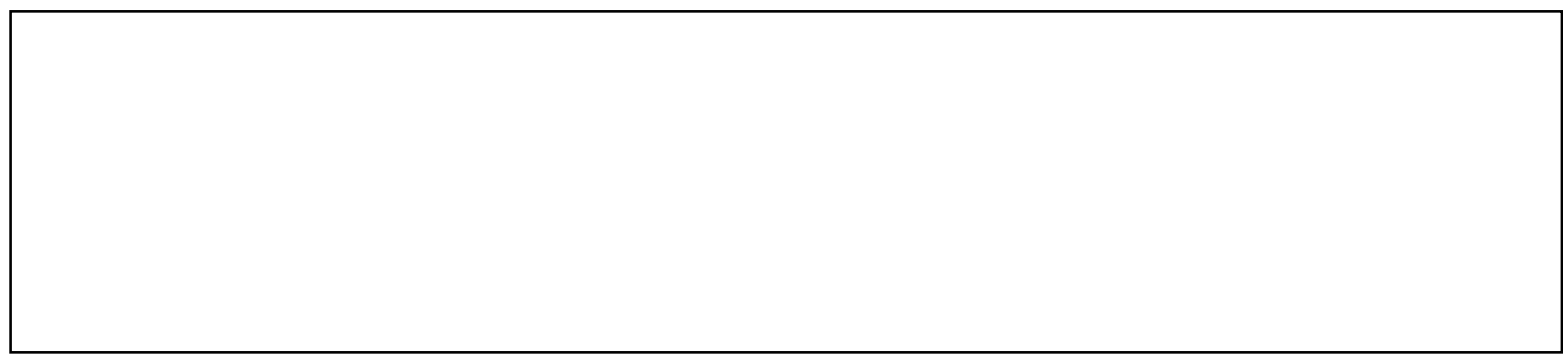


Francesco Galuppo: Writing, Modeling, Validation, Investigation, Writing- Reviewing and Editing

Thomas Reiche: Conceptualization, Methodology,

Data collection

Vincent Lemort: Methodology, Supervision,

Reviewing and Editing

Pascal Dufour: Software, Methodology, Supervision, Reviewing and Editing

Madiha Nadri-Wolf: Software, Methodology, Supervision, Reviewing and Editing 


\section{Highlights}

- Gain scheduling multi-model PI controller is useful for tracking superheat and subcooling

- Control of the condensation pressure is necessary to improve performance

- Higher condensation pressure is set at high load transients and high air temperature at the inlet of the condenser 


\section{Organic Rankine Cycle based waste heat recovery modeling and control of the low pressure side using direct condensation and dedicated fans}

July 28, 2020

\section{Introduction}

The recent European Union regulations for long-haul heavy-duty trucks, that set to $15 \%$ the reduction of $\mathrm{CO}_{2}$ emissions in 2025 with respect to the fleet baseline of 2019, pushed the automotive industry to adopt new effective to meet the new limits by decreasing the fuel consumption of the fleet (Rodriguez, 2018). The Organic Rankine Cycle (ORC) based waste heat recovery is considered one of the most promising technologies to reduce fuel consumption and increase the brake thermal efficiency of the vehicle (Wang et al., 2013); (Koeberlein, 2012); (Allain et al., 2012). The results of recent studies, supported by road cycle simulations and experimental campaigns, show an effective potential of the technology. (Zhao et al., 2018) claim an increase in thermal efficiency of $3.57 \%$ and a Break Specific Fuel Consumption (BSFC) reduction of $10.09 \mathrm{~g} / \mathrm{kWh}$ as a result of steady-state simulations, over different engine operating points, using GT-Suite and MATLAB/Simulink models, by recovering heat from exhaust gas. Extensive literature is available about constraints and limiting factors of the Rankine Cycle based waste heat recovery systems in long-haul heavy duty trucks: (Di Battista et al., 2018) investigated on the engine additional backpressure induced by the Rankine evaporator. (Karvountzis-Kontakiotis et al., 2017) studied the effects of the ORC on fuel economy of a heavy duty vehicle; the main focus of the analysis is a trade-off between the heat transfer area of the evaporator and the pressure drop that it imposes to the exhaust gas used as main heat source. The authors also identified the weight of the ORC system as one of the main limitations for the integration of the system in the vehicle. The final results show an optimal value when looking for a trade-off between exhaust back-pressure, ORC required net power and weight. (Hountalas et al., 2012) studied the problem of the rejection of excess heat of a ORC system, using exhaust gas flow as the main heat source. Adding the recuperation of the waste heat from the Exhaust Gas Recirculation flow (EGR) and a Charge Air Cooler $(\mathrm{CAC})$, the authors proved a further increase of the expander output power and in the same time a reduction of the thermal load in the cooling radiator, leading 
to the reduction of the fan power demand.

During the operation of a heavy duty truck in highway paths, external disturbances lead to a variation of the engine operating point and, consequently, to variable thermal power that can be recovered from the heat source. Therefore controllers are implemented in order to ensure at any time the suitable conditions of the working fluid (pressure, temperature, mass flow rate) in the system (and in particular at the inlet of the expansion machine and pump) and high standards of the system power production. (Grelet et al., 2015) compared the use of a non linear inverse model and a PI controller to track the set point of the temperature at the inlet of the expander; the inverse model leads to the best strategy. (Seitz et al., 2016) designed a feedforward controller, with online parameter adaptation, to control the temperature at the outlet of the evaporator; however according to the author the inverse model must be rechecked to increase the performance in highly transient situations. (Torregrosa et al., 2016) proposed an adaptive PID controller of the pump speed in a Rankine system fed by thermal power from a 2-liter gasoline engine; the adaptive gains are evaluated based on the working fluid temperature at the outlet of the evaporator and the estimation of the power released by the exhaust gas. A map based controller of the volumetric expander speed is also included. The controller is validated on test bench and, according to the authors, allows the control of the ORC in real driving conditions. Another example of feedforward controller designed to control the superheat (defined as the difference of the working fluid temperature and saturation temperature at the given pressure) at the inlet of the expander is presented by (Peralez et al., 2013); the authors used an inverse reduced model in the feedforward path and a gain-scheduling PID controller in the feedback path. Experimental results show a good performance of the controller, that allows to track the superheat set-point, set to the value of $40 \mathrm{~K}$. The same author in (Peralez, 2015) designed an energy monitoring algorithm addressed to the optimal control of a Rankine based waste heat recovery in a Diesel - electrical train; the condenser is cooled down by air and the condensation pressure is manipulated in high load transients in order to complete the condensation phase. The dynamic optimization shows an improvement of the net power produced that is higher with respect to static optimization strategies.

This last work that has been mentioned is a rare example of manipulation of condensation pressure in automotive waste heat recovery in literature, as most of the studies focus on the control of the working fluid conditions at the inlet of the expander to ensure high standards of power production of the system. In particular, direct condensation with air leads, in most of applications, to poor air mass flow rate at the inlet of the condenser. Therefore the increase of the condensation pressure is necessary to ensure the complete condensation of the working fluid. Additionally, in the applications consisting of a dedicated fan to supply the cooling air flow, the manipulation of the condensation pressure could be useful in terms of energy management, as the increase of the condensation pressure implies the reduction of the expander power of the system, but, in the same time, implies higher temperature difference between the working fluid and the air flow. Consequently a lower amount of air mass flow rate is needed to 
have the same working fluid condition at the outlet of the condenser; therefore the fan power demand is reduced as well. The reduction of the expander power production and the fan power demand could lead to an increase of the net power production of the system.

In this work, to design a model based control, a 1D finite volume model of the evaporator and direct condenser is firstly developed (both validated according to experimental results or data supplier), using MATLAB/Simulink. Furthermore, the complete model of the Rankine Cycle is proposed, as well as the model-based controllers. Particular attention is paid to the control of the subcooling of the working fluid at the inlet of the pump, by means of the dedicated fans speed and condensation pressure; additionally, a model-based optimization is run in order to find the best trade-off between the fans speed and the condensation pressure, ensuring the tracking of the subcooling and the maximization of the net power production of the Rankine system.

\section{Proposed Rankine architecture}

The Rankine Cycle architecture that is proposed in this work, presented in Fig. 1 , recovers heat from the exhaust gas flow and delivers electrical energy to the $48 \mathrm{~V}$ mild-hybrid drive-line. The pressure of the working fluid (in liquid state) is increased by a volumetric pump. The pre-heating, evaporation and superheating processes take place in the tailpipe heat exchanger. The working fluid is then expanded in the expander to produce useful work and the excess heat is rejected via the condenser, using ambient air as heat sink. This Rankine layout clarifies the possibility to manipulate the condensation (low) pressure in the system, via pressurized air stored in the dedicated air reservoir available in the vehicle; the control valve regulates the pressure of the air in the reservoir and, by consequence, the pressure of the working fluid. In the reservoir a membrane ensures the separation between the air and the working fluid, avoiding a drop in the performance and safety issues that appear in case of mixing. A similar system has been tested successfully and patented in order to ensure the desired condition of the working fluid at the inlet of the pump, avoiding its cavitation in all the operating points (Lutz et al., 2015); the main difference between the system presented here and the patented system is that in the latter an additional valve is installed between the reservoir and the Rankine line in order to have the possibility to disconnect the Rankine system and the reservoir. In order to improve the performance of the studied ORC, (Dickes, 2019) investigated on the sensitivity of the system to the charge of the working fluid in the system; the variation of the charge of working fluid is achieved by pressurizing an inert gas in a reservoir, connected to the Rankine line.

Fig. 2 clarifies the position of the Rankine system in the vehicle. The exhaust gas stream at the outlet of the Exhaust After Treatment System (EATS) flows in the Rankine system and cedes a portion of its thermal energy to the working 


\section{Nomenclature}

\begin{tabular}{|c|c|c|c|}
\hline \multicolumn{2}{|c|}{ Acronyms } & \multirow[t]{2}{*}{$c p$} & \multirow{2}{*}{$\begin{array}{l}\text { Specific Heat at Constant Pres- } \\
\text { sure }\left(\frac{\mathrm{J}}{\mathrm{kgK}}\right)\end{array}$} \\
\hline Bo & Boiling number & & \\
\hline \multirow{2}{*}{$B S F C$} & \multirow{2}{*}{$\begin{array}{l}\text { Break Specific Fuel Consump- } \\
\text { tion }\left(\frac{g}{k W h}\right)\end{array}$} & $D_{h}$ & Hydraulic diameter $(m)$ \\
\hline & & $h$ & Specific Enthalpy $\left(\frac{J}{k g}\right)$ \\
\hline$C A C$ & Charge Air Cooler & $K_{p}$ & Fan pressure coefficient \\
\hline \multirow[t]{2}{*}{$C F D$} & \multirow{2}{*}{$\begin{array}{l}\text { Computational Fluid Dynam- } \\
\text { ics }\end{array}$} & $K_{q}$ & Fan flow coefficient \\
\hline & & $K_{w}$ & Fan power coefficient \\
\hline Co & Convection number & $N$ & Rotational Speed (rpm) \\
\hline \multicolumn{2}{|c|}{$C O_{\text {ratio }}$ Cut-Off Ratio (-) } & $N u$ & Nusselt Number (-) \\
\hline$E G R$ & Exhaust Gas Recirculation & $\operatorname{Pr}$ & Prandtl Number (-) \\
\hline Err & Error (-) & $q$ & Vapor Quality (-) \\
\hline$F K$ & Frankfurt-Koblenz & Re & Reynolds Number (-) \\
\hline$F V$ & Finite Volume & $U$ & Specific Internal Energy $\left(\frac{J}{k g}\right)$ \\
\hline$I M C$ & Internal Model Control & $u$ & Model Input \\
\hline$M M P I$ & $\begin{array}{l}\text { Multi-Model proportional in- } \\
\text { tegral }\end{array}$ & $u_{c}$ & $\begin{array}{l}\text { Velocity in the minimum flow } \\
\text { area }(\mathrm{m} / \mathrm{s})\end{array}$ \\
\hline ORC & Organic Rankine Cycle & V & Volume $\left(m^{3}\right)$ \\
\hline$P I D$ & Proportional-Integral-Derivative & $V_{0}$ & Clearance Volume $\left(\mathrm{m}^{3}\right)$ \\
\hline$R A M$ & Air Intake & $w$ & Weight \\
\hline$S C$ & Subcooling $(K)$ & $x$ & State \\
\hline$S H$ & Superheat $(K)$ & $y$ & Model Output \\
\hline \multirow[t]{2}{*}{$S I M C$} & Skogestad Internal Model Con- & \multicolumn{2}{|c|}{ Subscripts } \\
\hline & trol & $c$ & Control \\
\hline$S P$ & Set-point & cond & Condenser \\
\hline & Working Fluid & cool & Coolant \\
\hline \multicolumn{2}{|c|}{ Greek letters } & $d$ & Derivative \\
\hline$\alpha$ & Heat Transfer Coefficient & $e q$ & Equivalent \\
\hline$\eta$ & $\begin{array}{l}\mathrm{kgm}^{2} \\
\text { Efficiency }(-)\end{array}$ & $e v$ & Evaporator \\
\hline \multirow[t]{3}{*}{$\psi$} & Ratio between two-phases and & $e x$ & Exit \\
\hline & single phase heat transfer coef- & $e x h$ & Exhaust gas \\
\hline & ficient & $\exp$ & Expander \\
\hline$\rho$ & Density $\left(\frac{\mathrm{kg}}{\mathrm{m}^{3}}\right)$ & expe & Experimental \\
\hline$\sigma$ & Standard Deviation & $g l$ & Global \\
\hline$\tau$ & Time Constant $(s)$ & $I$ & Integral \\
\hline$\theta$ & Delay $(s)$ & $p$ & Proportional \\
\hline$D_{h}$ & Transfer function & $P_{\text {red }}$ & Reduced Pressure (-) \\
\hline \multicolumn{2}{|c|}{ Latin letters } & sim & Simulated \\
\hline$\dot{m}$ & Mass Flow Rate $\left(\frac{\mathrm{kg}}{\mathrm{s}}\right)$ & $s p$ & Single phase \\
\hline$\dot{Q}$ & Thermal Power $(W)$ & su & Suction \\
\hline$\dot{W}$ & Mechanical Power $(W)$ & suit & Suitable \\
\hline C & Displacement $\left(m^{3}\right)$ & $V_{\text {cap }}$ & Volume Capacity $\left(m^{3}\right)$ \\
\hline
\end{tabular}




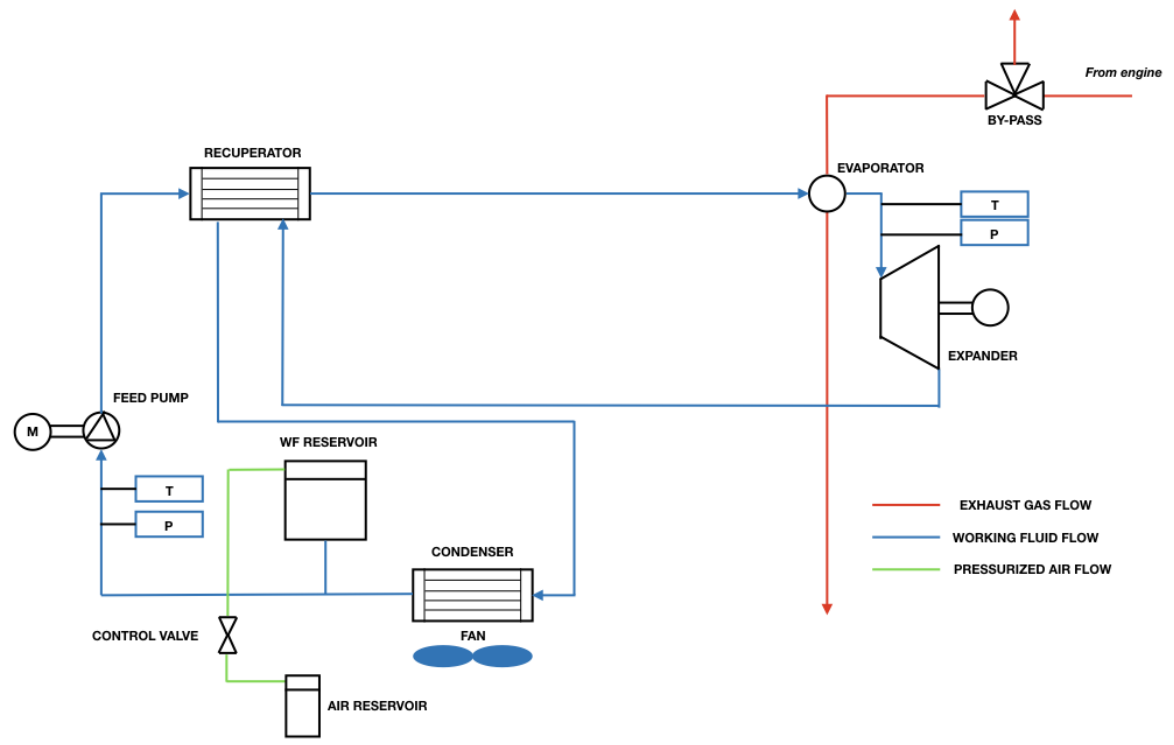

Figure 1: Rankine layout, recovering heat from exhaust gas, producing electrical power.

fluid in the evaporator. Additionally it can be noticed that the condenser and dedicated fans are placed on the side of the vehicle and the total cooling capacity is provided by the fan cooling airflow; consequently the removal of the excess heat from the condenser has no impact on the cooling system of the truck. The system produces electrical energy, therefore the expansion machine is coupled with a motor-generator electrical machine and it is mechanically disconnected from the drive-line. The working fluid is chosen in Sec. 2.2 following the analysis of the results of a simulation study where 4 different working fluids have been compared in terms of net power production of the system.

\subsection{Heat sources and sink}

Although several heat sources (such as engine coolant, EGR flow, Charge Air Cooler) are available on the vehicle for waste heat recovery applications, with different amount and variability of mass flow rate and temperature, in the proposed architecture the exhaust gas flow is used as the only heat source. The engine coolant is characterized by lower temperature (less than $100{ }^{\circ} \mathrm{C}$ ) and higher mass flow rate than the exhaust gas stream; the EGR flow is characterized by higher temperature and lower mass flow rate, as well as higher fluctuation of the available thermal power than the exhaust gas stream. Additionally 
Figure 2: Rankine system position in the truck (view from the top, not to scale).

(Grelet, 2016) observed that the heat source represented by the engine coolant flow is more interesting than the exhaust gas considering the first principle of thermodynamics, but results of a second principle of thermodynamic analysis show that the exhaust gas flow is the heat source that is characterized by the highest amount of exergy. This can be explained by noticing that the exhaust gas flow is at higher average temperature than the engine coolant flow.

In the current case study, the heat sink is represented by ambient air and no RAM Air Intake flow is supplied to the condenser, therefore the whole amount of air mass flow is provided by the electrically-driven fans. As already remarked, this architecture does not influence the cooling system of the truck, avoiding additional fan power demand of the cooling system (Galuppo et al., 2018b) because of the higher temperature of the air in the cooling package.

Moreover, the temperature of the cooling air, provided by the dedicated electricallydriven fans, at the inlet of the condenser has a strong impact on the overall performance of the system. Depending on the temperature of the cooling air, different strategies can be adopted to cool down the working fluid in the condenser, maximizing the net power production of the Rankine system. The strategies, that lead to a different handling of the condensation pressure and the rotating speed of the cooling fan, are presented and analyzed in Sec. 4.3.

\subsection{Working fluid selection}

The choice of the most suitable working fluid involves several aspects and performance is one of the major criteria; a working fluid should match well with 
the heat source, in order to reduce the exergy destruction and should be characterized by low heat of vaporization (Vaja and Gambarotta, 2010). Recently, (Preißinger et al., 2017) performed a computational chemical and thermodynamic selection among 72 millions of substances, to be used in an Organic Rankine Cycle recovering energy from internal combustion engine heat rejection; two different configurations of the ORC and three different cooling concepts were investigated. The multi-criteria evaluation considers thermodynamic aspects as well as regulations and safety issues and a trade-off occurs. Among the fluids with highest score, ethanol is present. In (Scaccabarozzi et al., 2018), the authors performed a working fluid selection and a cycle optimization based on thermodynamic and performance aspects. Among the organic fluids, cyclopentane is always considered as an optimal fluid.

Despite the numerous works about fluid selection, it is hard to recognize the best possible fluid to use in any waste heat recovery application for long-haul heavy-duty trucks (the architecture of the Rankine system strongly impacts the choice of the working fluids, (Guillaume and Lemort, 2019)). As for the Rankine system configuration that is presented in Fig. 1, the choice of the fluid is supported by an internal steady-state simulation work that considers the specific boundary conditions of the current architecture (heat source and sink) and the components that are used. In this work, four working fluids have been analyzed (cyclopentane, ethanol, Novec649 and R1233ZD) considering constant inputs, as the mass flow and temperature of the exhaust gas and the temperature of the air coolant flow. The size of the components is also considered as a constant input, because of packaging reasons.

On the other hand, specific parameters are changed because of the different nature of the working fluids. The lower heat of vaporization of Novec649 and R1233ZD leads to higher mass flow rate in the system. In the same time, the temperature and the density of both fluids in superheated conditions change very much as well with respect to cyclopentane and ethanol, affecting the operation of the expansion machine. One major change to be adopted in order to perform a fair comparison consists in the modification of the cut-off ratio of the volumetric expander (definition in Sec. 3.1.3), according to the temperature and the volumetric flow rate of the working fluid at the inlet of the expander. In order to take into account this feature of Novec649 and R1233ZD, the cutoff ratio of the expander is reduced as well as the set-point of the evaporation pressure; in this way it is possible to create the best operating conditions for the four fluids and then compare the different concepts as fairly as possible.

The performance analysis of the four working fluids is carried out in a specific operating point, $T_{e x h, s u, e v}=350^{\circ} \mathrm{C}$ and $\dot{m}_{e x h, s u, e v}=0.2 \mathrm{~kg} / \mathrm{s}$, found as the average of the exhaust mass flow rate and temperature provided by the 13-liter non-EGR engine driving a common highway road cycle and cooling air temperature $T_{\text {cool, su,cond }}=40{ }^{\circ} \mathrm{C}$; the performance is evaluated calculating the system net power produced $\dot{W}_{\text {net }}(1)$, that is obtained subtracting to the expander power produced $\dot{W}_{\text {exp }}$ the fan power $\dot{W}_{f a n}$ and pump power $\dot{W}_{\text {pump }}$ demand.

$$
\dot{W}_{n e t}=\dot{W}_{e x p}-\dot{W}_{f a n}-\dot{W}_{\text {pump }}
$$


The main variables results of the steady state simulations related to the four working fluids are listed in Tab. 1.

\begin{tabular}{cccccc} 
Fluid & $\rho_{\text {su,exp }}\left(\frac{\mathrm{kg}}{\mathrm{m}^{3}}\right)$ & $\dot{V}_{\text {su,exp }}\left(\frac{\mathrm{dm} \mathrm{m}^{3}}{\mathrm{~s}}\right)$ & $P_{\text {ev }}($ bar $)$ & $P_{\text {cond }}($ bar $)$ & NetPower $(k W)$ \\
\hline Cyclopentane & 61.2 & 1.410 & 25 & 3 & 3.76 \\
Ethanol & 35.5 & 1.135 & 25 & 2 & 3.69 \\
Novec649 & 235.1 & 1.895 & 16 & 3 & 2.26 \\
R1233ZD & 111.2 & 2.114 & 25 & 5 & 2.11 \\
\hline
\end{tabular}

Table 1: Main results of the simulation study basing on the different fluids.

The evaporation pressure set-point is 25 bar for ethanol, cyclopentane and R1233ZD, while the evaporation pressure of Novec649 is limited to 16 bar because of its lower critical pressure with respect to the other fluids; consequently, the expander power, as well as the net power produced by the system are reduced using Novec649. The condensation pressure that is set using the R1233ZD is higher than the values that are used for the other fluids because of the lowest normal boiling point of the R1233ZD among all the fluids that are currently considered; consequently the condensation pressure is raised in order to make feasible the removal of the excess heat from the condenser operating with the same cooling air temperature. The higher condensation pressure leads to a lower expander power produced, penalizing the global power balance of the system and reducing the net power produced.

Fig. 3 shows the different contributions of the net power produced (1); the reduced evaporation pressure of the Novec649 and the high condensation pressure of the R1233ZD lead to a lower expander power produced with respect to cyclopentane and ethanol and consequently to a lower net power produced.

Cyclopentane and ethanol are the best fluids for this specific architecture because their boiling points match better with the heat sink temperature and the design of the expander suits better with respect to the remaining fluids (according to the volumetric flow rate of the fluids at the inlet of the expander). However it can be noticed that the net power production of the system, using cyclopentane is higher, consequently cyclopentane is the selected working fluid for further analysis. 
Figure 3: Power demands and production of the Rankine system using the four fluids: the net performance of the Rankine system is evaluated subtracting the pump and fan power demand to the expander power produced.

\subsection{Actuators}

In order to deal with the disturbances induced by the road cycle, in terms of variation of mass flow and temperature of the heat source, controllers have to be implemented to adjust online specific important variables in the system. Indeed, as an example, a certain thermodynamic condition at the inlet of the expander and at the outlet of the condenser must be kept in order to avoid respectively liquid droplets in the expander and cavitation of the pump. In this process, the following five actuators are used as manipulated variables in different controllers:

- Feed pump speed, to control the thermodynamic conditions of the working fluid at the inlet of the expander

- Exhaust by-pass valve, that opens in case of over-temperature or overpressure of the working fluid

- Expander speed, to control the evaporation pressure

- Fan speed, to control the thermodynamic conditions of the working fluid at the outlet of the condenser

- Condensation pressure, to contribute to the control of the thermodynamic conditions of the working fluid at the outlet of the condenser, as well as to the improvement of the net power production of the system 


\section{Modeling}

Component models of the described Rankine architecture are developed and are implemented with the control algorithm in MATLAB/Simulink 2017. They are detailed in the following parts.

\subsection{Plant model}

The plant model is based on the interactions among the components of the Rankine and the thermodynamic state of the working fluid. The development of $1 \mathrm{D}$ models of the subsystems composing the plant model leads to the evaluation of physical relevant phenomena, as the thermal inertia in the heat exchangers, that are useful for the real assessment of the performance of the system.

This section shows the modeling approach of each component of the Rankine system and provides the validation of the evaporator and condenser models according to experimental results and data supplier; the plant that is presented in Fig. 9 uses cyclopentane as working fluid (that is selected as the most performing fluid for the current direct condensation architecture in Sec. 2.2) and pressure losses, as well as thermal losses are neglected in the current analysis.

\subsubsection{Pump model}

The pump model receives as input the pump speed from the controller and the pressure ratio, defined as the ratio between the evaporation pressure (supplied by the expander model, Sec. 3.1.3) and the condensation pressure that is determined by the dedicated controller.

The pressure at the outlet of the pump is calculated in the expander model, as the volumetric expander imposes the high pressure of the Rankine Cycle (assuming no pressure drops in the evaporator); the pressure at the inlet of the pump is a function of the mass flow rate (Sec. 4.3). As a function of the rotating speed $N_{\text {pump }}$, pressure ratio and displacement of the pump $C$, the model computes the mass flow rate of working fluid (2) and the pump power demand (3).

$$
\begin{gathered}
\dot{m}_{w f}=N_{\text {pump }} C \rho \\
\dot{W}_{\text {pump }}=\frac{\dot{m}_{w f}\left(h_{e x, i s}-h_{s u}\right)}{\eta_{g l, p u m p}}
\end{gathered}
$$

\subsubsection{Evaporator model}

The evaporator that is modeled and tested is a plate-fin heat exchanger, widely used in small-scale waste heat recovery applications (Lopes et al., 2012). Fig. 4 shows a frontal and side view of the evaporator as well as the inlet and outlet sections of the working fluid and exhaust gas; plates, where the working fluid

flows, are disposed in parallel with respect to the view from the top, therefore a counter-flow approach for modeling is fully justified. 
The model of the evaporator is a 1D finite volume (FV) model, where $N_{v o l}$ volumes are identified by discretizing the component along the longest dimension. In this application, the heat exchanger model is, as first approach, simulated as a standalone component, afterwards it is integrated into a complete Organic Rankine Cycle model and finally in a complete vehicle model, where cooling system, driver and all the mechanical components are modelled. Taking into account the frame of the work, the number of volumes $N_{v o l}$ is set to 10 , as a trade-off between accuracy and stability of the model and computational cost.

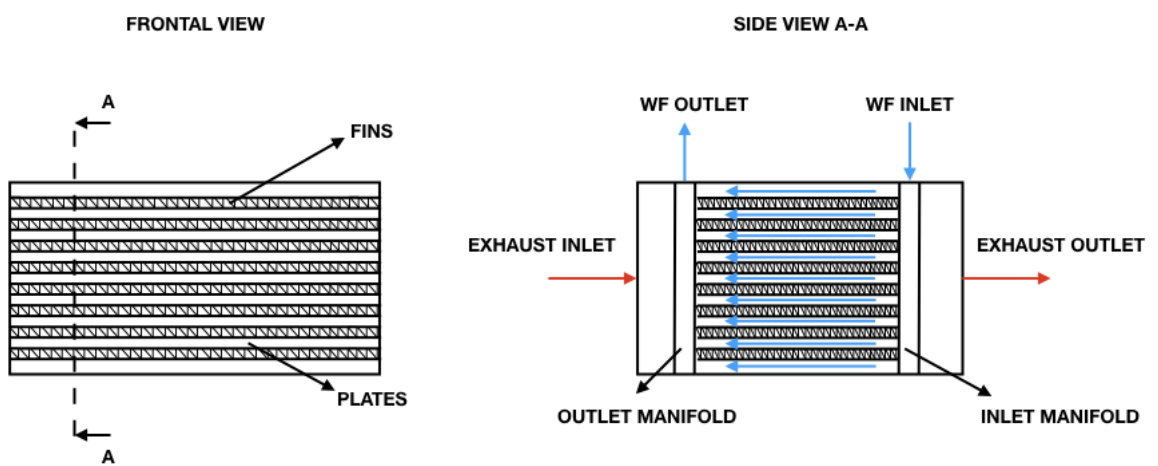

Figure 4: Frontal and side evaporator views; inlet and outlet of working fluid and exhaust flow as well as fins and plates are highlighted.

Fig. 5 shows that each volume is divided into three zones: the fluid side, the separation wall and the gas side. On the fluid and gas sides, mass and energy balance equations are applied in order to calculate the fluid state and the temperature of the exhaust gas at the outlet of each volume; in the separation wall the only energy balance equation is applied in order to calculate the average temperature of the wall in the specific volume. It can be noticed that the number of volumes is $N_{v o l}$ and the two nodes before and after the volume $i$ are named $i-1$ and $i$ respectively. In order to distinguish the volume variables from the node variables, the latter are denoted by a ' subscript. 


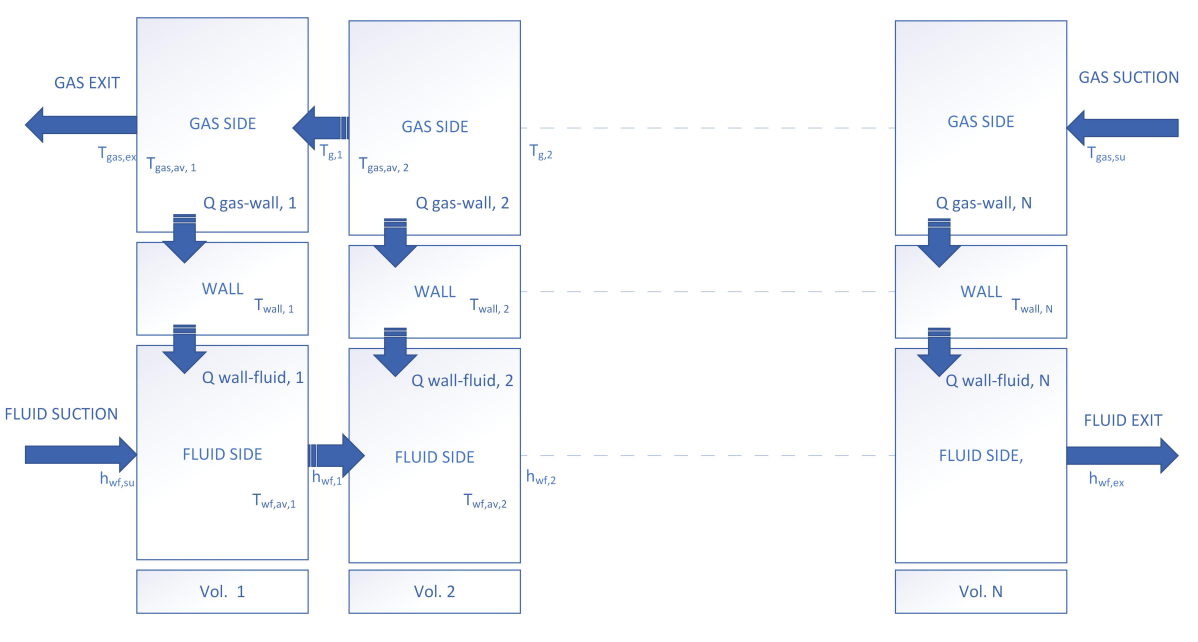

Figure 5: Discretization schema of the evaporator.

The discrete mass variation in time for each volume can be expressed by means of the differential of the enthalpy and pressure, as follows: (Quoilin, Sylvain, 2011):

$$
\frac{d M_{i}}{d t}=V \frac{\partial \rho}{\partial t}=V\left(\frac{\partial \rho}{\partial h} \frac{\partial h}{\partial t}+\frac{\partial \rho}{\partial p} \frac{\partial p}{\partial t}\right)=\dot{m}_{i}^{\prime}-\dot{m}_{i-1}^{\prime}
$$

The energy balance can be written as follows:

$$
\frac{d U_{i}}{d t}=\dot{m}_{i-1}^{\prime} h_{i-1}^{\prime}-m_{i}^{\prime} h_{i}^{\prime}+\dot{Q}_{i}+\dot{W}_{i}-p \frac{d V_{i}}{d t}
$$

Considering that no work is exchanged by the control volumes, using the definition of the internal energy $(U=H-p V)$ and the equation (4), the energy balance can be written as follow:

$$
\rho_{i} V_{i} \frac{\partial h_{i}}{\partial t}=\dot{m}_{i-1}^{\prime}\left(h_{i-1}^{\prime}-h_{i}\right)-\dot{m}_{i}^{\prime}\left(h_{i}^{\prime}-h_{i}\right)+\dot{Q}_{i}+V \frac{d p}{d t}
$$

Equ. (6) can be also written for the gas side considering that the enthalpy can be replaced by the product between the gas specific heat $c p$ and temperature $T$. The power balance equation applied to the wall is:

$$
\rho_{i} V_{i} c p \frac{\partial T_{i}}{\partial t}=\dot{m}_{i-1}^{\prime} c p\left(T_{i-1}^{\prime}-T_{i}\right)-\dot{m}_{i}^{\prime} c p\left(T_{i}^{\prime}-T_{i}\right)+\dot{Q}_{i}
$$

considering the specific heat $c p$ constant and the gas as incompressible fluid. The energy balance equation applied to the wall can be finally written as follows:

$$
M_{w} c p_{w} \frac{\partial T_{w, i}}{\partial t}=\dot{Q}_{g a s-w a l l, i}-\dot{Q}_{\text {wall-fluid }, i}
$$

In order to evaluate the heat transfer occurring between the exhaust gas and the fluid flow (via the internal wall of the heat exchanger) external and internal dimensions of the component are measured or calculated. In particular, the following geometrical data used in the evaluation of the heat transfer: 
- Heat transfer area for fluid and gas sides

- Flow section for fluid and gas

- Volume for fluid and gas sides

- Separation wall volume

The thermal power that is exchanged between the exhaust gas and the fluid can be calculated by $(9)$ :

$$
\dot{Q}_{t h}=A_{g l} U_{g l} \Delta T_{\text {suit }}
$$

$\Delta T_{\text {suit }}$ is a suitable temperature difference between exhaust gas and fluid (i.e. the mean logarithmic temperature difference) and the product $A_{g l} U_{g l}$ is the global heat transfer coefficient (Incropera et al., 1993). (9) can be written for each side of the heat exchanger by introducing the wall properties. Consequently the thermal power exchanged between the exhaust gas and the separation wall $\dot{Q}_{t h, g a s-w a l l}$ and between the separation wall and the fluid $\dot{Q}_{t h, w a l l-f l u i d}$ can be written respectively as in (10) and (11)

$$
\begin{gathered}
\dot{Q}_{\text {th,gas-wall }}=A_{\text {gas }} U_{\text {gas }} \Delta T_{\text {gas-wall }} \\
\dot{Q}_{\text {th,wall-fluid }}=A_{\text {fluid }} U_{\text {fluid }} \Delta T_{\text {wall-fluid }}
\end{gathered}
$$

The heat transfer coefficient $U$ should be determined for the gas and fluid. As reminded by (Quoilin, Sylvain, 2011), the gas heat transfer coefficient in singlephase flow is mainly dependent on the mass flow rate.

In this work, the heat transfer coefficient of the fluid is calculated taking into account the flow regime as well as the nature of the fluid; the Dittus-Boelter and the Shah correlations are used to calculate the Nusselt number (directly correlated to the heat transfer coefficient) respectively for single phase and twophase flow.

Dittus-Boelter correlation, according to turbulent flow in ducts (Winterton, 1998):

$$
N u_{s p}=0.023 R e_{D_{h}}^{0.8} \operatorname{Pr}^{0.4},
$$

where $R e_{D_{h}}$ is the Reynolds number calculated in the flow area fluid side and $\mathrm{Pr}$ is the Prandtl number. Then using Shah correlations ((Shah, 1976) for boiling flow (13) , (Shah, 1979) for condensing flow (14)), $N u$ is given by:

$$
N u=\left\{\begin{array}{l}
\psi N u_{s p} \\
N u_{s p}\left[(1-q)^{0.8}+\frac{3.8 q^{0.76}(1-q)^{0.04}}{P_{r e d}^{0.38}}\right]
\end{array}\right.
$$

where $\psi$ is a factor depending on the boiling number $B o$ and convection number Co defined in (Shah, 1976), $q$ is the quality of vapor and $P_{r e d}$ is the reduced pressure defined as the ratio of the actual fluid pressure to the critical pressure 
of the fluid.

Focusing on the evaporator, the experiments are realized in steady state condition in different engine operating points and consequently thermal power from 20 to $70 \mathrm{~kW}$. In each experiment the working fluid mass flow is adjusted in order to obtain the same superheat conditions at the outlet of the evaporator.

In the test bench the following variables can be measured:

- Mass flow rate of the working fluid by means of a Coriolis flow-meter at the outlet of the feed pump and mass flow rate of the exhaust gas by means of a Annubar flow-meter at the inlet of the evaporator

- Pressure on the fluid side by means of differential pressure sensors, at the inlet and outlet of the evaporator

- Temperature on the fluid side by means of thermocouples $\mathrm{T}$, one at the inlet and one at the outlet of the evaporator and on the gas side, three thermocouples $\mathrm{K}$ at the inlet of the evaporator and one at the outlet of the evaporator.

The thermal power exchanged between exhaust gas and working fluid has been plotted in Fig. 6. The error between the thermal power predicted by the model and measured from experiments, defined as in (15), is $0.51 \%$.

$$
E r r=100 \times\left\|\frac{\dot{Q}_{\text {expe }}-\dot{Q}_{\text {sim }}}{\dot{Q}_{\text {exp }}}\right\|
$$

Fig. 7 shows the prediction of the exhaust gas temperature at the outlet of the evaporator. In this case the absolute error of the prediction is $7.83 \mathrm{~K}$. Therefore, Fig. 6 and 7 show that the model is able to predict the performance of the evaporator.

\subsubsection{Expander model}

The considered expansion machine is a volumetric expander whose the following data are available:

- Clearance volume $V_{0}$ expressed in $m^{3}$

- The volume capacity $V_{c a p}$, expressed in $m^{3}$, that is the volume at the end of the expansion process

- The cut-off ratio $C O_{\text {ratio }}$, that is the fraction of the stroke that is involved in the admission process.

These data are useful to compute the volume at the end of the suction process, in other words the expander displacement, $V_{s}$, as shown in (16).

$$
V_{s}=V_{\text {cap }} C O_{\text {ratio }} .
$$




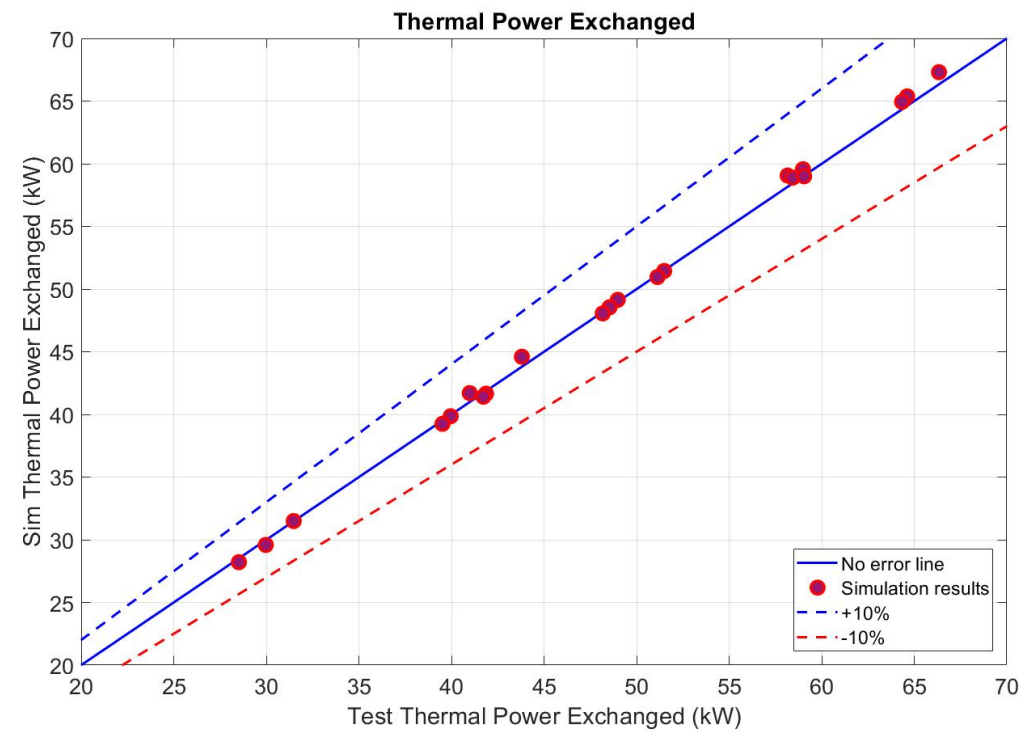

Figure 6: Comparison between predicted and measured thermal power exchanged in the evaporator.

Such an expander, rotating at variable speed, is responsible of the high pressure in the Rankine loop. The expander chambers accept in their volume a mass of working fluid that is function of the mass flow rate of the working fluid and its rotating speed. As a first approach, the density is calculated in the following time step $i+1$ as a function of the mass that is stored in the expander chambers in the time step $i$ for one revolution and the geometrical data of the machine :

$$
\rho(i+1)=\frac{\frac{\dot{m}_{w f}(i)}{N_{e x p}}(i)}{V_{\text {cap }} C O_{\text {ratio }}+V_{0}}
$$

where $i$ is the current time step.

The denominator of (17) represents the volume occupied by the working fluid at the end of the suction process, in other words when the supply valve closes. From density, calculated in (17) and temperature, calculated as the temperature at the outlet of the evaporator in the evaporator model, it is possible to obtain the pressure of the working fluid at the inlet of the expander. This information is also used by the pump model to consider the pressure ratio between inlet and outlet of the pump.

Once the state of the working fluid at the inlet of the expander is completely defined, it is possible to calculate, considering that the working fluid at the outlet of the expander is always in vapor state, the gross power production of the expander (18) taking advantage of the map of the total expander isentropic efficiency in Fig. (8) and the pressure at the outlet of the expansion machine: 


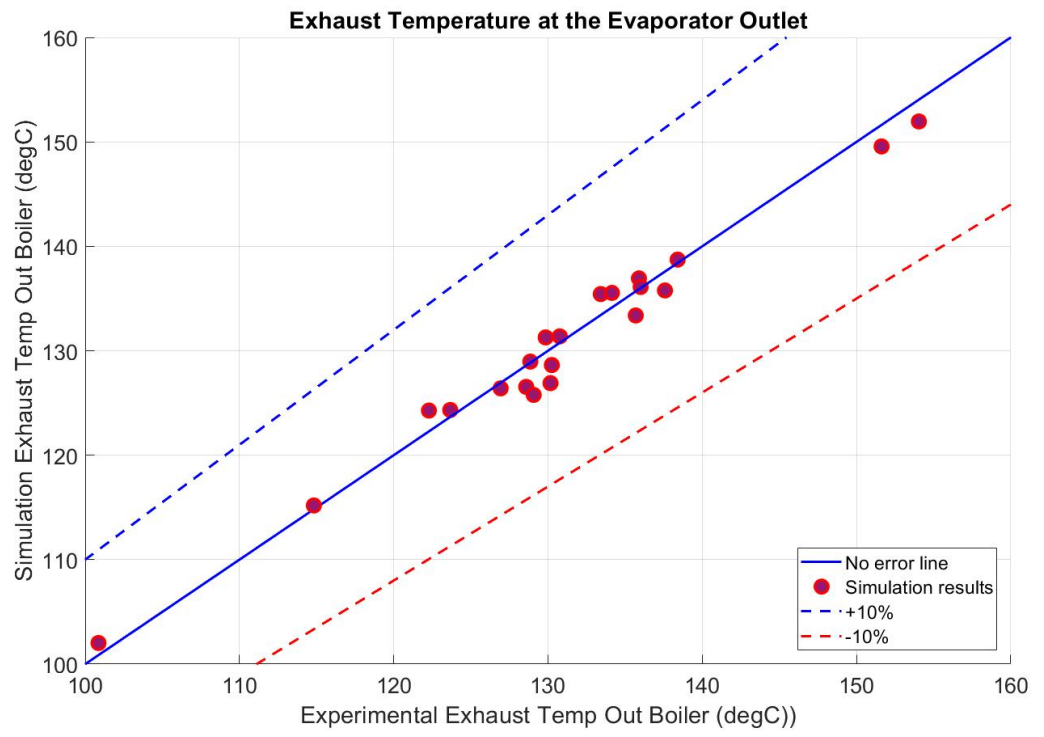

Figure 7: Comparison between the predicted and measured exhaust temperature at the outlet of the evaporator.

$$
\dot{W}_{g r o s s, \exp }=\dot{m}_{w f}\left(h_{s u, e x p}\left(T_{w f, s u, e x p}, p_{w f, s u, e x p}\right)-h_{e x, \exp }\left(T_{w f, \operatorname{ex}, \exp }, p_{w f, e x, \exp }\right)\right)
$$

\subsubsection{Direct Condenser and fan model}

The selected condenser is an aluminum heat exchanger made up of flat extruded tubes and of corrugated louvered fins. Assuming a perfect distribution of the cooling air on the surface of the condenser, it is possible to consider a cross-flow pattern as Fig. 9 shows.

The condenser model is obtained using a 1D finite volume (FV) discretization. Energy and mass balance conservation equations are applied to the gas side, fluid side and separation wall (eq. 4, 6, 7, 8.) The overall mass flow of cooling air is divided by the number of volumes adopted for the discretization and its outlet temperature is computed as the average of the outlet temperature of the cooling air from each volume.

In order to compute correctly the thermal power exchanged between the fluid and the wall, and between the wall and air flow, a geometrical analysis of the condenser is necessary. Geometrical data can be retrieved by calculations, once the fluid side and air side exchange areas are set (these data available from the supplier). In particular, the following data are retrieved or calculated: 


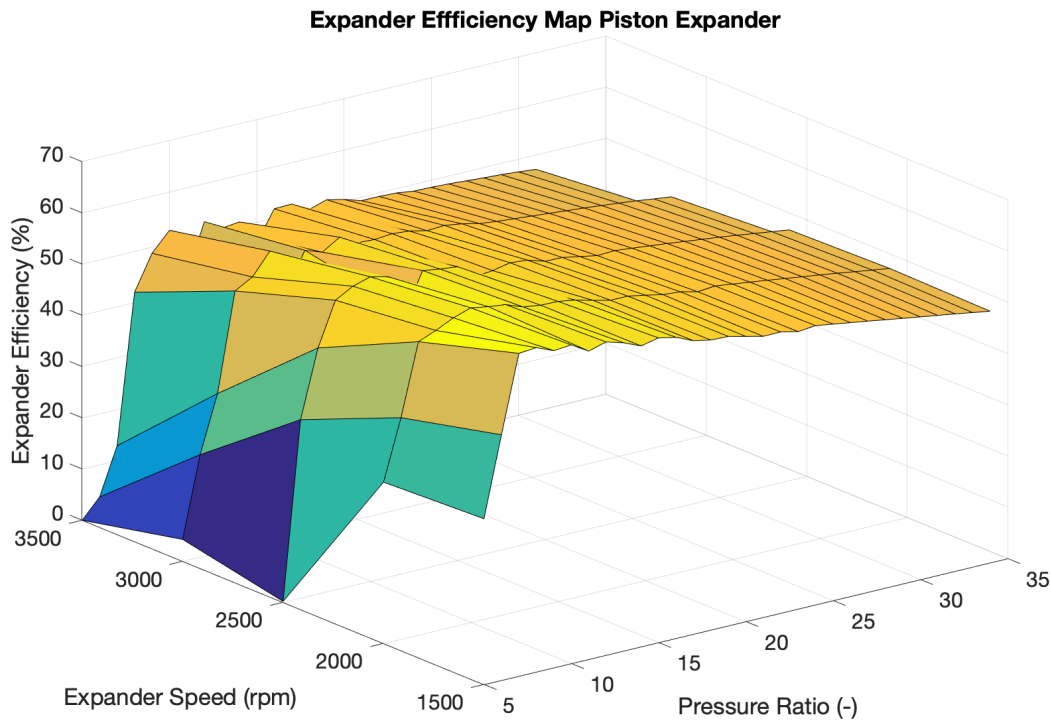

Figure 8: Total expander efficiency as a function of the pressure ratio and the expander speed.

- Number of tubes

- Fin density $\left(\frac{N_{f i n}}{d m}\right)$

- Heat transfer area for fluid and gas sides

- Flow section for fluid and gas

- Volume for fluid and gas sides

- Separation wall volume

Considering the fluid side, the fluid flows in channels that are obtained in the tubes; according to the classification of (Kandlikar, 2002), channels of the size between 0.2 and $3 \mathrm{~mm}$ are considered as mini-channels Here the mini channels have a rectangular section. Using this data and knowing the fluid side heat exchange area, it is possible to compute the fluid flow area and the number of mini channels per tube. These data are useful for the definition of the flow regime and calculation of the heat transfer coefficients in single phase and two-phase ((12), (14)). Regarding the air side, several other studies have been conducted in the last decades (Chang and Wang, 1997), (Chan Kang and Jun, 2011), (El Hajal et al., 2003). For this work, the correlation proposed by (Chan Kang and Jun, 2011) has been chosen because of the wide combination of different geometries of louvers and fins that have been investigated. The empirical correlations 
WF CONDENSER SUCTION

allow to compute the Colburn number $j$ and the friction factor $f$ (Fig. 10.a), that are useful to find respectively the heat transfer coefficient on air side $h_{a s}$ (Fig. 10.b) and the the pressure drop of the air through the condenser. In this work, we consider that the Colburn number $j$ and heat transfer coefficient $h$ are correlated as follow (Chan Kang and Jun, 2011):

$$
j=\frac{\eta_{f i n} h P r^{2 / 3}}{\rho u_{c} c p},
$$

where $\eta$ is the fin efficiency, $c p$ is the specific heat of the air at constant pressure and $u_{c}$ is the velocity of the air in the louver section (minimum flow section). The heat transfer coefficient and the air pressure drop as a function of the Reynolds number are shown in Fig. 10.b.

Fig. 10.a and 10.b show coherent results according to literature in terms of absolute values and variation with the Reynolds number.

Fan suppliers provide the fan curve, which expresses the static pressure $(\Delta P)$ variation through the fan as a function of the volumetric flow rate $\left(\mathrm{m}^{3} / h\right)$ at nominal speed. Curves at other speeds can be modeled thanks to the Fan Laws (20) (Kanefsky et al., 1999). Plotting in the same graph the fan curves at different fan speeds and the pressure drop curve characteristic of the condenser, it is possible to identify the intersections, hence the operating points of the system. The condenser model predicts the condenser pressure drop from data supplier with a relative error of $1 \%$ in the range of interest of volume flow rate (Fig. 11).

$$
\left\{\begin{array}{l}
\dot{Q}=K_{q} D^{3} N \\
\Delta P=K_{p} D^{2} N^{2} \rho \\
\dot{W}=K_{w} D^{5} N^{3} \rho
\end{array}\right.
$$




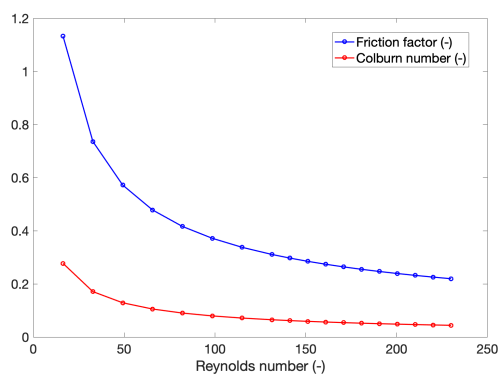

(a) $f-j$

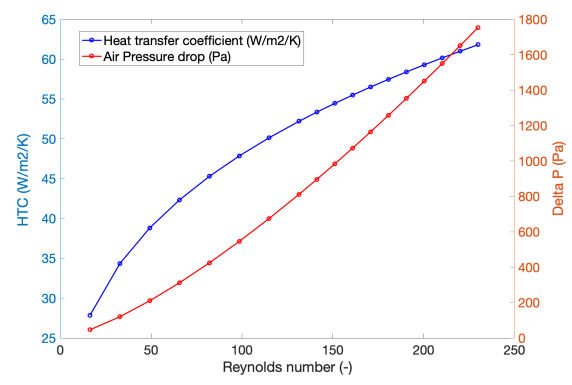

(b) $h-\Delta P$

Figure 10: (a) Friction factor and Colburn number as a function of the Reynolds number calculated in the minimum flow section (louver section). (b) Heat transfer coefficient and pressure drop as a function of the Reynolds number calculated in the minimum flow section (louver section).

where $K_{q}, K_{p}, K_{w}$ are the flow, pressure and power coefficients, $D$ is the fan diameter, $N$ is the fan speed.

\section{Base control strategy}

The main actuators of the proposed Rankine system have been already mentioned in Sec.2.3. In this section the control strategy that is adopted for each actuator is described.

The linear models that are adopted for control are Single Input Single Output (SISO) that can be written in the form:

$$
\begin{aligned}
& \dot{x}=f(x, y) \\
& y=g(x, u),
\end{aligned}
$$

where $x \in \mathcal{R}^{n}$ is the state, $u \in \mathcal{R}^{n_{u}}$ the input variable and $y \in \mathcal{R}^{n_{y}}$ is the output variable and $f$ and $g$ are two vector functions with appropriate dimension.

Considering the control of the thermodynamic conditions of the working fluid at the inlet of the expander, the variable $u$ is represented by the pump speed and the variable $y$ is represented by the specific variable that is necessary to keep close to a set-point by acting on the pump speed.

The same approach is not applicable, for the presented architecture and the purpose of control, for the control of the thermodynamic conditions at the outlet of the condenser; in this case, the considered system is treated as a Multiple Input Single Output (MISO), as the manipulated variables are the rotating fan speed and the condensation pressure. Sec.4.3 shows how the problem is treated in order to ensure good control performance and power production. 


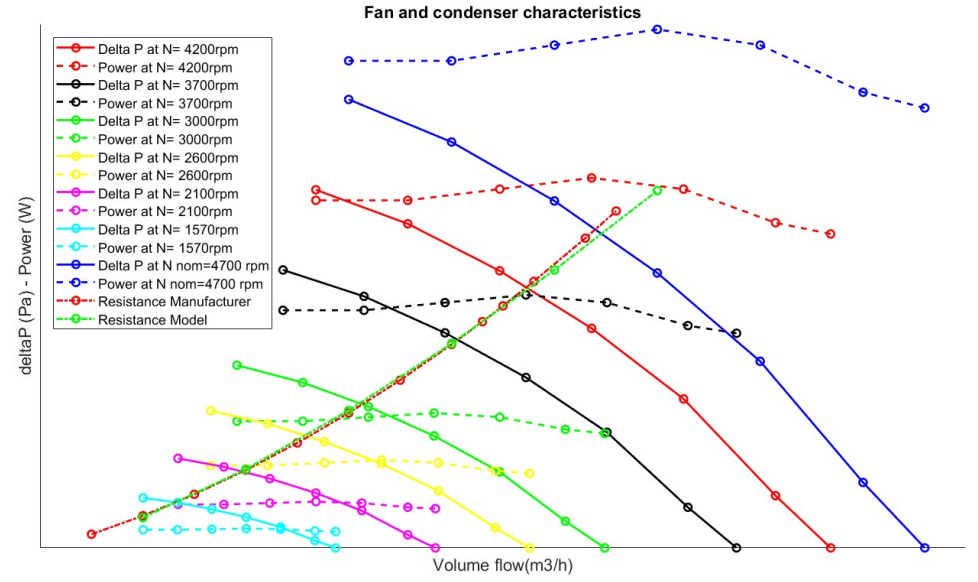

Figure 11: Fan static pressures and power demands at different fan speeds and condenser pressure drops. The condenser pressure drop is predicted (green resistance line) with an error of $1 \%$ with respect to the supplier data (red resistance line).

\subsection{Superheat control}

The control of the superheat $S H_{\text {su,exp }}$ is necessary to control the thermodynamic conditions of the working fluid at the inlet of the expander, ensuring performance and safe operation of the component.

$$
S H_{s u, e x p}=T_{s u, e x p}-T_{s a t}\left(P_{e v}\right) .
$$

The superheat must be kept at a positive value in order to ensure vapor supply to the expander. The set-point is tracked varying the pump speed, consequently the working fluid mass flow rate is changed.

In this work, a Multi Model PI controller is used, where the structure of the algorithm has been presented by (Grelet, 2016). The determination of the parameters of the PI control is usually a key aspect to ensure high performance of the controller; meta-heuristic approaches are available for such a goal, as the novel grouped grey world optimizer and democratic joint operation algorithm proposed in (Yang et al., 2017) and (Yang et al., 2018) and applied to a wind energy conversion system. In both cases, those strategies, according to the results, allow a larger amount of wind energy, lower tracking error and control costs with respect to other algorithms.

In this work, a step and response experimental campaign has been performed in different operating points chosen using the algorithm proposed in (Galuppo et al., 2018a). In general, it is possible to write a discrete nonlinear model in the form (24), for one operating point. 


$$
\left\{\begin{array}{l}
x(k+1)=f(x(k), u(k)) \\
y(k)=g(x(k), u(k))
\end{array}\right.
$$

with $y \in \mathcal{R}^{n_{y}}$ the measured outputs, $u \in \mathcal{R}^{n_{u}}$ the measured inputs. A set of local linear models can be written as (25)

$$
\left\{\begin{array}{l}
x_{i}(k+1)=f_{i}\left(x_{i}(k), u(k)\right) \\
y_{i}(k)=g_{i}\left(x_{i}(k), u(k)\right)
\end{array}\right.
$$

each tuned to approximate (24) around an operating point. To obtain a global model, these local models have to be combined. The chosen approach is to construct a global model by linearly interpolating between the local models:

$$
\hat{y}(k)=\sum_{i=1}^{N} w_{i}(k) y_{i}(k)
$$

Here, the weights $w_{i}$ provide a time-varying adaptation and they are calculated according to Bayesian estimators as in (Aufderheide and Bequette, 2003). As shown in (Galuppo et al., 2018a), the relationship between pump actuator and superheat at evaporator outlet can be modeled locally by a low order linear system around an equilibrium point; a first order plus time delay model (FOPTD) is used (27)

$$
\frac{y_{u}(s)}{u(s)}=\frac{G_{u}}{\left(1+\tau_{u} s\right)} e^{-L_{u} s}
$$

The Bayesian estimator identifies a single set of FOPTD parameters that are composed of an equivalent static gain $G_{e q}$, time constant $\tau_{e q}$ and delay $\theta_{e q}$ and computed as in (28).

$$
\left\{\begin{array}{l}
G_{e q}=\sum_{i=1}^{N} w_{i, k} G_{i} \\
\tau_{e q}=\sum_{i=1}^{N} w_{i, k} \tau_{i} \\
\theta_{e q}=\sum_{i=1}^{N} w_{i, k} \theta_{i}
\end{array}\right.
$$

where $N$ is the total number of FOPTD models (37 in the current application). In Tab. 2, the equivalent mean values of the FOPTD time varying parameters over a complete road cycle are shown, as well as their standard deviations.

Table 2: FOPTD parameters, statistical analysis.

\begin{tabular}{ccccccc} 
Weighting scheme & $\bar{G}$ & $\bar{\tau}$ & $\bar{\theta}$ & $\sigma(G)$ & $\sigma(\tau)$ & $\sigma(\theta)$ \\
\hline Bayesian & -0.37 & 9.10 & 0.54 & $2.3 \mathrm{e}-3$ & $3.6 \mathrm{e}-2$ & $3.9 \mathrm{e}-4$ \\
\hline
\end{tabular}

For each time step, a PID controller is tuned using the equivalent FOPTD model, applying the SIMC approach proposed by (Skogestad, 2006), where one 
additional tuning parameter $\tau_{c}$ is required to govern the desired closed-loop time response (29).

$$
\left\{\begin{array}{l}
K_{p}=\frac{1}{G_{e q}} \frac{\tau_{e q}}{\tau_{c} \theta_{e q}} \\
T_{I}=\min \left(\tau_{e q}, 4\left(\tau_{c}+\theta_{e q}\right)\right) \\
T_{d}=0
\end{array}\right.
$$

Fig. 12 shows the effect of the change of operating point of the engine on the mass flow rate of working fluid and, consequently on pressure and temperature at the inlet of the expansion machine; the controller of the superheat at the inlet of the expander reacts quickly and keep the actual value of superheat very close to the set-point.
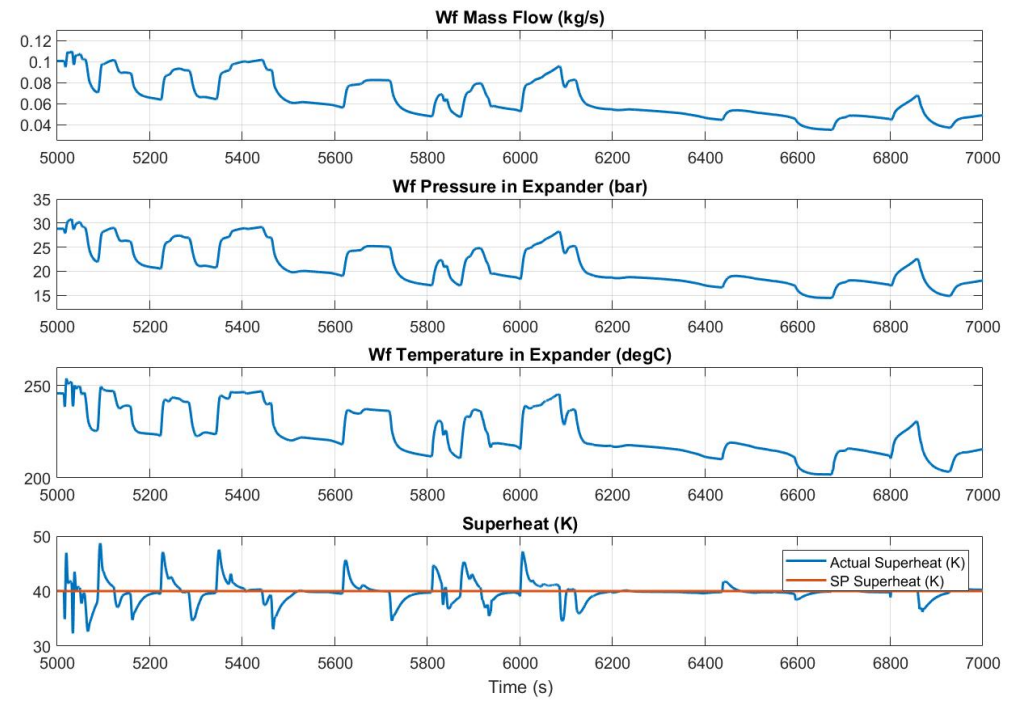

Figure 12: Superheat, depending on temperature and pressure, control acting on pump speed and consequently on the mass flow rate of the working fluid.

\subsection{Expander speed and exhaust by-pass control}

The exhaust by-pass valve is a safety component that reduces the thermal power input to the Rankine system in case of over-temperature or over-pressure detected in the working fluid. The control of the exhaust by-pass valve is mapbased and by-pass opens as soon as the maximum temperature of the working fluid reaches $240^{\circ} \mathrm{C}$. Fig. 14 shows how the exhaust by-pass is fully closed in the phases that are characterized by the working fluid maximum temperature below $240{ }^{\circ} \mathrm{C}$ and the progressive opening of the by-pass as soon as the working 
fluid temperature is larger than $240{ }^{\circ} \mathrm{C}$.

The expander speed influences the high pressure loop of the Rankine system (17) and the tracking of an optimal set-point leads to the operation of the expansion machine within the points that are characterized by highest efficiency values (8); the expander speed varies between 1000 and $3500 \mathrm{rpm}$, the exhaust bypass value varies from 0 , by-pass completely opened, to 100 , by-pass completely closed). The controller is a PI (Proportional-Integral controller) that varies the expander speed to track the evaporation pressure set-point. The controller is tuned using the IMC technique (Rivera et al., 1986) and the computation of the gain and time constant is based on step and response campaign on the expander model. The tracking results are shown in Fig 13; the evaporation pressure setpoint varies according to the working fluid mass flow and the expander speed regulation ensures the tracking of the set-point.
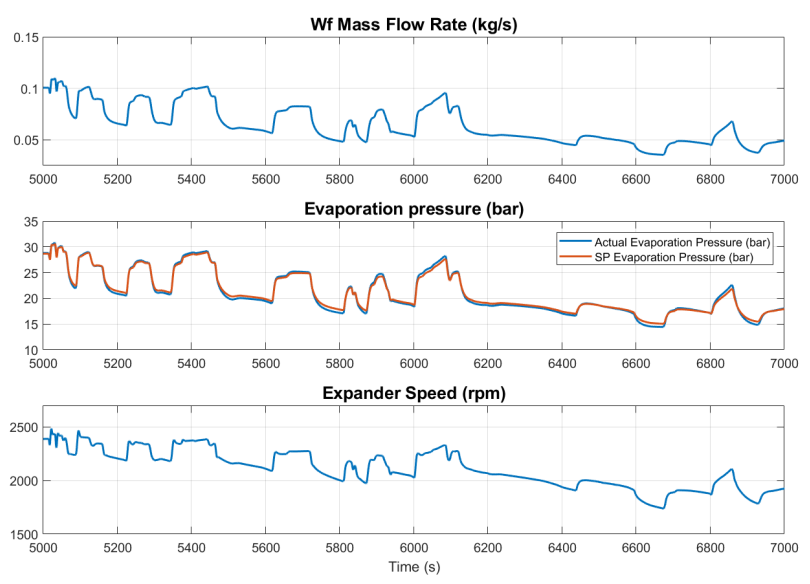

Figure 13: Evaporation pressure control; the evaporator pressure set-point is computed for each time step as a function of the working fluid mass flow rate.

\subsection{Subcooling control}

The subcooling is an useful variable to establish the phase of the fluid at the outlet of the condenser (30).

$$
S C_{e x, \text { cond }}=T_{\text {sat }}\left(P_{\text {cond }}\right)-T_{\text {ex }, \text { cond }} .
$$

The choice of set-point of the subcooling at the outlet of the condenser is, at a first sight, straightforward. It is clear that, a higher subcooling value leads to higher energy demand of the cooling actuators, with a negative impact on the energy balance of the whole Rankine system. In the same time, a higher subcooling strongly impacts on the efficiency of the thermodynamic cycle, by 
Figure 14: Exhaust by-pass control depending on the maximum working fluid temperature admitted in the Rankine system.

reducing it. Therefore, the main interest is to keep the subcooling particularly low, in order to reduce the impact on the energy balance and efficiency. Unfortunately, in real experiments, two main problems arise when reducing the subcooling at the outlet of the condenser (inlet of the pump):

- When the subcooling is particularly low and the working fluid is very close to the saturation conditions, local phenomena of condensation, with formations of bubbles can appear. This situation is particularly dangerous for the correct operation of the pump, that requires a liquid fluid at the inlet section.

- The use of complicated controllers is forbidden in automotive applications. Therefore, the actual value of the subcooling deviates from the set-point in highly transient conditions and choosing a too low value of subcooling would increase the risk of having a two-phase fluid at the inlet of the pump.

Considering the necessity to reduce the subcooling and, in the same time, ensure a positive actual value in all the possible conditions, a subcooling set-point $S C_{S P}=9 K$ is chosen and a controller is designed.

The Bayesian estimators and the SIMC technique (presented in Sec. 4.1) have been used to determine the parameters of the PID controllers of the subcooling at the outlet of the condenser (a step and response campaign on the condenser model has been performed). However the fan speed can reach a maximum value at high loads, consequently the air flow provided to the condenser is not enough to reach the complete condensation of the working fluid.

In order to face the high loads and to ensure a subcooled liquid supply to the pump, the condensation pressure has to be raised. This leads to the fact that 
the mean temperature difference between the cooling air and the working fluid is higher; consequently a lower air flow rate to the condenser is necessary to ensure the subcooling set-point at the inlet of the pump and, in the same time, the gross power production of the expander reduces consistently (more details in Sec. 5).

In this work, three different strategies for the control of the subcooling at the outlet of the condenser are presented:

1. PID controller acting on the fan speed and constant condensation pressure

2. PID controller acting on the fan speed, computing the desired condensation pressure setting a constant pressure ratio $P R$ between the inlet and outlet of the expansion machine

3. PID controller acting on the fan speed and an optimized strategy for the condensation pressure taking into account the temperature of the air flow at the inlet of the condenser. The controller scheme in Fig. 15 shows the optimization block, that has as output the optimal condensation pressure $P_{\text {cond }} ; G_{c, S C}(s)$ and $G_{p}(s)$ are the subcooling controller and the plant transfer functions. The vector $x_{p}$ is the vector of states, that is actively used in the computation of the optimal condensation pressure.

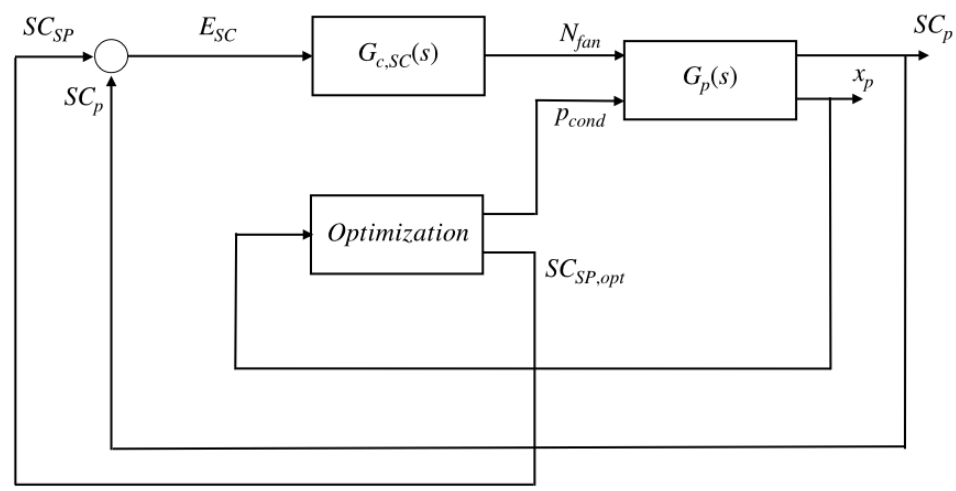

Figure 15: Optimal control strategy of the subcooling.

The same approach adopted in Sec. 4.1 to tune the PID controller of the subcooling at the inlet of the pump has been applied.

The condensation pressure can be modified by pressurizing the low pressure side of the Rankine system using the air storage at 7 bar that is available in the vehicle; an increase of the condensation pressure determines an increase of the subcooling (30) with faster dynamics than the fan speed. In the case of strategy 2 , the desired condensation pressure is calculated on-line considering the evaporation pressure and a fixed pressure ratio, that has been identified with the value of $P R=9$, according to the efficiency table of the current expander (Fig. $8)$. This solution is adopted to ensure the tracking of the subcooling at the inlet 
of the pump and, in the same, working with high values of expander efficiency. In the case of strategy 3 , the condensation pressure value to adopt is varied according to a model based optimization, that ensures the tracking of the subcooling set-point and improves the performance of the system (1) with respect to the strategy 1 and 2. A simplified analytical model has been developed, in order to compute the net power produced as a function of few variables that will be further available as measurements in the following experimental campaign. These known variables are listed hereafter and the complete equation of the net power produced as a quadratic form with respect to the fan speed $N_{f a n}$ and condensation pressure $p_{\text {cond }}$ is presented in (31):

- Pressure and temperature at the inlet of the expander

- Pressure and temperature at the outlet of the condenser

- Pump, expander and fan speed

$$
\dot{W}_{\text {net }}=A_{1} N_{\text {fan }}^{2}+A_{2} p_{\text {cond }}^{2}+B_{1} N_{\text {fan }}+B_{2} p_{\text {cond }}+C .
$$

where the coefficients $A_{1}, A_{2}, B_{i}, B_{2}$ and $C$ are depending on the plant state vector $x_{p}$, consequently they are variable in time.

The analytical model predicts the net power output as a function of the fan speed and condensation pressure and a trade-off between the two variables can be found (in other words, a trade-off between the fan power demand and the expander power production); therefore strategy 3 represents a solution that maximizes the net power, taking into account the temperature of the air at the inlet of the condenser (results in Sec. 5).

The comparison of the three strategies in terms of subcooling control is shown in Fig. 16, considering the ambient cooling air set at $40{ }^{\circ} \mathrm{C}$ at the inlet of the condenser and in Fig. 17, considering the ambient cooling air set at $20^{\circ} \mathrm{C}$. The subcooling set-point is well tracked in most of the road cycle phases, except adopting the strategy 1 , that, in particular during the phases characterized by low thermal load in the condenser and ambient cooling air set at $20^{\circ} \mathrm{C}$, has not the property to adapt (reduce in this case) the condensation pressure when the fan speed saturated to its lowest value; consequently the actual value of the subcooling is higher than the set-point. As for the strategies 2 and 3 , it is possible to notice that a different trade-off between condensation pressure and fan speed can be found ensuring the tracking of the same subcooling set-point. As for ambient cooling air set at $40{ }^{\circ} \mathrm{C}$, the strategy 3 leads to a global increase of the condensation pressure and a reduction of the fan speed, as a result of the fact that the high temperature of the cooling air at the inlet of the condenser. This result is physically logical, as for higher temperature of the air at the inlet of the condenser, the thermal exchange in the condenser is less performing and it is more convenient, from an energetic point of view, to pressurize the condensing side of the system, reducing in the same time the expander power produced and the fan power demand and eventually increasing the net power produced. 

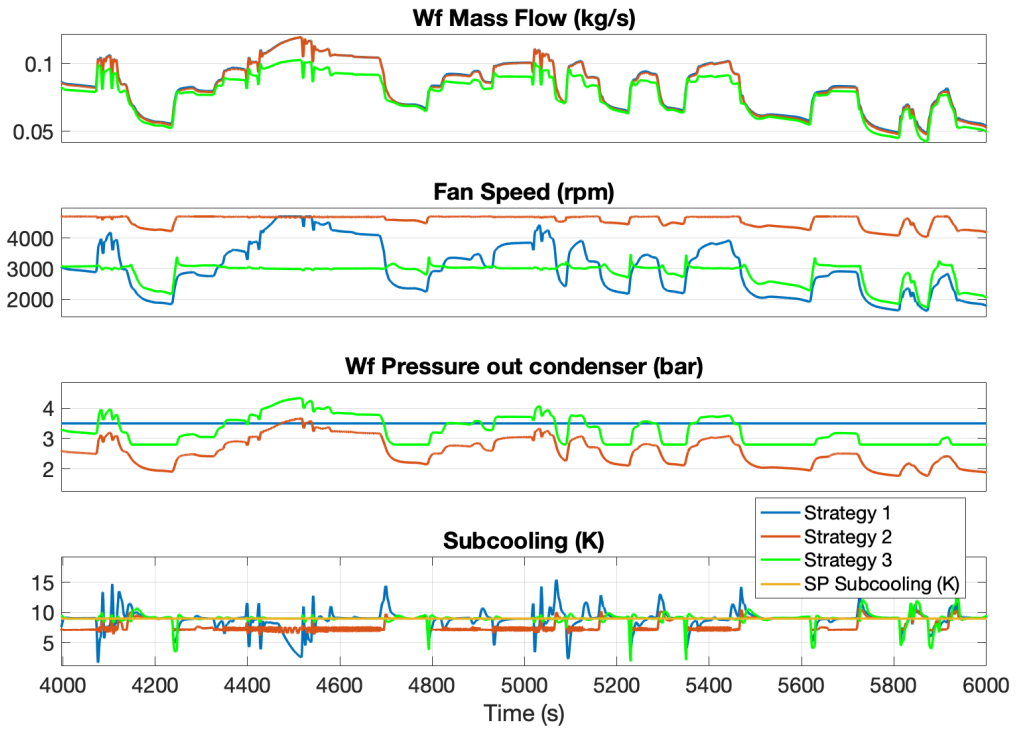

Figure 16: Comparison of the three strategies for subcooling control setting the air cooling temperature at $40^{\circ} \mathrm{C}$.

On the other hand, as for ambient cooling air set at $20^{\circ} \mathrm{C}$, the strategy 3 leads to an increase of the fan speed and a reduction of the condensation pressure with respect to the strategy 2 (Fig. 17), as it is more favorable to increase the air flow rate to the condenser when cooling air temperature is lower. The results in terms of net power produced by the Rankine system are shown in Sec. 5 .

\section{Road cycle results}

Road cycle simulations, using cyclopentane as working fluid, in a highly transient environment are necessary to estimate the potential of the Rankine technology in long-haul heavy-duty trucks. The engine is a 13-liter non-EGR and the road cycle, Frankfurt-Koblenz lately called FK, is characterized by the average thermal power of $50 \mathrm{~kW}$, with important variability of the heat source in terms of temperature and mass flow of the exhaust gas, due to braking phases over the 150 minutes of the cycle duration, as it is shown in Fig. 18.

For the three strategies previously presented and air cooling temperature set at $40{ }^{\circ} \mathrm{C}$ and $20{ }^{\circ} \mathrm{C}$ respectively, Fig. 19 and 20 show the net and expander power produced and the pump and fan power demands; the graphs confirm that the strategy 3 is able to improve the net power produced by the strategy 1 and 2, respecting the constraint represented by the subcooling set-point (Fig. 16 and 17). In order to compare the different strategies along the complete road cycle, 
Figure 17: Comparison of the three strategies for subcooling control setting the air cooling temperature at $20^{\circ} \mathrm{C}$.
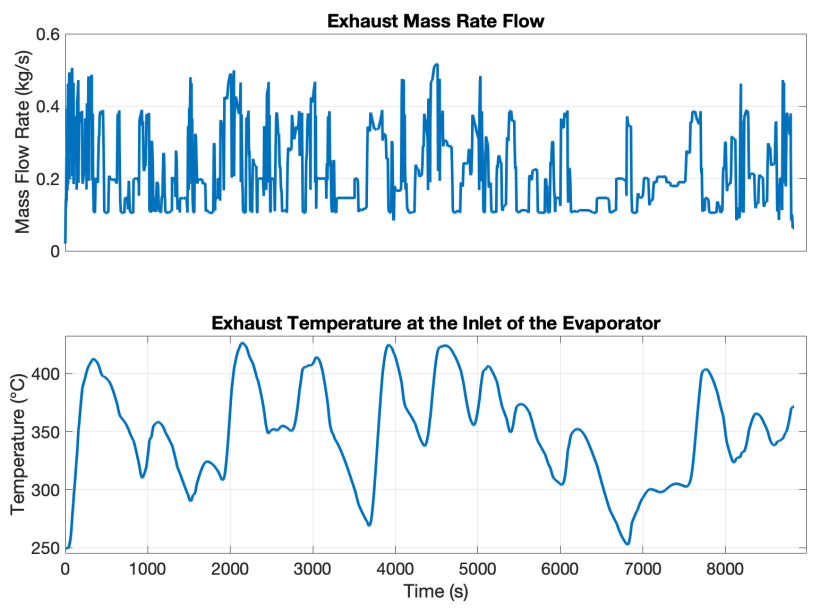

Figure 18: Exhaust mass flow rate and temperature at the inlet of the Rankine evaporator along the whole FK road cycle.

mean values are shown, normalizing each value with respect to the highest value of the expander gross power produced (Fig. 21); the graph confirms that the strategy 3 is able to improve the net power produced by the strategy 1 and 2, 
setting the air cooling temperature at 20 and $40{ }^{\circ} \mathrm{C}$. In particular, as for air cooling temperature set to $20{ }^{\circ} \mathrm{C}$, the net power is improved by 8 and $3 \%$ with respect to the strategies 1 and 2; as for air cooling temperature set to $40{ }^{\circ} \mathrm{C}$, the net power is improved by 12 and $3 \%$ with respect to the strategies 1 and 2 .
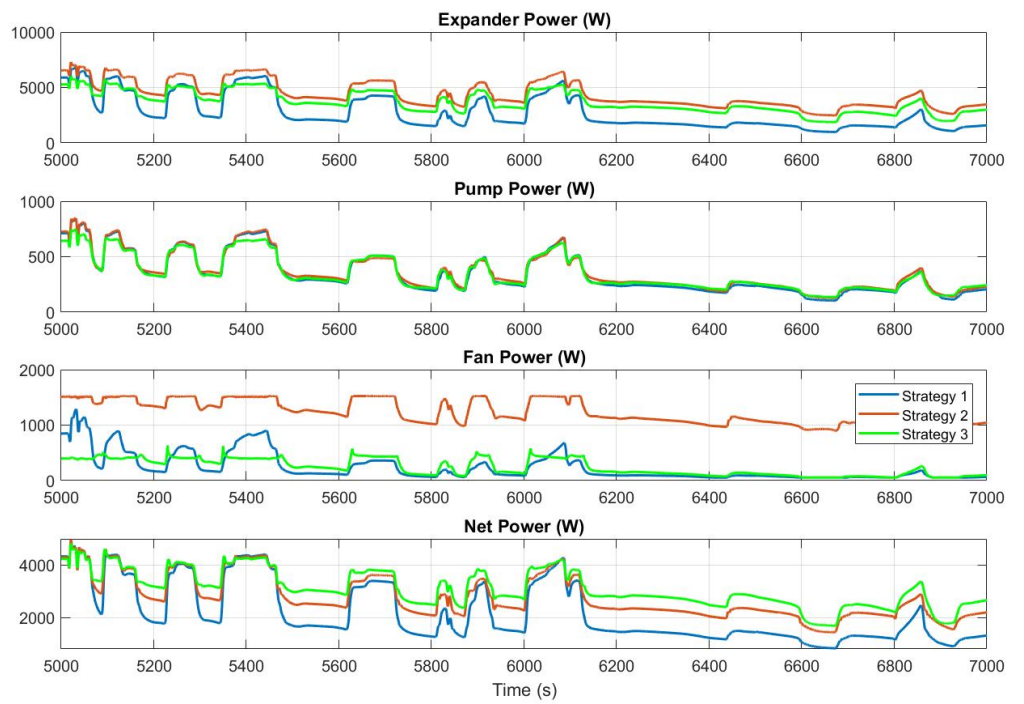

Figure 19: Comparison of the gross power produced and pump and fan power demands setting the air cooling temperature at $40^{\circ} \mathrm{C}$.

\section{Conclusion}

This work presented the complete modeling of a Rankine Cycle based waste heat recovery system for long-haul heavy-duty trucks. The proposed architecture recovers the energy from the exhaust gas and used ambient air as heat sink; this solution does not impact the operation of the cooling system of the vehicle, but in the same time it does not take advantage of any RAM air intake.

The main results can be summarized as follows:

- Evaporator and direct condenser models are validated according to experimental results and data suppliers.

- The manipulation of the condensation pressure using the current architecture and cyclopentane as working fluid is necessary, in order to track the lowest subcooling admitted in the current application and, in the same time, ensure high standard of performance. 
Figure 20: Comparison of the gross power produced and pump and fan power demands setting the air cooling temperature at $20^{\circ} \mathrm{C}$.

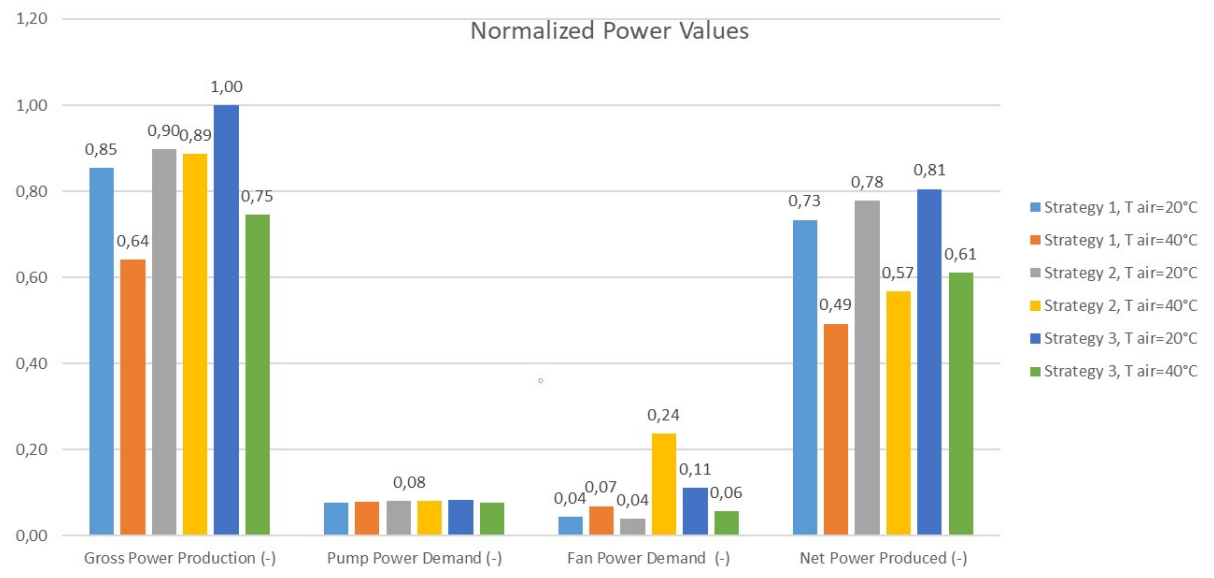

Figure 21: Comparison of the three strategies in terms of power produced and demand; the strategy 3 is able to increase the net power produced by the Rankine system, reducing the fan power demand when the air cooling temperature is $40^{\circ} \mathrm{C}$ and increasing the fan power demand when the air cooling temperature is $20^{\circ} \mathrm{C}$. Comparison of the gross power produced and pump and fan power demands setting the air cooling temperature at $20^{\circ} \mathrm{C}$. All the values are normalized with respect to the gross power in strategy 3 and air cooling temperature $20^{\circ} \mathrm{C}$. 
- The model-based optimization (strategy 3 ) improves the net power production of the system by 8 and $3 \%$ with respect to strategies 1 and 2 and air cooling temperature set at $20{ }^{\circ} \mathrm{C}$.

- The model-based optimization (strategy 3 ) improves the net power production of the system by 12 and $3 \%$ with respect to strategies 1 and 2 and air cooling temperature set at $40{ }^{\circ} \mathrm{C}$.

- In the case of the air cooling temperature $20^{\circ} \mathrm{C}$, the optimization (strategy 3 ) leads to an increase of the fan speed and a reduction of the condensation pressure with respect to strategies 1 and 2 .

- In the case of the air cooling temperature $40{ }^{\circ} \mathrm{C}$, the optimization (strategy 3 ) leads to an decrease of the fan speed and an increase of the condensation pressure with respect to strategies 1 and 2 .

\section{References}

Allain, M., Atherton, D., Gruden, I., Singh, S., and Sisken, K. (2012). Daimler ' s super truck program ; $50 \%$ brake thermal efficiency 2012 directions in engine-efficiency and emissions.

Aufderheide, B. and Bequette, B. W. (2003). Extension of dynamic matrix control to multiple models. Computers and Chemical Engineering, 27(8-9):10791096.

Chan Kang, H. and Jun, G. W. (2011). Heat transfer and flow resistance characteristics of Louver fin geometry for automobile applications. Journal of Heat Transfer, 133(10):101802(6pages).

Chang, Y. J. and Wang, C. C. (1997). A generalized heat transfer correlation for louver fin geometry. International Journal of Heat and Mass Transfer, $40(3): 533-544$.

Di Battista, D., Di Bartolomeo, M., Villante, C., and Cipollone, R. (2018). On the limiting factors of the waste heat recovery via ORC-based power units for on-the-road transportation sector. Energy Conversion and Management, 155:68-77.

Dickes, R. (2019). Charge-sensitive methods for the off-design performance characterization of organic Rankine cycle (ORC) power systems. PhD thesis, University of Liège, Belgium.

El Hajal, J., Thome, J. R., and Cavallini, A. (2003). Condensation in horizontal tubes, part 1: two-phase flow pattern map. International Journal of Heat and Mass Transfer, 46(18):3349-3363. 
Galuppo, F., Dufour, P., Nadri, M., Reiche, T., and Lemort, V. (2018a). Experiment design for waste heat recovery modeling in heavy duty trucks. IFACPapersOnLine, 51(31):726-731.

Galuppo, F., Reiche, T., Lemort, V., Dufour, P., Nadri, M., and Huin, X. (2018b). Waste heat recovery (WHR) assessment in complete truck simulation environment. In 2018 SIA POWERTRAIN conference, May 2018, Rouen, France.

Grelet, V. (2016). Rankine cycle based waste heat recovery system applied to heavy duty vehicles: topological optimization and model based control. PhD thesis, University de Lyon, France and University of Liège, Belgium.

Grelet, V., Dufour, P., Nadri, M., Reiche, T., and Lemort, V. (2015). Modeling and control of Rankine based waste heat recovery systems for heavy duty trucks. In IFAC-PapersOnLine, volume 48, pages 568-573.

Guillaume, L. and Lemort, V. (2019). Comparison of different ORC typologies for heavy-duty trucks by means of a thermo-economic optimization. Energy, 182:706-728.

Hountalas, D. T., Mavropoulos, G. C., Katsanos, C., and Knecht, W. (2012). Improvement of bottoming cycle efficiency and heat rejection for HD truck applications by utilization of EGR and CAC heat. Energy Conversion and Management, 53(1):19-32.

Incropera, F., Dewitt, D., Bergman, T., and Lavine, A. (1993). Fundamentals of heat and mass transfer. Number 1986.

Kandlikar, S. G. (2002). Fundamental issues related to flow boiling in minichannels and microchannels. Experimental Thermal and Fluid Science, 26(24):389-407.

Kanefsky, P., Nelson, V., and Ranger, M. (1999). A systems engineering approach to engine cooling design. SAE Technical Papers, Paper 1999-01-3780.

Karvountzis-Kontakiotis, A., Pesiridis, A., Zhao, H., Alshammari, F., Franchetti, B., Pesmazoglou, I., and Tocci, L. (2017). Effect of an ORC waste heat recovery system on diesel engine fuel economy for off-highway vehicles. SAE Technical Papers, 2017-01-0136.

Koeberlein, D. (2012). Cummins SuperTruck program relevance - Program objectives. Cummins.

Lopes, J., Douglas, R., McCullough, G., O'Shaughnessy, R., Hanna, A., Rouaud, C., and Seaman, R. (2012). Review of Rankine cycle systems components for hybrid engines waste heat recovery. SAE Technical Paper Series, 2012-01-1942. 
Lutz, R., Motisi, G., and Bruemmer, R. (2015). Device and method for recovering waste heat energy and a utility vehicle. United States Patent, DE102015016783A1.

Peralez, J. (2015). Recuperation d'énergie par cycle de Rankine à bord d'un véhicule : commande et gestion d'énergie. PhD thesis, University de Lyon, France.

Peralez, J., Tona, P., Lepreux, O., Sciarretta, A., Voise, L., Dufour, P., and Nadri, M. (2013). Improving the control performance of an organic rankine cycle system for waste heat recovery from a heavy-duty diesel engine using a model-based approach. Proceedings of the IEEE Conference on Decision and Control, pages 6830-6836.

Preißinger, M., Schwöbel, J. A. H., Klamt, A., and Brüggemann, D. (2017). Multi-criteria evaluation of several million working fluids for waste heat recovery by means of Organic Rankine Cycle in passenger cars and heavy-duty trucks. Applied Energy, 206:887-899.

Quoilin, Sylvain (2011). Sustainable energy conversion through the use of Organic Rankine Cycles for waste heat recovery and solar applications. PhD Thesis, University of Liège, Belgium.

Rivera, D., Morari, M., and Skogestad, S. (1986). Internal Model Control. 4. PID Controller Design. American Chemical Society, 25:252-265.

Rodriguez, F. (2018). The European Commission's Proposed CO2 Standards For Heavy-Duty Vehicles. IcCT.

Scaccabarozzi, R., Tavano, M., Invernizzi, C. M., and Martelli, E. (2018). Comparison of working fluids and cycle optimization for heat recovery ORCs from large internal combustion engines. Energy, 158:396-416.

Seitz, D., Gehring, O., Bunz, C., Brunschier, M., and Sawodny, O. (2016). Design of a nonlinear, dynamic feedforward part for the evaporator control of an Organic Rankine Cycle in heavy duty vehicles. IFAC-PapersOnLine, $49(11): 625-632$.

Shah, M. M. (1976). New correlation for heat transfer during boiling flow through pipes. ASHRAE Transactions, 2407:66-86.

Shah, M. M. (1979). A general correlation for heat transfer during film condensation inside pipes. International Journal of Heat and Mass Transfer, $22(4): 547-556$.

Skogestad, S. (2006). Tuning for Smooth PID Control with Acceptable Disturbance Rejection. Industrial \& Engineering Chemistry Research, 45(23):78177822 . 
Torregrosa, A., Galindo, J., Dolz, V., Royo-Pascual, L., Haller, R., and Melis, J. (2016). Dynamic tests and adaptive control of a bottoming organic Rankine cycle of IC engine using swash-plate expander. Energy Conversion and Management, 126:168-176.

Vaja, I. and Gambarotta, A. (2010). Internal Combustion Engine (ICE) bottoming with Organic Rankine Cycles (ORCs). Energy, 35(2):1084-1093.

Wang, T., Zhang, Y., Zhang, J., Shu, G., and Peng, Z. (2013). Analysis of recoverable exhaust energy from a light-duty gasoline engine. Applied Thermal Engineering, 53(2):414-419.

Winterton, R. H. S. (1998). Where did the Dittus and Boelter equation come from? International Journal of Heat and Mass Transfer, 41(4-5):809-810.

Yang, B., Yu, T., Shu, H., Zhang, X., Qu, K., and Jiang, L. (2018). Democratic joint operations algorithm for optimal power extraction of PMSG based wind energy conversion system. Energy Conversion and Management, 159:312-326.

Yang, B., Zhang, X., Yu, T., Shu, H., and Fang, Z. (2017). Grouped grey wolf optimizer for maximum power point tracking of doubly-fed induction generator based wind turbine. Energy Conversion and Management, 133:427443.

Zhao, R., Zhang, H., Song, S., Tian, Y., Yang, Y., and Liu, Y. (2018). Integrated simulation and control strategy of the diesel engine-organic Rankine cycle (ORC) combined system. Energy Conversion and Management, 156(100):639-654. 


\section{Authors' Response \\ Paper Ref. EGY-D-20-00541}

We would like to express again our sincere thanks to you and to the reviewers for their valuable comments and suggestions. According to the comments, we provide below the responses to each comment and the corresponding changes made in the manuscript (in red).

\section{Main changes compared to the previous version}

Following the reviewers' suggestions, we have made several modifications in our paper (in red). We summarize the main changes as follows:

1. We added a relevant example in literature about the low pressure manipulation, highlighting the gap in the literature and we tried to better explain the advantages of controlling the low-pressure in the system.

2. We provided more details about the operation of the actuator that is used for the manipulation of the low pressure; it is clearly stated that there is no mix between the working fluid and the air, as a membrane separates the two substances in a reservoir.

3. We improved the quality of the figures.

4. We detailed the usage of the Shah correlations for the calculation of the Nusselt number.

\section{Reply to the editor}

- The Reviewers present important points of criticism and a series of recommendations. We kindly ask you to consider all comments and revise the paper accordingly in order to respond fully and in detail to the Reviewers' recommendations. If this process is completed thoroughly, the paper will be acceptable for a second review.

We studied carefully each of the reviewers' new comments and we provided detailed answers to their questions. Their advices improved once again our paper by pointing out adjustments and by suggesting clarifications, however, our technical modifications are few.

In the following, we address each of the reviewer's comments. 


\section{Reviewer 4}

- Comment 1:The authors revised the last part of introduction to illustrate what has been done in current paper. However, the literature review part is not modified, which I think the state-of-the art and the research gap should be included. You should state that why you feel this topic is worthy of investigation. From this section, readers should have a clear understanding of the research status and research gap. In current version of the paper, only listed relevant papers were listed to prove 1) the potential of ORC and 2) the status of controller design. However, the main idea is to control low pressure of ORC. So I suggest the authors state that 1) the necessity of controlling low-pressure, 2) the research status regarding controlling low-pressure, by adding relevant papers.

We recognize the lack of relevant literature addressed to the manipulation of the low pressure. Therefore the citation Peralez (2015) has been added. However this is a rare example, at our best knowledge, available in literature, as most of the control studies address the control of the working fluid state at the evaporator outlet. Other examples regarding the control of the working fluid subcooling at the inlet of the pump (which is our interest in our paper) are existing (Dickes, 2019), (Lutz et al., 2018), but in a different system and without any active manipulation of the condensation pressure.

The necessity of controlling the low pressure, as well as the literature gap are highlighted in the revised version of the paper, in the section 1, page 2:

"The same author in (Peralez, 2015) designed an energy monitoring algorithm addressed to the optimal control of a Rankine based waste heat recovery in a Diesel - electrical train; the condenser is cooled down by air and the condensation pressure is manipulated in high load transients in order to complete the condensation phase. The dynamic optimization shows an improvement of the net power produced that is higher with respect to static optimization strategies.

This last work that has been mentioned is a rare example of manipulation of condensation pressure in automotive waste heat recovery in literature, as most of the studies focus on the control of the working fluid conditions at the inlet of the expander to ensure high standards of power production of the system. In particular, direct condensation with air leads, in most of applications, to poor air mass flow rate at the inlet of the condenser. Therefore the increase of the condensation pressure is necessary to ensure the complete condensation of the working fluid. Additionally, in the applications consisting of a dedicated fan to supply the cooling air flow, the manipulation of the condensation pressure could be useful in terms of energy management, as the increase of the condensation pressure implies the reduction of the expander power of the system, but, in the same time, implies higher temperature difference between the working fluid and the air flow. Consequently a lower amount of air mass flow rate is needed to have the same working fluid condition at the outlet of the condenser; therefore the fan power demand is reduced as well. The reduction of the expander power production and the fan power demand could lead to an increase of the net power production of the system. "

- Comment 2 :Highlights: the third item is not precise. Typically, higher condenser pressure will lead to performance reduction.

We agree that the item may be confusing. The third item has been rephrased, highlighting the fact that the increase of the low pressure is needed because of the high loads and low cooling capacity. Item 3: "Higher condensation pressure is set at high load transients and high air temperature at the inlet of the condenser."

In the current system, the increase of the condensation pressure could lead to a higher net power production of the system even though it reduces the expander gross power, as it reduces the fan power demand as well. Physically speaking, the increase of the condensation pressure increases the temperature difference between the working fluid and the air flow, consequently a lower amount of air mass flow rate is needed to have the same working fluid condition at the outlet of the condenser. In the end of page 2 , section 1 , this physical concept has been explained. 
- Comment 3: Page 6, Line 56, cooling air temperature is $40 \mathrm{deg} C$ while ambient air temperature of $\operatorname{deg} C$ in figure 3. Both the two temperatures were considered in the study. I suggest the authors make it clearer.

A mistake in the title of the figure generated the misunderstanding, we thank you for the important remark. The only one temperature of the air considered at the inlet of the condenser is $40 \mathrm{degC}$.

- Comment 4: Five actuators were considered. However, the fan speed and condensation pressure were not decoupled, within the operating range of the fan. In this case, they should not been considered as two variables. In addition, if the fan speed exceeds its upper limit, how to adjust condensation pressure? Using the air storage also leads to a complex system and also integration issues. It is definitely the WF will be mixed with air. The mixture will influence the cycle performance as the thermodynamic properties are changed. Have you considered this? Besides, mixing air with flammable cyclopentane will risk safety issues. How to deal with this? In this way, I cannot agree with adjusting condensation pressure by air storage.

We thank you for this remark that gives us the possibility to clarify the aspects related to the condensation pressure manipulation. In order to make it clearer, the figure 1 has been modified and the system regulating the low pressure has been added. Additionally, the following sentence is introduced in order to explain the operation of the pressurized air system: "This Rankine layout clarifies the possibility to manipulate the condensation (low) pressure in the system, via pressurized air stored in the dedicated air reservoir available in the vehicle; the control valve regulates the pressure of the air in the reservoir and, by consequence, the pressure of the working fluid. In the reservoir a membrane ensures the separation between the air and the working fluid, avoiding a drop in the performance and safety issues that appear in case of mixing."

As described above, the condensation pressure is regulated via the control valve and the fan speed is varied via dedicated controller; therefore, the two variables are modified independently of each other.

- Comment 5: Figure 8, a fixed expander map was adopted. What is the expander outlet pressure when obtaining such a map? In your study, the condensation pressure changes, which means the expander outlet pressure changes. To what extent the calculation is reliable since the expander efficiency as a function of pressure ratio is used while the pressure also influences?

The pressure ratio is widely used, together with the expander speed, to correlate the expander efficiency (Lemort et al., 2009) (Ziviani et al., 2018). In this work, the efficiency map of the expander is created from about 50 operating points, where the condensation pressure is varied from 1 to 3 bar and the evaporation pressure is varied from to 30 bar.

- Comment 6: Page 19, line 46, "a step and response experimental campaign has been performed" to obtain the PI parameters. In different operating conditions (boundaries, steps), the dynamic characteristics (eg. time constant and settling time) will vary. Which one did you use? Averaged? See Experimental comparison of dynamic responses of CO2 transcritical power cycle systems used for engine waste heat recovery. Energy Conversion and Management. The effects of design parameters on the dynamic behavior of organic ranking cycle for the engine waste heat recovery, Energy.

Indeed the parameters of the PI controller may vary a lot depending on the operating points; in (Galuppo et al., 2018) the authors presented an algorithm used for the selection of the most representative operating points in the engine maps to perform the step and response analysis. In this work, a Bayesian weighting scheme presented by (Aufderheide and Bequette, 2003) has been used in order to compute, for each time step, a resulting model whose parameters (gain $\left(G_{e q}\right)$, time constant $\left(\tau_{e q}\right)$ and delay $\left(\theta_{e q}\right)$ are used to design online an adaptive PID controller parameters as 
follows

$$
\left\{\begin{array}{l}
K_{p}=\frac{1}{G_{e q}} \frac{\tau_{e q}}{\tau_{c} \theta_{e q}} \\
T_{I}=\min \left(\tau_{e q}, 4\left(\tau_{c}+\theta_{e q}\right)\right) \\
T_{d}=0,
\end{array}\right.
$$

where $\tau_{c}$ is a tuning parameter to fixe the desired closed-loop time response.

In page 21, we provide the details in the Eq. 26, 27, 28.

- Comment 7: Fig.10, the label and axis title are too small.

The font size of the labels, axis and legend has been increased.

- Comment 8: Fig. 16 and Fig. 17, enlarge vertical axis scale coz some curves are out of the layer.

The vertical axis scale has been adapted in order to fit all the curves in the graph.

- Comment 9: Fig. 21, all values are normalized by the gross power production of strategy 3, T=?

Yes, they are. In order to make it clearer the sentence "All the values are normalized with respect to the gross power in strategy 3 and air cooling temperature $20^{\circ} C$." has been added in the caption of the Fig. 21.

\section{Reviewer 5}

- Comment 1: About Eq. (12) referred to in 3rd comment of last review, authors may not catch me. My confusion is that it seems Eq. (12) is applied to both evaporation and condensation by authors.

We thank you for your comment, that is useful to clarify the usage of the Shah correlations (Shah (1976), Shah (1979)).

The Shah correlations are applied to both evaporation and condensation of the working fluid. The equation (13), previously (12) according to the reviewer comment, has been modified to show the difference between boiling (2) and condensing flow (3) as follows:

$$
N u=\left\{\begin{array}{l}
\psi N u_{s p} \\
N u_{s p}\left[(1-q)^{0.8}+\frac{3.8 q^{0.76}(1-q)^{0.04}}{P_{r e d}^{0.38}}\right]
\end{array}\right.
$$

\section{References}

Aufderheide, B. and Bequette, B. W. (2003). Extension of dynamic matrix control to multiple models. Computers and Chemical Engineering, 27(8-9):1079-1096.

Dickes, R. (2019). Charge-sensitive methods for the off-design performance characterization of organic Rankine cycle (ORC) power systems. PhD thesis, University of Liège, Belgium.

Galuppo, F., Dufour, P., Nadri, M., Reiche, T., and Lemort, V. (2018). Experiment Design for Waste Heat Recovery Modeling in Heavy Duty Trucks. IFAC-PapersOnLine, 51(31).

Lemort, V., Quoilin, S., Cuevas, C., and Lebrun, J. (2009). Testing and modeling a scroll expander integrated into an Organic Rankine Cycle. Applied Thermal Engineering, 29(14-15):3094-3102. 
Lutz, R., Motisi, G., and Bruemmer, R. (2018). Device and method for recovering waste heat energy and a utility vehicle. United States Patent, DE102015016783A1.

Peralez, J. (2015). Recuperation d'énergie par cycle de Rankine à bord d'un véhicule : commande et gestion d'énergie. PhD thesis, University de Lyon, France.

Shah, M. M. (1976). New Correlation for Heat Transfer During Boiling Flow Through Pipes. ASHRAE Transactions, 2407:66-86.

Shah, M. M. (1979). A general correlation for heat transfer during film condensation inside pipes. International Journal of Heat and Mass Transfer, 22(4):547-556.

Ziviani, D., Dickes, R., Lemort, V., Braun, J. E., and Groll, E. A. (2018). Effects of the Working Fluid Charge in Organic Rankine Cycle Power Systems: Numerical and Experimental Analyses. Organic Rankine Cycle Technology for Heat Recovery. 


\section{Organic Rankine Cycle based waste heat recovery modeling and control of the low pressure side using direct condensation and dedicated fans}

July 28, 2020

\section{Introduction}

The recent European Union regulations for long-haul heavy-duty trucks, that set to $15 \%$ the reduction of $\mathrm{CO}_{2}$ emissions in 2025 with respect to the fleet baseline of 2019, pushed the automotive industry to adopt new effective to meet the new limits by decreasing the fuel consumption of the fleet (Rodriguez, 2018). The Organic Rankine Cycle (ORC) based waste heat recovery is considered one of the most promising technologies to reduce fuel consumption and increase the brake thermal efficiency of the vehicle (Wang et al., 2013); (Koeberlein, 2012); (Allain et al., 2012). The results of recent studies, supported by road cycle simulations and experimental campaigns, show an effective potential of the technology. (Zhao et al., 2018) claim an increase in thermal efficiency of $3.57 \%$ and a Break Specific Fuel Consumption (BSFC) reduction of $10.09 \mathrm{~g} / \mathrm{kWh}$ as a result of steady-state simulations, over different engine operating points, using GT-Suite and MATLAB/Simulink models, by recovering heat from exhaust gas. Extensive literature is available about constraints and limiting factors of the Rankine Cycle based waste heat recovery systems in long-haul heavy duty trucks: (Di Battista et al., 2018) investigated on the engine additional backpressure induced by the Rankine evaporator. (Karvountzis-Kontakiotis et al., 2017) studied the effects of the ORC on fuel economy of a heavy duty vehicle; the main focus of the analysis is a trade-off between the heat transfer area of the evaporator and the pressure drop that it imposes to the exhaust gas used as main heat source. The authors also identified the weight of the ORC system as one of the main limitations for the integration of the system in the vehicle. The final results show an optimal value when looking for a trade-off between exhaust back-pressure, ORC required net power and weight. (Hountalas et al., 2012) studied the problem of the rejection of excess heat of a ORC system, using exhaust gas flow as the main heat source. Adding the recuperation of the waste heat from the Exhaust Gas Recirculation flow (EGR) and a Charge Air Cooler $(\mathrm{CAC})$, the authors proved a further increase of the expander output power and in the same time a reduction of the thermal load in the cooling radiator, leading 
to the reduction of the fan power demand.

During the operation of a heavy duty truck in highway paths, external disturbances lead to a variation of the engine operating point and, consequently, to variable thermal power that can be recovered from the heat source. Therefore controllers are implemented in order to ensure at any time the suitable conditions of the working fluid (pressure, temperature, mass flow rate) in the system (and in particular at the inlet of the expansion machine and pump) and high standards of the system power production. (Grelet et al., 2015) compared the use of a non linear inverse model and a PI controller to track the set point of the temperature at the inlet of the expander; the inverse model leads to the best strategy. (Seitz et al., 2016) designed a feedforward controller, with online parameter adaptation, to control the temperature at the outlet of the evaporator; however according to the author the inverse model must be rechecked to increase the performance in highly transient situations. (Torregrosa et al., 2016) proposed an adaptive PID controller of the pump speed in a Rankine system fed by thermal power from a 2-liter gasoline engine; the adaptive gains are evaluated based on the working fluid temperature at the outlet of the evaporator and the estimation of the power released by the exhaust gas. A map based controller of the volumetric expander speed is also included. The controller is validated on test bench and, according to the authors, allows the control of the ORC in real driving conditions. Another example of feedforward controller designed to control the superheat (defined as the difference of the working fluid temperature and saturation temperature at the given pressure) at the inlet of the expander is presented by (Peralez et al., 2013); the authors used an inverse reduced model in the feedforward path and a gain-scheduling PID controller in the feedback path. Experimental results show a good performance of the controller, that allows to track the superheat set-point, set to the value of $40 \mathrm{~K}$. The same author in (Peralez, 2015) designed an energy monitoring algorithm addressed to the optimal control of a Rankine based waste heat recovery in a Diesel - electrical train; the condenser is cooled down by air and the condensation pressure is manipulated in high load transients in order to complete the condensation phase. The dynamic optimization shows an improvement of the net power produced that is higher with respect to static optimization strategies.

This last work that has been mentioned is a rare example of manipulation of condensation pressure in automotive waste heat recovery in literature, as most of the studies focus on the control of the working fluid conditions at the inlet of the expander to ensure high standards of power production of the system. In particular, direct condensation with air leads, in most of applications, to poor air mass flow rate at the inlet of the condenser. Therefore the increase of the condensation pressure is necessary to ensure the complete condensation of the working fluid. Additionally, in the applications consisting of a dedicated fan to supply the cooling air flow, the manipulation of the condensation pressure could be useful in terms of energy management, as the increase of the condensation pressure implies the reduction of the expander power of the system, but, in the same time, implies higher temperature difference between the working fluid and the air flow. Consequently a lower amount of air mass flow rate is needed to 
have the same working fluid condition at the outlet of the condenser; therefore the fan power demand is reduced as well. The reduction of the expander power production and the fan power demand could lead to an increase of the net power production of the system.

In this work, to design a model based control, a 1D finite volume model of the evaporator and direct condenser is firstly developed (both validated according to experimental results or data supplier), using MATLAB/Simulink. Furthermore, the complete model of the Rankine Cycle is proposed, as well as the model-based controllers. Particular attention is paid to the control of the subcooling of the working fluid at the inlet of the pump, by means of the dedicated fans speed and condensation pressure; additionally, a model-based optimization is run in order to find the best trade-off between the fans speed and the condensation pressure, ensuring the tracking of the subcooling and the maximization of the net power production of the Rankine system.

\section{Proposed Rankine architecture}

The Rankine Cycle architecture that is proposed in this work, presented in Fig. 1 , recovers heat from the exhaust gas flow and delivers electrical energy to the $48 \mathrm{~V}$ mild-hybrid drive-line. The pressure of the working fluid (in liquid state) is increased by a volumetric pump. The pre-heating, evaporation and superheating processes take place in the tailpipe heat exchanger. The working fluid is then expanded in the expander to produce useful work and the excess heat is rejected via the condenser, using ambient air as heat sink. This Rankine layout clarifies the possibility to manipulate the condensation (low) pressure in the system, via pressurized air stored in the dedicated air reservoir available in the vehicle; the control valve regulates the pressure of the air in the reservoir and, by consequence, the pressure of the working fluid. In the reservoir a membrane ensures the separation between the air and the working fluid, avoiding a drop in the performance and safety issues that appear in case of mixing. A similar system has been tested successfully and patented in order to ensure the desired condition of the working fluid at the inlet of the pump, avoiding its cavitation in all the operating points (Lutz et al., 2015); the main difference between the system presented here and the patented system is that in the latter an additional valve is installed between the reservoir and the Rankine line in order to have the possibility to disconnect the Rankine system and the reservoir. In order to improve the performance of the studied ORC, (Dickes, 2019) investigated on the sensitivity of the system to the charge of the working fluid in the system; the variation of the charge of working fluid is achieved by pressurizing an inert gas in a reservoir, connected to the Rankine line.

Fig. 2 clarifies the position of the Rankine system in the vehicle. The exhaust gas stream at the outlet of the Exhaust After Treatment System (EATS) flows in the Rankine system and cedes a portion of its thermal energy to the working 


\section{Nomenclature}

\begin{tabular}{|c|c|c|c|}
\hline \multicolumn{2}{|c|}{ Acronyms } & \multirow[t]{2}{*}{$c p$} & \multirow{2}{*}{$\begin{array}{l}\text { Specific Heat at Constant Pres- } \\
\text { sure }\left(\frac{\mathrm{J}}{\mathrm{kgK}}\right)\end{array}$} \\
\hline Bo & Boiling number & & \\
\hline \multirow{2}{*}{$B S F C$} & \multirow{2}{*}{$\begin{array}{l}\text { Break Specific Fuel Consump- } \\
\text { tion }\left(\frac{g}{k W h}\right)\end{array}$} & $D_{h}$ & Hydraulic diameter $(m)$ \\
\hline & & $h$ & Specific Enthalpy $\left(\frac{J}{k g}\right)$ \\
\hline$C A C$ & Charge Air Cooler & $K_{p}$ & Fan pressure coefficient \\
\hline \multirow[t]{2}{*}{$C F D$} & \multirow{2}{*}{$\begin{array}{l}\text { Computational Fluid Dynam- } \\
\text { ics }\end{array}$} & $K_{q}$ & Fan flow coefficient \\
\hline & & $K_{w}$ & Fan power coefficient \\
\hline Co & Convection number & $N$ & Rotational Speed (rpm) \\
\hline \multicolumn{2}{|c|}{$C O_{\text {ratio }}$ Cut-Off Ratio (-) } & $N u$ & Nusselt Number (-) \\
\hline$E G R$ & Exhaust Gas Recirculation & $\operatorname{Pr}$ & Prandtl Number (-) \\
\hline Err & Error (-) & $q$ & Vapor Quality (-) \\
\hline$F K$ & Frankfurt-Koblenz & Re & Reynolds Number (-) \\
\hline$F V$ & Finite Volume & $U$ & Specific Internal Energy $\left(\frac{J}{k g}\right)$ \\
\hline$I M C$ & Internal Model Control & $u$ & Model Input \\
\hline$M M P I$ & $\begin{array}{l}\text { Multi-Model proportional in- } \\
\text { tegral }\end{array}$ & $u_{c}$ & $\begin{array}{l}\text { Velocity in the minimum flow } \\
\text { area }(\mathrm{m} / \mathrm{s})\end{array}$ \\
\hline ORC & Organic Rankine Cycle & V & Volume $\left(m^{3}\right)$ \\
\hline$P I D$ & Proportional-Integral-Derivative & $V_{0}$ & Clearance Volume $\left(\mathrm{m}^{3}\right)$ \\
\hline$R A M$ & Air Intake & $w$ & Weight \\
\hline$S C$ & Subcooling $(K)$ & $x$ & State \\
\hline$S H$ & Superheat $(K)$ & $y$ & Model Output \\
\hline \multirow[t]{2}{*}{$S I M C$} & Skogestad Internal Model Con- & \multicolumn{2}{|c|}{ Subscripts } \\
\hline & trol & $c$ & Control \\
\hline$S P$ & Set-point & cond & Condenser \\
\hline & Working Fluid & cool & Coolant \\
\hline \multicolumn{2}{|c|}{ Greek letters } & $d$ & Derivative \\
\hline$\alpha$ & Heat Transfer Coefficient & $e q$ & Equivalent \\
\hline$\eta$ & $\begin{array}{l}\mathrm{kgm}^{2} \\
\text { Efficiency }(-)\end{array}$ & $e v$ & Evaporator \\
\hline \multirow[t]{3}{*}{$\psi$} & Ratio between two-phases and & $e x$ & Exit \\
\hline & single phase heat transfer coef- & $e x h$ & Exhaust gas \\
\hline & ficient & $\exp$ & Expander \\
\hline$\rho$ & Density $\left(\frac{\mathrm{kg}}{\mathrm{m}^{3}}\right)$ & expe & Experimental \\
\hline$\sigma$ & Standard Deviation & $g l$ & Global \\
\hline$\tau$ & Time Constant $(s)$ & $I$ & Integral \\
\hline$\theta$ & Delay $(s)$ & $p$ & Proportional \\
\hline$D_{h}$ & Transfer function & $P_{\text {red }}$ & Reduced Pressure (-) \\
\hline \multicolumn{2}{|c|}{ Latin letters } & sim & Simulated \\
\hline$\dot{m}$ & Mass Flow Rate $\left(\frac{\mathrm{kg}}{\mathrm{s}}\right)$ & $s p$ & Single phase \\
\hline$\dot{Q}$ & Thermal Power $(W)$ & su & Suction \\
\hline$\dot{W}$ & Mechanical Power $(W)$ & suit & Suitable \\
\hline C & Displacement $\left(m^{3}\right)$ & $V_{\text {cap }}$ & Volume Capacity $\left(m^{3}\right)$ \\
\hline
\end{tabular}




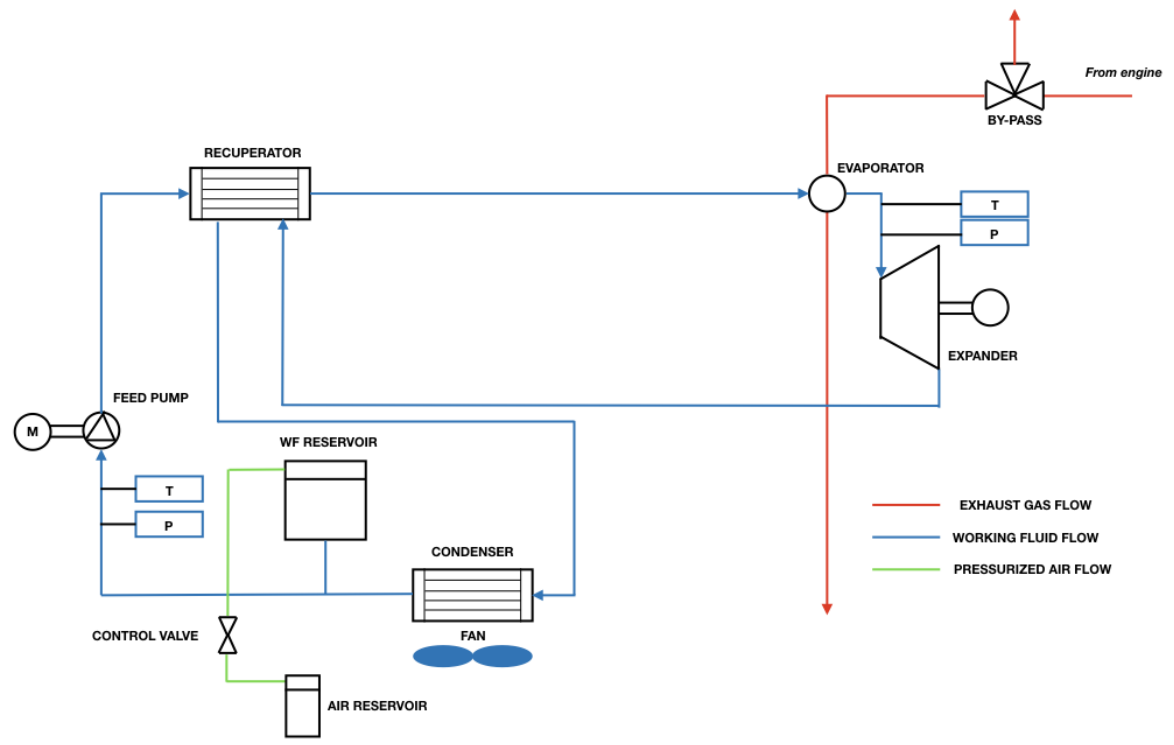

Figure 1: Rankine layout, recovering heat from exhaust gas, producing electrical power.

fluid in the evaporator. Additionally it can be noticed that the condenser and dedicated fans are placed on the side of the vehicle and the total cooling capacity is provided by the fan cooling airflow; consequently the removal of the excess heat from the condenser has no impact on the cooling system of the truck. The system produces electrical energy, therefore the expansion machine is coupled with a motor-generator electrical machine and it is mechanically disconnected from the drive-line. The working fluid is chosen in Sec. 2.2 following the analysis of the results of a simulation study where 4 different working fluids have been compared in terms of net power production of the system.

\subsection{Heat sources and sink}

Although several heat sources (such as engine coolant, EGR flow, Charge Air Cooler) are available on the vehicle for waste heat recovery applications, with different amount and variability of mass flow rate and temperature, in the proposed architecture the exhaust gas flow is used as the only heat source. The engine coolant is characterized by lower temperature (less than $100{ }^{\circ} \mathrm{C}$ ) and higher mass flow rate than the exhaust gas stream; the EGR flow is characterized by higher temperature and lower mass flow rate, as well as higher fluctuation of the available thermal power than the exhaust gas stream. Additionally 
Figure 2: Rankine system position in the truck (view from the top, not to scale).

(Grelet, 2016) observed that the heat source represented by the engine coolant flow is more interesting than the exhaust gas considering the first principle of thermodynamics, but results of a second principle of thermodynamic analysis show that the exhaust gas flow is the heat source that is characterized by the highest amount of exergy. This can be explained by noticing that the exhaust gas flow is at higher average temperature than the engine coolant flow.

In the current case study, the heat sink is represented by ambient air and no RAM Air Intake flow is supplied to the condenser, therefore the whole amount of air mass flow is provided by the electrically-driven fans. As already remarked, this architecture does not influence the cooling system of the truck, avoiding additional fan power demand of the cooling system (Galuppo et al., 2018b) because of the higher temperature of the air in the cooling package.

Moreover, the temperature of the cooling air, provided by the dedicated electricallydriven fans, at the inlet of the condenser has a strong impact on the overall performance of the system. Depending on the temperature of the cooling air, different strategies can be adopted to cool down the working fluid in the condenser, maximizing the net power production of the Rankine system. The strategies, that lead to a different handling of the condensation pressure and the rotating speed of the cooling fan, are presented and analyzed in Sec. 4.3.

\subsection{Working fluid selection}

The choice of the most suitable working fluid involves several aspects and performance is one of the major criteria; a working fluid should match well with 
the heat source, in order to reduce the exergy destruction and should be characterized by low heat of vaporization (Vaja and Gambarotta, 2010). Recently, (Preißinger et al., 2017) performed a computational chemical and thermodynamic selection among 72 millions of substances, to be used in an Organic Rankine Cycle recovering energy from internal combustion engine heat rejection; two different configurations of the ORC and three different cooling concepts were investigated. The multi-criteria evaluation considers thermodynamic aspects as well as regulations and safety issues and a trade-off occurs. Among the fluids with highest score, ethanol is present. In (Scaccabarozzi et al., 2018), the authors performed a working fluid selection and a cycle optimization based on thermodynamic and performance aspects. Among the organic fluids, cyclopentane is always considered as an optimal fluid.

Despite the numerous works about fluid selection, it is hard to recognize the best possible fluid to use in any waste heat recovery application for long-haul heavy-duty trucks (the architecture of the Rankine system strongly impacts the choice of the working fluids, (Guillaume and Lemort, 2019)). As for the Rankine system configuration that is presented in Fig. 1, the choice of the fluid is supported by an internal steady-state simulation work that considers the specific boundary conditions of the current architecture (heat source and sink) and the components that are used. In this work, four working fluids have been analyzed (cyclopentane, ethanol, Novec649 and R1233ZD) considering constant inputs, as the mass flow and temperature of the exhaust gas and the temperature of the air coolant flow. The size of the components is also considered as a constant input, because of packaging reasons.

On the other hand, specific parameters are changed because of the different nature of the working fluids. The lower heat of vaporization of Novec649 and R1233ZD leads to higher mass flow rate in the system. In the same time, the temperature and the density of both fluids in superheated conditions change very much as well with respect to cyclopentane and ethanol, affecting the operation of the expansion machine. One major change to be adopted in order to perform a fair comparison consists in the modification of the cut-off ratio of the volumetric expander (definition in Sec. 3.1.3), according to the temperature and the volumetric flow rate of the working fluid at the inlet of the expander. In order to take into account this feature of Novec649 and R1233ZD, the cutoff ratio of the expander is reduced as well as the set-point of the evaporation pressure; in this way it is possible to create the best operating conditions for the four fluids and then compare the different concepts as fairly as possible.

The performance analysis of the four working fluids is carried out in a specific operating point, $T_{e x h, s u, e v}=350^{\circ} \mathrm{C}$ and $\dot{m}_{e x h, s u, e v}=0.2 \mathrm{~kg} / \mathrm{s}$, found as the average of the exhaust mass flow rate and temperature provided by the 13-liter non-EGR engine driving a common highway road cycle and cooling air temperature $T_{\text {cool, su,cond }}=40{ }^{\circ} \mathrm{C}$; the performance is evaluated calculating the system net power produced $\dot{W}_{\text {net }}(1)$, that is obtained subtracting to the expander power produced $\dot{W}_{\text {exp }}$ the fan power $\dot{W}_{f a n}$ and pump power $\dot{W}_{\text {pump }}$ demand.

$$
\dot{W}_{n e t}=\dot{W}_{e x p}-\dot{W}_{f a n}-\dot{W}_{\text {pump }}
$$


The main variables results of the steady state simulations related to the four working fluids are listed in Tab. 1.

\begin{tabular}{cccccc} 
Fluid & $\rho_{\text {su,exp }}\left(\frac{\mathrm{kg}}{\mathrm{m}^{3}}\right)$ & $\dot{V}_{\text {su,exp }}\left(\frac{\mathrm{dm} \mathrm{m}^{3}}{\mathrm{~s}}\right)$ & $P_{\text {ev }}($ bar $)$ & $P_{\text {cond }}($ bar $)$ & NetPower $(k W)$ \\
\hline Cyclopentane & 61.2 & 1.410 & 25 & 3 & 3.76 \\
Ethanol & 35.5 & 1.135 & 25 & 2 & 3.69 \\
Novec649 & 235.1 & 1.895 & 16 & 3 & 2.26 \\
R1233ZD & 111.2 & 2.114 & 25 & 5 & 2.11 \\
\hline
\end{tabular}

Table 1: Main results of the simulation study basing on the different fluids.

The evaporation pressure set-point is 25 bar for ethanol, cyclopentane and R1233ZD, while the evaporation pressure of Novec649 is limited to 16 bar because of its lower critical pressure with respect to the other fluids; consequently, the expander power, as well as the net power produced by the system are reduced using Novec649. The condensation pressure that is set using the R1233ZD is higher than the values that are used for the other fluids because of the lowest normal boiling point of the R1233ZD among all the fluids that are currently considered; consequently the condensation pressure is raised in order to make feasible the removal of the excess heat from the condenser operating with the same cooling air temperature. The higher condensation pressure leads to a lower expander power produced, penalizing the global power balance of the system and reducing the net power produced.

Fig. 3 shows the different contributions of the net power produced (1); the reduced evaporation pressure of the Novec649 and the high condensation pressure of the R1233ZD lead to a lower expander power produced with respect to cyclopentane and ethanol and consequently to a lower net power produced.

Cyclopentane and ethanol are the best fluids for this specific architecture because their boiling points match better with the heat sink temperature and the design of the expander suits better with respect to the remaining fluids (according to the volumetric flow rate of the fluids at the inlet of the expander). However it can be noticed that the net power production of the system, using cyclopentane is higher, consequently cyclopentane is the selected working fluid for further analysis. 
Figure 3: Power demands and production of the Rankine system using the four fluids: the net performance of the Rankine system is evaluated subtracting the pump and fan power demand to the expander power produced.

\subsection{Actuators}

In order to deal with the disturbances induced by the road cycle, in terms of variation of mass flow and temperature of the heat source, controllers have to be implemented to adjust online specific important variables in the system. Indeed, as an example, a certain thermodynamic condition at the inlet of the expander and at the outlet of the condenser must be kept in order to avoid respectively liquid droplets in the expander and cavitation of the pump. In this process, the following five actuators are used as manipulated variables in different controllers:

- Feed pump speed, to control the thermodynamic conditions of the working fluid at the inlet of the expander

- Exhaust by-pass valve, that opens in case of over-temperature or overpressure of the working fluid

- Expander speed, to control the evaporation pressure

- Fan speed, to control the thermodynamic conditions of the working fluid at the outlet of the condenser

- Condensation pressure, to contribute to the control of the thermodynamic conditions of the working fluid at the outlet of the condenser, as well as to the improvement of the net power production of the system 


\section{Modeling}

Component models of the described Rankine architecture are developed and are implemented with the control algorithm in MATLAB/Simulink 2017. They are detailed in the following parts.

\subsection{Plant model}

The plant model is based on the interactions among the components of the Rankine and the thermodynamic state of the working fluid. The development of $1 \mathrm{D}$ models of the subsystems composing the plant model leads to the evaluation of physical relevant phenomena, as the thermal inertia in the heat exchangers, that are useful for the real assessment of the performance of the system.

This section shows the modeling approach of each component of the Rankine system and provides the validation of the evaporator and condenser models according to experimental results and data supplier; the plant that is presented in Fig. 9 uses cyclopentane as working fluid (that is selected as the most performing fluid for the current direct condensation architecture in Sec. 2.2) and pressure losses, as well as thermal losses are neglected in the current analysis.

\subsubsection{Pump model}

The pump model receives as input the pump speed from the controller and the pressure ratio, defined as the ratio between the evaporation pressure (supplied by the expander model, Sec. 3.1.3) and the condensation pressure that is determined by the dedicated controller.

The pressure at the outlet of the pump is calculated in the expander model, as the volumetric expander imposes the high pressure of the Rankine Cycle (assuming no pressure drops in the evaporator); the pressure at the inlet of the pump is a function of the mass flow rate (Sec. 4.3). As a function of the rotating speed $N_{\text {pump }}$, pressure ratio and displacement of the pump $C$, the model computes the mass flow rate of working fluid (2) and the pump power demand (3).

$$
\begin{gathered}
\dot{m}_{w f}=N_{\text {pump }} C \rho \\
\dot{W}_{\text {pump }}=\frac{\dot{m}_{w f}\left(h_{e x, i s}-h_{s u}\right)}{\eta_{g l, p u m p}}
\end{gathered}
$$

\subsubsection{Evaporator model}

The evaporator that is modeled and tested is a plate-fin heat exchanger, widely used in small-scale waste heat recovery applications (Lopes et al., 2012). Fig. 4 shows a frontal and side view of the evaporator as well as the inlet and outlet sections of the working fluid and exhaust gas; plates, where the working fluid

flows, are disposed in parallel with respect to the view from the top, therefore a counter-flow approach for modeling is fully justified. 
The model of the evaporator is a 1D finite volume (FV) model, where $N_{v o l}$ volumes are identified by discretizing the component along the longest dimension. In this application, the heat exchanger model is, as first approach, simulated as a standalone component, afterwards it is integrated into a complete Organic Rankine Cycle model and finally in a complete vehicle model, where cooling system, driver and all the mechanical components are modelled. Taking into account the frame of the work, the number of volumes $N_{v o l}$ is set to 10 , as a trade-off between accuracy and stability of the model and computational cost.

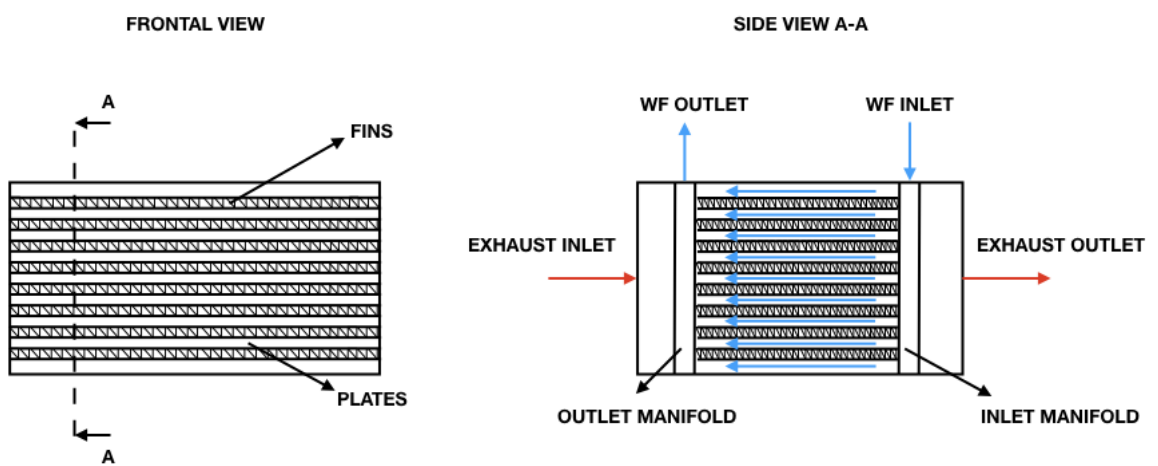

Figure 4: Frontal and side evaporator views; inlet and outlet of working fluid and exhaust flow as well as fins and plates are highlighted.

Fig. 5 shows that each volume is divided into three zones: the fluid side, the separation wall and the gas side. On the fluid and gas sides, mass and energy balance equations are applied in order to calculate the fluid state and the temperature of the exhaust gas at the outlet of each volume; in the separation wall the only energy balance equation is applied in order to calculate the average temperature of the wall in the specific volume. It can be noticed that the number of volumes is $N_{v o l}$ and the two nodes before and after the volume $i$ are named $i-1$ and $i$ respectively. In order to distinguish the volume variables from the node variables, the latter are denoted by a ' subscript. 


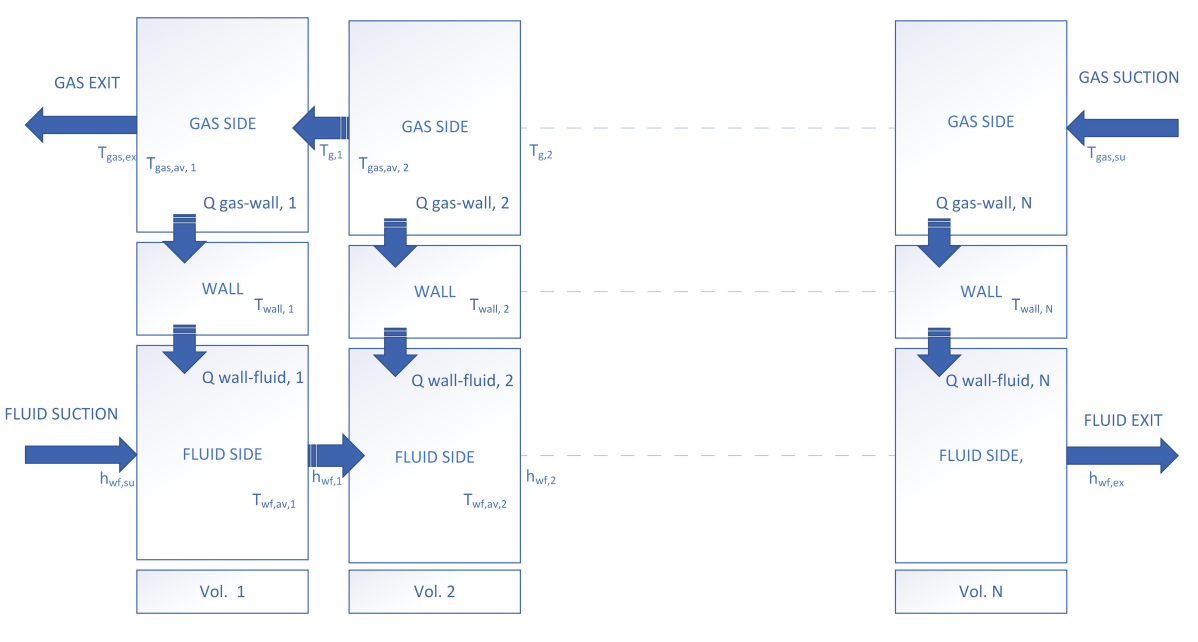

Figure 5: Discretization schema of the evaporator.

The discrete mass variation in time for each volume can be expressed by means of the differential of the enthalpy and pressure, as follows: (Quoilin, Sylvain, 2011):

$$
\frac{d M_{i}}{d t}=V \frac{\partial \rho}{\partial t}=V\left(\frac{\partial \rho}{\partial h} \frac{\partial h}{\partial t}+\frac{\partial \rho}{\partial p} \frac{\partial p}{\partial t}\right)=\dot{m}_{i}^{\prime}-\dot{m}_{i-1}^{\prime}
$$

The energy balance can be written as follows:

$$
\frac{d U_{i}}{d t}=\dot{m}_{i-1}^{\prime} h_{i-1}^{\prime}-m_{i}^{\prime} h_{i}^{\prime}+\dot{Q}_{i}+\dot{W}_{i}-p \frac{d V_{i}}{d t}
$$

Considering that no work is exchanged by the control volumes, using the definition of the internal energy $(U=H-p V)$ and the equation (4), the energy balance can be written as follow:

$$
\rho_{i} V_{i} \frac{\partial h_{i}}{\partial t}=\dot{m}_{i-1}^{\prime}\left(h_{i-1}^{\prime}-h_{i}\right)-\dot{m}_{i}^{\prime}\left(h_{i}^{\prime}-h_{i}\right)+\dot{Q}_{i}+V \frac{d p}{d t}
$$

Equ. (6) can be also written for the gas side considering that the enthalpy can be replaced by the product between the gas specific heat $c p$ and temperature $T$. The power balance equation applied to the wall is:

$$
\rho_{i} V_{i} c p \frac{\partial T_{i}}{\partial t}=\dot{m}_{i-1}^{\prime} c p\left(T_{i-1}^{\prime}-T_{i}\right)-\dot{m}_{i}^{\prime} c p\left(T_{i}^{\prime}-T_{i}\right)+\dot{Q}_{i}
$$

considering the specific heat $c p$ constant and the gas as incompressible fluid. The energy balance equation applied to the wall can be finally written as follows:

$$
M_{w} c p_{w} \frac{\partial T_{w, i}}{\partial t}=\dot{Q}_{g a s-w a l l, i}-\dot{Q}_{\text {wall-fluid }, i}
$$

In order to evaluate the heat transfer occurring between the exhaust gas and the fluid flow (via the internal wall of the heat exchanger) external and internal dimensions of the component are measured or calculated. In particular, the following geometrical data used in the evaluation of the heat transfer: 
- Heat transfer area for fluid and gas sides

- Flow section for fluid and gas

- Volume for fluid and gas sides

- Separation wall volume

The thermal power that is exchanged between the exhaust gas and the fluid can be calculated by (9):

$$
\dot{Q}_{t h}=A_{g l} U_{g l} \Delta T_{\text {suit }}
$$

$\Delta T_{\text {suit }}$ is a suitable temperature difference between exhaust gas and fluid (i.e. the mean logarithmic temperature difference) and the product $A_{g l} U_{g l}$ is the global heat transfer coefficient (Incropera et al., 1993). (9) can be written for each side of the heat exchanger by introducing the wall properties. Consequently the thermal power exchanged between the exhaust gas and the separation wall $\dot{Q}_{t h, \text { gas-wall }}$ and between the separation wall and the fluid $\dot{Q}_{\text {th,wall-fluid }}$ can be written respectively as in (10) and (11)

$$
\begin{gathered}
\dot{Q}_{\text {th,gas-wall }}=A_{\text {gas }} U_{\text {gas }} \Delta T_{\text {gas-wall }} \\
\dot{Q}_{\text {th,wall-fluid }}=A_{\text {fluid }} U_{\text {fluid }} \Delta T_{\text {wall-fluid }}
\end{gathered}
$$

The heat transfer coefficient $U$ should be determined for the gas and fluid. As reminded by (Quoilin, Sylvain, 2011), the gas heat transfer coefficient in singlephase flow is mainly dependent on the mass flow rate.

In this work, the heat transfer coefficient of the fluid is calculated taking into account the flow regime as well as the nature of the fluid; the Dittus-Boelter and the Shah correlations are used to calculate the Nusselt number (directly correlated to the heat transfer coefficient) respectively for single phase and twophase flow.

Dittus-Boelter correlation, according to turbulent flow in ducts (Winterton, 1998):

$$
N u_{s p}=0.023 R e_{D_{h}}^{0.8} \operatorname{Pr}^{0.4},
$$

where $R e_{D_{h}}$ is the Reynolds number calculated in the flow area fluid side and $\operatorname{Pr}$ is the Prandtl number. Then using Shah correlations ((Shah, 1976) for boiling flow (13) , (Shah, 1979) for condensing flow (14)), $N u$ is given by:

$$
N u=\left\{\begin{array}{l}
\psi N u_{s p} \\
N u_{s p}\left[(1-q)^{0.8}+\frac{3.8 q^{0.76}(1-q)^{0.04}}{P_{r e d}^{0.38}}\right]
\end{array}\right.
$$

where $\psi$ is a factor depending on the boiling number $B o$ and convection number Co defined in (Shah, 1976), $q$ is the quality of vapor and $P_{r e d}$ is the reduced pressure defined as the ratio of the actual fluid pressure to the critical pressure 
of the fluid.

Focusing on the evaporator, the experiments are realized in steady state condition in different engine operating points and consequently thermal power from 20 to $70 \mathrm{~kW}$. In each experiment the working fluid mass flow is adjusted in order to obtain the same superheat conditions at the outlet of the evaporator.

In the test bench the following variables can be measured:

- Mass flow rate of the working fluid by means of a Coriolis flow-meter at the outlet of the feed pump and mass flow rate of the exhaust gas by means of a Annubar flow-meter at the inlet of the evaporator

- Pressure on the fluid side by means of differential pressure sensors, at the inlet and outlet of the evaporator

- Temperature on the fluid side by means of thermocouples $\mathrm{T}$, one at the inlet and one at the outlet of the evaporator and on the gas side, three thermocouples $\mathrm{K}$ at the inlet of the evaporator and one at the outlet of the evaporator.

The thermal power exchanged between exhaust gas and working fluid has been plotted in Fig. 6. The error between the thermal power predicted by the model and measured from experiments, defined as in (15), is $0.51 \%$.

$$
E r r=100 \times\left\|\frac{\dot{Q}_{\text {expe }}-\dot{Q}_{\text {sim }}}{\dot{Q}_{\text {exp }}}\right\|
$$

Fig. 7 shows the prediction of the exhaust gas temperature at the outlet of the evaporator. In this case the absolute error of the prediction is $7.83 \mathrm{~K}$. Therefore, Fig. 6 and 7 show that the model is able to predict the performance of the evaporator.

\subsubsection{Expander model}

The considered expansion machine is a volumetric expander whose the following data are available:

- Clearance volume $V_{0}$ expressed in $m^{3}$

- The volume capacity $V_{c a p}$, expressed in $m^{3}$, that is the volume at the end of the expansion process

- The cut-off ratio $C O_{\text {ratio }}$, that is the fraction of the stroke that is involved in the admission process.

These data are useful to compute the volume at the end of the suction process, in other words the expander displacement, $V_{s}$, as shown in (16).

$$
V_{s}=V_{\text {cap }} C O_{\text {ratio }} .
$$




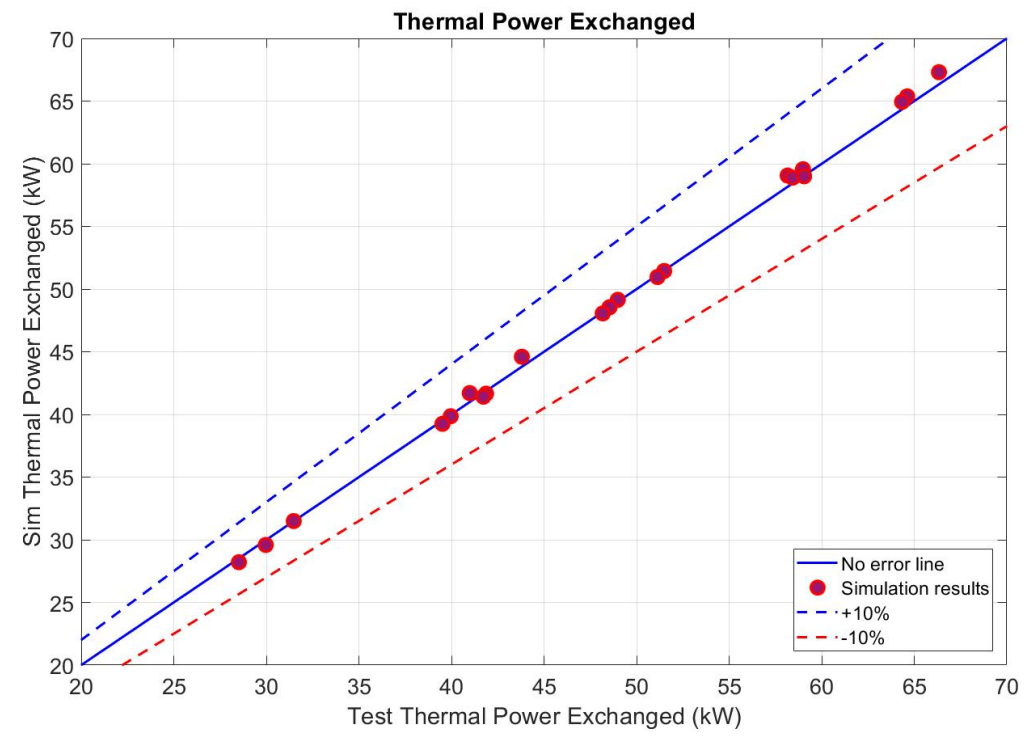

Figure 6: Comparison between predicted and measured thermal power exchanged in the evaporator.

Such an expander, rotating at variable speed, is responsible of the high pressure in the Rankine loop. The expander chambers accept in their volume a mass of working fluid that is function of the mass flow rate of the working fluid and its rotating speed. As a first approach, the density is calculated in the following time step $i+1$ as a function of the mass that is stored in the expander chambers in the time step $i$ for one revolution and the geometrical data of the machine :

$$
\rho(i+1)=\frac{\frac{\dot{m}_{w f}(i)}{N_{e x p}}(i)}{V_{\text {cap }} C O_{\text {ratio }}+V_{0}}
$$

where $i$ is the current time step.

The denominator of (17) represents the volume occupied by the working fluid at the end of the suction process, in other words when the supply valve closes. From density, calculated in (17) and temperature, calculated as the temperature at the outlet of the evaporator in the evaporator model, it is possible to obtain the pressure of the working fluid at the inlet of the expander. This information is also used by the pump model to consider the pressure ratio between inlet and outlet of the pump.

Once the state of the working fluid at the inlet of the expander is completely defined, it is possible to calculate, considering that the working fluid at the outlet of the expander is always in vapor state, the gross power production of the expander (18) taking advantage of the map of the total expander isentropic efficiency in Fig. (8) and the pressure at the outlet of the expansion machine: 


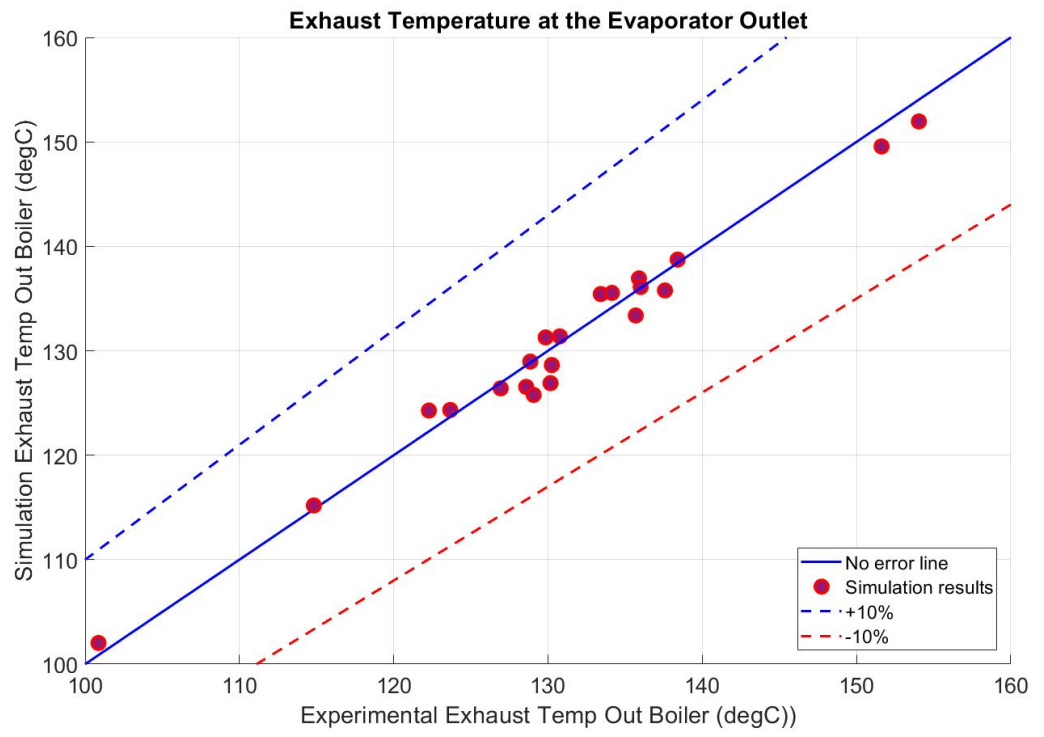

Figure 7: Comparison between the predicted and measured exhaust temperature at the outlet of the evaporator.

$$
\dot{W}_{g r o s s, \exp }=\dot{m}_{w f}\left(h_{s u, e x p}\left(T_{w f, s u, e x p}, p_{w f, s u, e x p}\right)-h_{e x, \exp }\left(T_{w f, \operatorname{ex}, \exp }, p_{w f, e x, \exp }\right)\right)
$$

\subsubsection{Direct Condenser and fan model}

The selected condenser is an aluminum heat exchanger made up of flat extruded tubes and of corrugated louvered fins. Assuming a perfect distribution of the cooling air on the surface of the condenser, it is possible to consider a cross-flow pattern as Fig. 9 shows.

The condenser model is obtained using a 1D finite volume (FV) discretization. Energy and mass balance conservation equations are applied to the gas side, fluid side and separation wall (eq. 4, 6, 7, 8.) The overall mass flow of cooling air is divided by the number of volumes adopted for the discretization and its outlet temperature is computed as the average of the outlet temperature of the cooling air from each volume.

In order to compute correctly the thermal power exchanged between the fluid and the wall, and between the wall and air flow, a geometrical analysis of the condenser is necessary. Geometrical data can be retrieved by calculations, once the fluid side and air side exchange areas are set (these data available from the supplier). In particular, the following data are retrieved or calculated: 


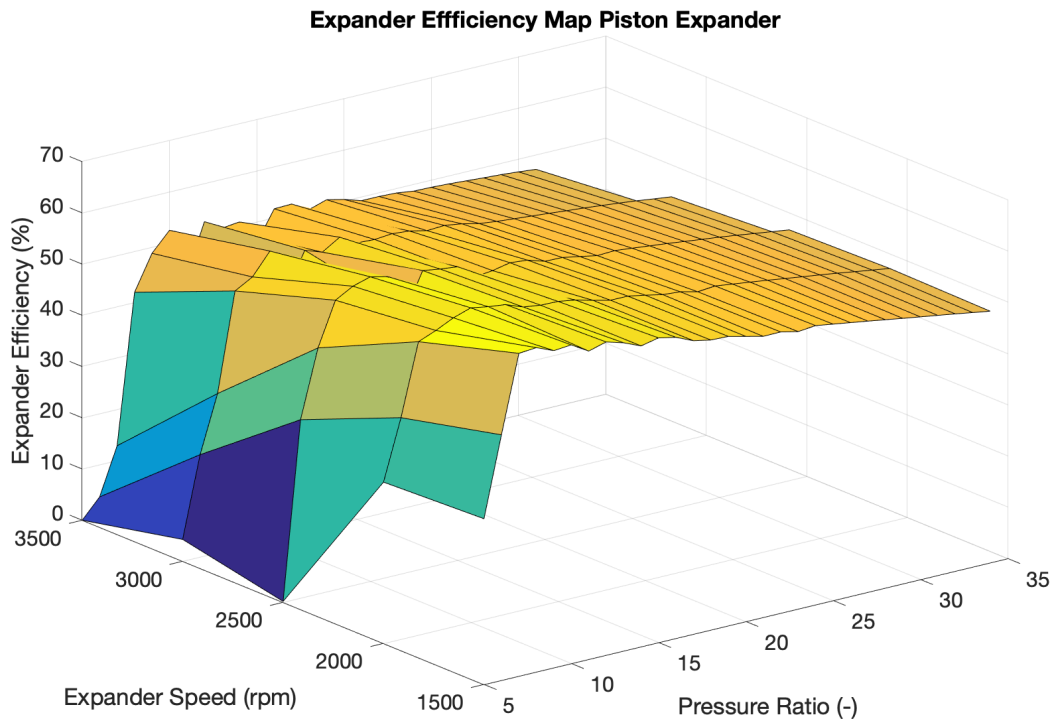

Figure 8: Total expander efficiency as a function of the pressure ratio and the expander speed.

- Number of tubes

- Fin density $\left(\frac{N_{f i n}}{d m}\right)$

- Heat transfer area for fluid and gas sides

- Flow section for fluid and gas

- Volume for fluid and gas sides

- Separation wall volume

Considering the fluid side, the fluid flows in channels that are obtained in the tubes; according to the classification of (Kandlikar, 2002), channels of the size between 0.2 and $3 \mathrm{~mm}$ are considered as mini-channels Here the mini channels have a rectangular section. Using this data and knowing the fluid side heat exchange area, it is possible to compute the fluid flow area and the number of mini channels per tube. These data are useful for the definition of the flow regime and calculation of the heat transfer coefficients in single phase and two-phase ((12), (14)). Regarding the air side, several other studies have been conducted in the last decades (Chang and Wang, 1997), (Chan Kang and Jun, 2011), (El Hajal et al., 2003). For this work, the correlation proposed by (Chan Kang and Jun, 2011) has been chosen because of the wide combination of different geometries of louvers and fins that have been investigated. The empirical correlations 
WF CONDENSER SUCTION

allow to compute the Colburn number $j$ and the friction factor $f$ (Fig. 10.a), that are useful to find respectively the heat transfer coefficient on air side $h_{a s}$ (Fig. 10.b) and the the pressure drop of the air through the condenser. In this work, we consider that the Colburn number $j$ and heat transfer coefficient $h$ are correlated as follow (Chan Kang and Jun, 2011):

$$
j=\frac{\eta_{f i n} h P r^{2 / 3}}{\rho u_{c} c p},
$$

where $\eta$ is the fin efficiency, $c p$ is the specific heat of the air at constant pressure and $u_{c}$ is the velocity of the air in the louver section (minimum flow section). The heat transfer coefficient and the air pressure drop as a function of the Reynolds number are shown in Fig. 10.b.

Fig. 10.a and 10.b show coherent results according to literature in terms of absolute values and variation with the Reynolds number.

Fan suppliers provide the fan curve, which expresses the static pressure $(\Delta P)$ variation through the fan as a function of the volumetric flow rate $\left(\mathrm{m}^{3} / h\right)$ at nominal speed. Curves at other speeds can be modeled thanks to the Fan Laws (20) (Kanefsky et al., 1999). Plotting in the same graph the fan curves at different fan speeds and the pressure drop curve characteristic of the condenser, it is possible to identify the intersections, hence the operating points of the system. The condenser model predicts the condenser pressure drop from data supplier with a relative error of $1 \%$ in the range of interest of volume flow rate (Fig. 11).

$$
\left\{\begin{array}{l}
\dot{Q}=K_{q} D^{3} N \\
\Delta P=K_{p} D^{2} N^{2} \rho \\
\dot{W}=K_{w} D^{5} N^{3} \rho
\end{array}\right.
$$




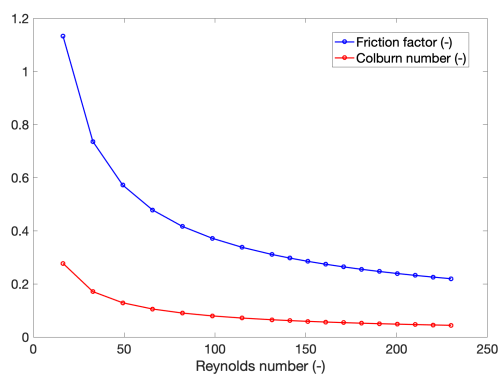

(a) $f-j$

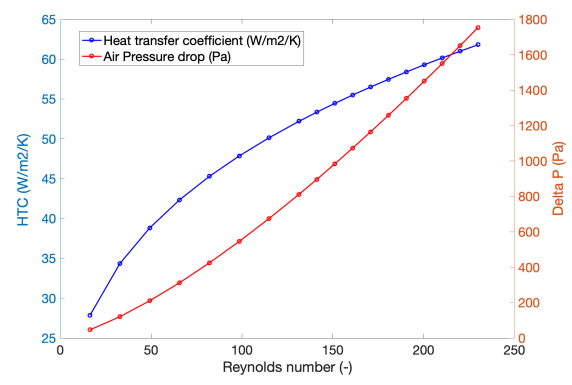

(b) $h-\Delta P$

Figure 10: (a) Friction factor and Colburn number as a function of the Reynolds number calculated in the minimum flow section (louver section). (b) Heat transfer coefficient and pressure drop as a function of the Reynolds number calculated in the minimum flow section (louver section).

where $K_{q}, K_{p}, K_{w}$ are the flow, pressure and power coefficients, $D$ is the fan diameter, $N$ is the fan speed.

\section{Base control strategy}

The main actuators of the proposed Rankine system have been already mentioned in Sec.2.3. In this section the control strategy that is adopted for each actuator is described.

The linear models that are adopted for control are Single Input Single Output (SISO) that can be written in the form:

$$
\begin{aligned}
& \dot{x}=f(x, y) \\
& y=g(x, u),
\end{aligned}
$$

where $x \in \mathcal{R}^{n}$ is the state, $u \in \mathcal{R}^{n_{u}}$ the input variable and $y \in \mathcal{R}^{n_{y}}$ is the output variable and $f$ and $g$ are two vector functions with appropriate dimension.

Considering the control of the thermodynamic conditions of the working fluid at the inlet of the expander, the variable $u$ is represented by the pump speed and the variable $y$ is represented by the specific variable that is necessary to keep close to a set-point by acting on the pump speed.

The same approach is not applicable, for the presented architecture and the purpose of control, for the control of the thermodynamic conditions at the outlet of the condenser; in this case, the considered system is treated as a Multiple Input Single Output (MISO), as the manipulated variables are the rotating fan speed and the condensation pressure. Sec.4.3 shows how the problem is treated in order to ensure good control performance and power production. 


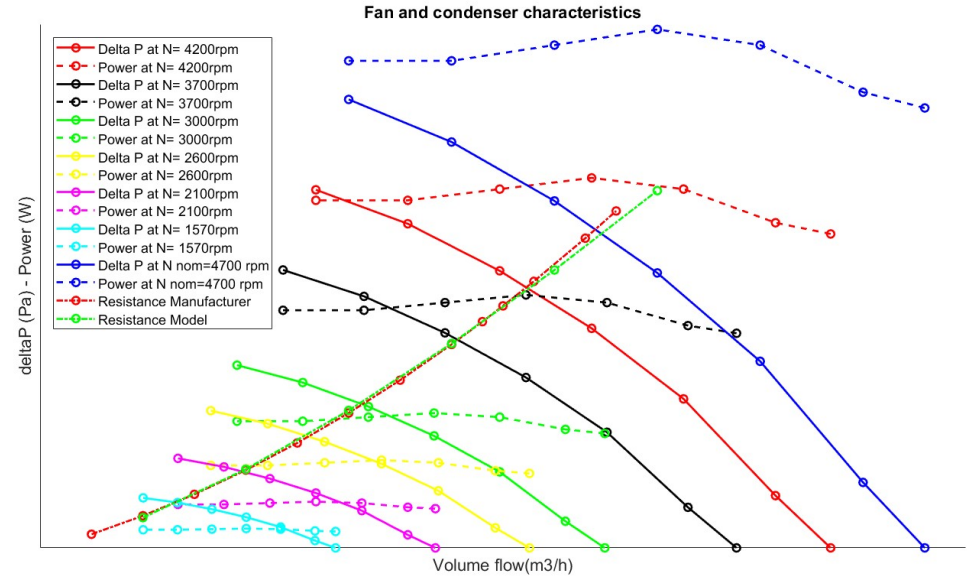

Figure 11: Fan static pressures and power demands at different fan speeds and condenser pressure drops. The condenser pressure drop is predicted (green resistance line) with an error of $1 \%$ with respect to the supplier data (red resistance line).

\subsection{Superheat control}

The control of the superheat $S H_{\text {su,exp }}$ is necessary to control the thermodynamic conditions of the working fluid at the inlet of the expander, ensuring performance and safe operation of the component.

$$
S H_{s u, e x p}=T_{s u, e x p}-T_{s a t}\left(P_{e v}\right) .
$$

The superheat must be kept at a positive value in order to ensure vapor supply to the expander. The set-point is tracked varying the pump speed, consequently the working fluid mass flow rate is changed.

In this work, a Multi Model PI controller is used, where the structure of the algorithm has been presented by (Grelet, 2016). The determination of the parameters of the PI control is usually a key aspect to ensure high performance of the controller; meta-heuristic approaches are available for such a goal, as the novel grouped grey world optimizer and democratic joint operation algorithm proposed in (Yang et al., 2017) and (Yang et al., 2018) and applied to a wind energy conversion system. In both cases, those strategies, according to the results, allow a larger amount of wind energy, lower tracking error and control costs with respect to other algorithms.

In this work, a step and response experimental campaign has been performed in different operating points chosen using the algorithm proposed in (Galuppo et al., 2018a). In general, it is possible to write a discrete nonlinear model in the form (24), for one operating point. 


$$
\left\{\begin{array}{l}
x(k+1)=f(x(k), u(k)) \\
y(k)=g(x(k), u(k))
\end{array}\right.
$$

with $y \in \mathcal{R}^{n_{y}}$ the measured outputs, $u \in \mathcal{R}^{n_{u}}$ the measured inputs. A set of local linear models can be written as (25)

$$
\left\{\begin{array}{l}
x_{i}(k+1)=f_{i}\left(x_{i}(k), u(k)\right) \\
y_{i}(k)=g_{i}\left(x_{i}(k), u(k)\right)
\end{array}\right.
$$

each tuned to approximate (24) around an operating point. To obtain a global model, these local models have to be combined. The chosen approach is to construct a global model by linearly interpolating between the local models:

$$
\hat{y}(k)=\sum_{i=1}^{N} w_{i}(k) y_{i}(k)
$$

Here, the weights $w_{i}$ provide a time-varying adaptation and they are calculated according to Bayesian estimators as in (Aufderheide and Bequette, 2003). As shown in (Galuppo et al., 2018a), the relationship between pump actuator and superheat at evaporator outlet can be modeled locally by a low order linear system around an equilibrium point; a first order plus time delay model (FOPTD) is used (27)

$$
\frac{y_{u}(s)}{u(s)}=\frac{G_{u}}{\left(1+\tau_{u} s\right)} e^{-L_{u} s}
$$

The Bayesian estimator identifies a single set of FOPTD parameters that are composed of an equivalent static gain $G_{e q}$, time constant $\tau_{e q}$ and delay $\theta_{e q}$ and computed as in (28).

$$
\left\{\begin{array}{l}
G_{e q}=\sum_{i=1}^{N} w_{i, k} G_{i} \\
\tau_{e q}=\sum_{i=1}^{N} w_{i, k} \tau_{i} \\
\theta_{e q}=\sum_{i=1}^{N} w_{i, k} \theta_{i}
\end{array}\right.
$$

where $N$ is the total number of FOPTD models (37 in the current application). In Tab. 2, the equivalent mean values of the FOPTD time varying parameters over a complete road cycle are shown, as well as their standard deviations.

Table 2: FOPTD parameters, statistical analysis.

\begin{tabular}{ccccccc} 
Weighting scheme & $\bar{G}$ & $\bar{\tau}$ & $\bar{\theta}$ & $\sigma(G)$ & $\sigma(\tau)$ & $\sigma(\theta)$ \\
\hline Bayesian & -0.37 & 9.10 & 0.54 & $2.3 \mathrm{e}-3$ & $3.6 \mathrm{e}-2$ & $3.9 \mathrm{e}-4$ \\
\hline
\end{tabular}

For each time step, a PID controller is tuned using the equivalent FOPTD model, applying the SIMC approach proposed by (Skogestad, 2006), where one 
additional tuning parameter $\tau_{c}$ is required to govern the desired closed-loop time response (29).

$$
\left\{\begin{array}{l}
K_{p}=\frac{1}{G_{e q}} \frac{\tau_{e q}}{\tau_{c} \theta_{e q}} \\
T_{I}=\min \left(\tau_{e q}, 4\left(\tau_{c}+\theta_{e q}\right)\right) \\
T_{d}=0
\end{array}\right.
$$

Fig. 12 shows the effect of the change of operating point of the engine on the mass flow rate of working fluid and, consequently on pressure and temperature at the inlet of the expansion machine; the controller of the superheat at the inlet of the expander reacts quickly and keep the actual value of superheat very close to the set-point.
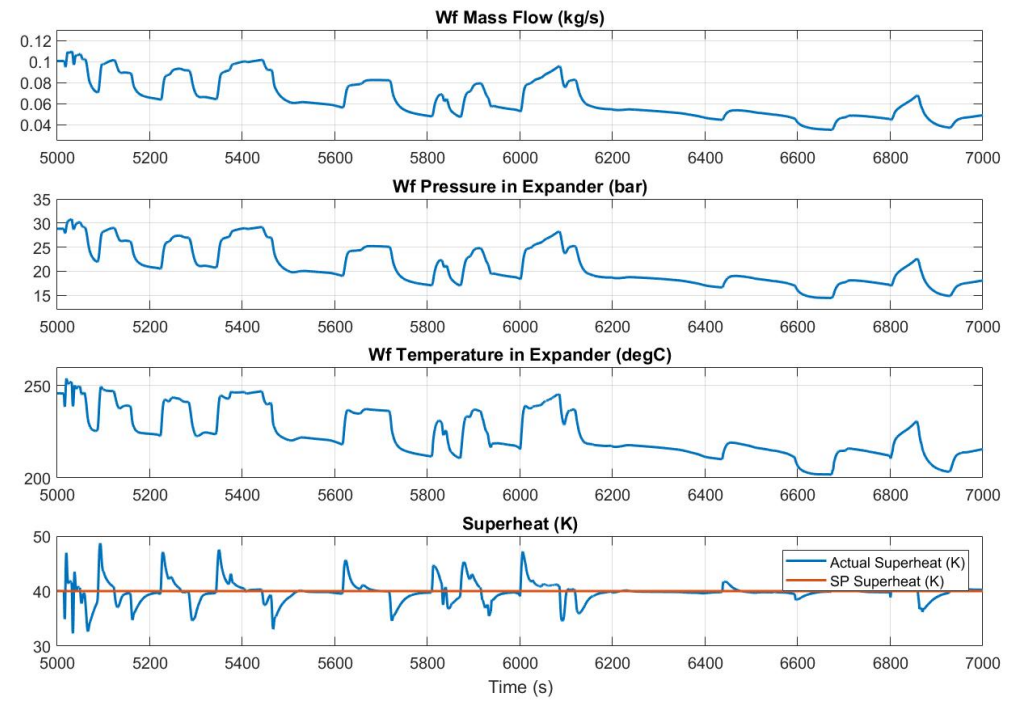

Figure 12: Superheat, depending on temperature and pressure, control acting on pump speed and consequently on the mass flow rate of the working fluid.

\subsection{Expander speed and exhaust by-pass control}

The exhaust by-pass valve is a safety component that reduces the thermal power input to the Rankine system in case of over-temperature or over-pressure detected in the working fluid. The control of the exhaust by-pass valve is mapbased and by-pass opens as soon as the maximum temperature of the working fluid reaches $240^{\circ} \mathrm{C}$. Fig. 14 shows how the exhaust by-pass is fully closed in the phases that are characterized by the working fluid maximum temperature below $240{ }^{\circ} \mathrm{C}$ and the progressive opening of the by-pass as soon as the working 
fluid temperature is larger than $240{ }^{\circ} \mathrm{C}$.

The expander speed influences the high pressure loop of the Rankine system (17) and the tracking of an optimal set-point leads to the operation of the expansion machine within the points that are characterized by highest efficiency values (8); the expander speed varies between 1000 and $3500 \mathrm{rpm}$, the exhaust bypass value varies from 0 , by-pass completely opened, to 100 , by-pass completely closed). The controller is a PI (Proportional-Integral controller) that varies the expander speed to track the evaporation pressure set-point. The controller is tuned using the IMC technique (Rivera et al., 1986) and the computation of the gain and time constant is based on step and response campaign on the expander model. The tracking results are shown in Fig 13; the evaporation pressure setpoint varies according to the working fluid mass flow and the expander speed regulation ensures the tracking of the set-point.
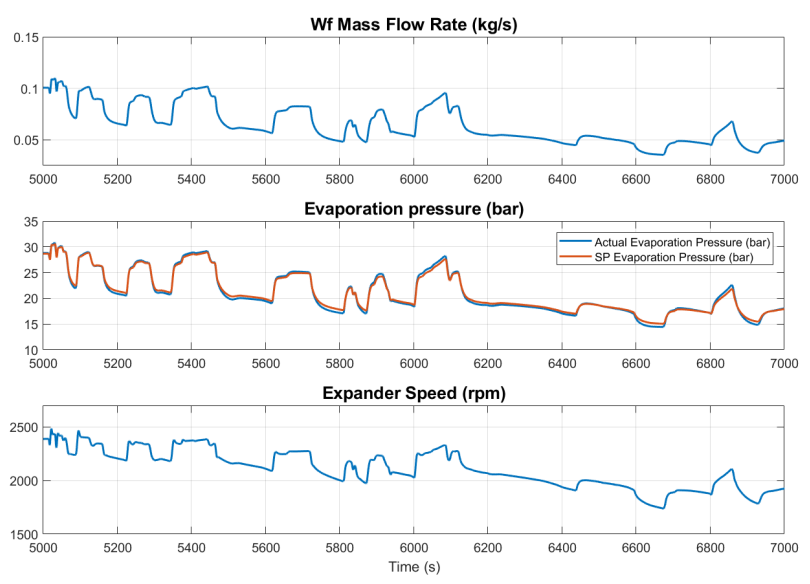

Figure 13: Evaporation pressure control; the evaporator pressure set-point is computed for each time step as a function of the working fluid mass flow rate.

\subsection{Subcooling control}

The subcooling is an useful variable to establish the phase of the fluid at the outlet of the condenser (30).

$$
S C_{e x, \text { cond }}=T_{\text {sat }}\left(P_{\text {cond }}\right)-T_{\text {ex }, \text { cond }} .
$$

The choice of set-point of the subcooling at the outlet of the condenser is, at a first sight, straightforward. It is clear that, a higher subcooling value leads to higher energy demand of the cooling actuators, with a negative impact on the energy balance of the whole Rankine system. In the same time, a higher subcooling strongly impacts on the efficiency of the thermodynamic cycle, by 
Figure 14: Exhaust by-pass control depending on the maximum working fluid temperature admitted in the Rankine system.

reducing it. Therefore, the main interest is to keep the subcooling particularly low, in order to reduce the impact on the energy balance and efficiency. Unfortunately, in real experiments, two main problems arise when reducing the subcooling at the outlet of the condenser (inlet of the pump):

- When the subcooling is particularly low and the working fluid is very close to the saturation conditions, local phenomena of condensation, with formations of bubbles can appear. This situation is particularly dangerous for the correct operation of the pump, that requires a liquid fluid at the inlet section.

- The use of complicated controllers is forbidden in automotive applications. Therefore, the actual value of the subcooling deviates from the set-point in highly transient conditions and choosing a too low value of subcooling would increase the risk of having a two-phase fluid at the inlet of the pump.

Considering the necessity to reduce the subcooling and, in the same time, ensure a positive actual value in all the possible conditions, a subcooling set-point $S C_{S P}=9 K$ is chosen and a controller is designed.

The Bayesian estimators and the SIMC technique (presented in Sec. 4.1) have been used to determine the parameters of the PID controllers of the subcooling at the outlet of the condenser (a step and response campaign on the condenser model has been performed). However the fan speed can reach a maximum value at high loads, consequently the air flow provided to the condenser is not enough to reach the complete condensation of the working fluid.

In order to face the high loads and to ensure a subcooled liquid supply to the pump, the condensation pressure has to be raised. This leads to the fact that 
the mean temperature difference between the cooling air and the working fluid is higher; consequently a lower air flow rate to the condenser is necessary to ensure the subcooling set-point at the inlet of the pump and, in the same time, the gross power production of the expander reduces consistently (more details in Sec. 5).

In this work, three different strategies for the control of the subcooling at the outlet of the condenser are presented:

1. PID controller acting on the fan speed and constant condensation pressure

2. PID controller acting on the fan speed, computing the desired condensation pressure setting a constant pressure ratio $P R$ between the inlet and outlet of the expansion machine

3. PID controller acting on the fan speed and an optimized strategy for the condensation pressure taking into account the temperature of the air flow at the inlet of the condenser. The controller scheme in Fig. 15 shows the optimization block, that has as output the optimal condensation pressure $P_{\text {cond }} ; G_{c, S C}(s)$ and $G_{p}(s)$ are the subcooling controller and the plant transfer functions. The vector $x_{p}$ is the vector of states, that is actively used in the computation of the optimal condensation pressure.

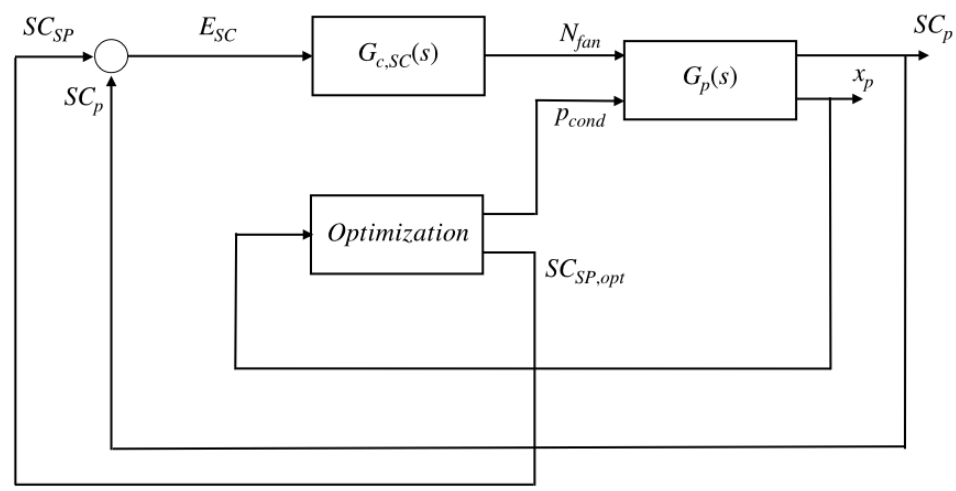

Figure 15: Optimal control strategy of the subcooling.

The same approach adopted in Sec. 4.1 to tune the PID controller of the subcooling at the inlet of the pump has been applied.

The condensation pressure can be modified by pressurizing the low pressure side of the Rankine system using the air storage at 7 bar that is available in the vehicle; an increase of the condensation pressure determines an increase of the subcooling (30) with faster dynamics than the fan speed. In the case of strategy 2 , the desired condensation pressure is calculated on-line considering the evaporation pressure and a fixed pressure ratio, that has been identified with the value of $P R=9$, according to the efficiency table of the current expander (Fig. $8)$. This solution is adopted to ensure the tracking of the subcooling at the inlet 
of the pump and, in the same, working with high values of expander efficiency. In the case of strategy 3 , the condensation pressure value to adopt is varied according to a model based optimization, that ensures the tracking of the subcooling set-point and improves the performance of the system (1) with respect to the strategy 1 and 2. A simplified analytical model has been developed, in order to compute the net power produced as a function of few variables that will be further available as measurements in the following experimental campaign. These known variables are listed hereafter and the complete equation of the net power produced as a quadratic form with respect to the fan speed $N_{f a n}$ and condensation pressure $p_{\text {cond }}$ is presented in (31):

- Pressure and temperature at the inlet of the expander

- Pressure and temperature at the outlet of the condenser

- Pump, expander and fan speed

$$
\dot{W}_{\text {net }}=A_{1} N_{\text {fan }}^{2}+A_{2} p_{\text {cond }}^{2}+B_{1} N_{\text {fan }}+B_{2} p_{\text {cond }}+C .
$$

where the coefficients $A_{1}, A_{2}, B_{i}, B_{2}$ and $C$ are depending on the plant state vector $x_{p}$, consequently they are variable in time.

The analytical model predicts the net power output as a function of the fan speed and condensation pressure and a trade-off between the two variables can be found (in other words, a trade-off between the fan power demand and the expander power production); therefore strategy 3 represents a solution that maximizes the net power, taking into account the temperature of the air at the inlet of the condenser (results in Sec. 5).

The comparison of the three strategies in terms of subcooling control is shown in Fig. 16, considering the ambient cooling air set at $40{ }^{\circ} \mathrm{C}$ at the inlet of the condenser and in Fig. 17, considering the ambient cooling air set at $20^{\circ} \mathrm{C}$. The subcooling set-point is well tracked in most of the road cycle phases, except adopting the strategy 1 , that, in particular during the phases characterized by low thermal load in the condenser and ambient cooling air set at $20^{\circ} \mathrm{C}$, has not the property to adapt (reduce in this case) the condensation pressure when the fan speed saturated to its lowest value; consequently the actual value of the subcooling is higher than the set-point. As for the strategies 2 and 3 , it is possible to notice that a different trade-off between condensation pressure and fan speed can be found ensuring the tracking of the same subcooling set-point. As for ambient cooling air set at $40{ }^{\circ} \mathrm{C}$, the strategy 3 leads to a global increase of the condensation pressure and a reduction of the fan speed, as a result of the fact that the high temperature of the cooling air at the inlet of the condenser. This result is physically logical, as for higher temperature of the air at the inlet of the condenser, the thermal exchange in the condenser is less performing and it is more convenient, from an energetic point of view, to pressurize the condensing side of the system, reducing in the same time the expander power produced and the fan power demand and eventually increasing the net power produced. 

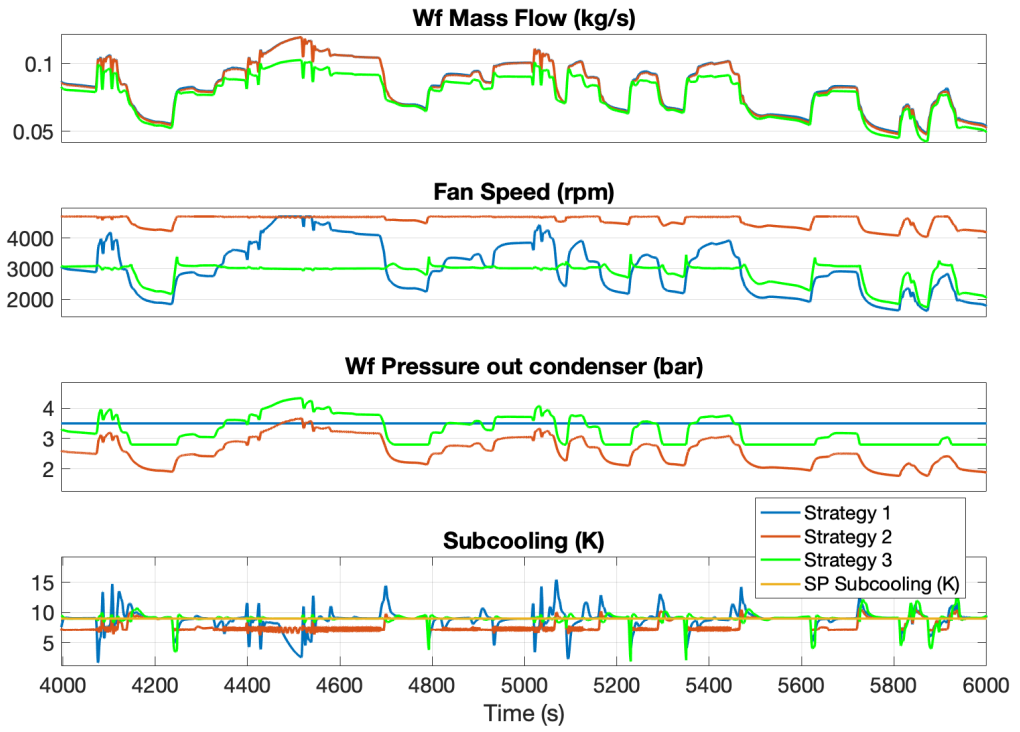

Figure 16: Comparison of the three strategies for subcooling control setting the air cooling temperature at $40^{\circ} \mathrm{C}$.

On the other hand, as for ambient cooling air set at $20^{\circ} \mathrm{C}$, the strategy 3 leads to an increase of the fan speed and a reduction of the condensation pressure with respect to the strategy 2 (Fig. 17), as it is more favorable to increase the air flow rate to the condenser when cooling air temperature is lower. The results in terms of net power produced by the Rankine system are shown in Sec. 5 .

\section{Road cycle results}

Road cycle simulations, using cyclopentane as working fluid, in a highly transient environment are necessary to estimate the potential of the Rankine technology in long-haul heavy-duty trucks. The engine is a 13-liter non-EGR and the road cycle, Frankfurt-Koblenz lately called FK, is characterized by the average thermal power of $50 \mathrm{~kW}$, with important variability of the heat source in terms of temperature and mass flow of the exhaust gas, due to braking phases over the 150 minutes of the cycle duration, as it is shown in Fig. 18.

For the three strategies previously presented and air cooling temperature set at $40{ }^{\circ} \mathrm{C}$ and $20{ }^{\circ} \mathrm{C}$ respectively, Fig. 19 and 20 show the net and expander power produced and the pump and fan power demands; the graphs confirm that the strategy 3 is able to improve the net power produced by the strategy 1 and 2, respecting the constraint represented by the subcooling set-point (Fig. 16 and 17). In order to compare the different strategies along the complete road cycle, 
Figure 17: Comparison of the three strategies for subcooling control setting the air cooling temperature at $20^{\circ} \mathrm{C}$.
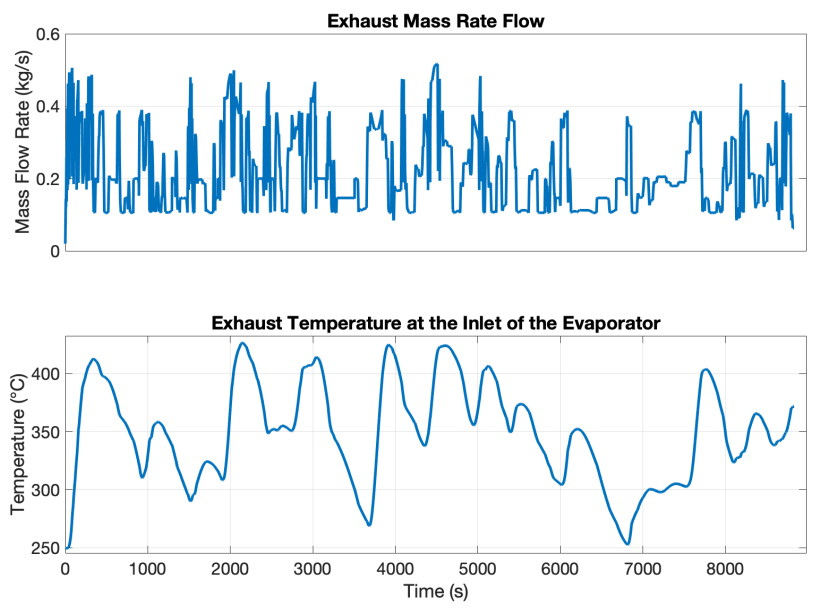

Figure 18: Exhaust mass flow rate and temperature at the inlet of the Rankine evaporator along the whole FK road cycle.

mean values are shown, normalizing each value with respect to the highest value of the expander gross power produced (Fig. 21); the graph confirms that the strategy 3 is able to improve the net power produced by the strategy 1 and 2, 
setting the air cooling temperature at 20 and $40{ }^{\circ} \mathrm{C}$. In particular, as for air cooling temperature set to $20{ }^{\circ} \mathrm{C}$, the net power is improved by 8 and $3 \%$ with respect to the strategies 1 and 2; as for air cooling temperature set to $40{ }^{\circ} \mathrm{C}$, the net power is improved by 12 and $3 \%$ with respect to the strategies 1 and 2 .
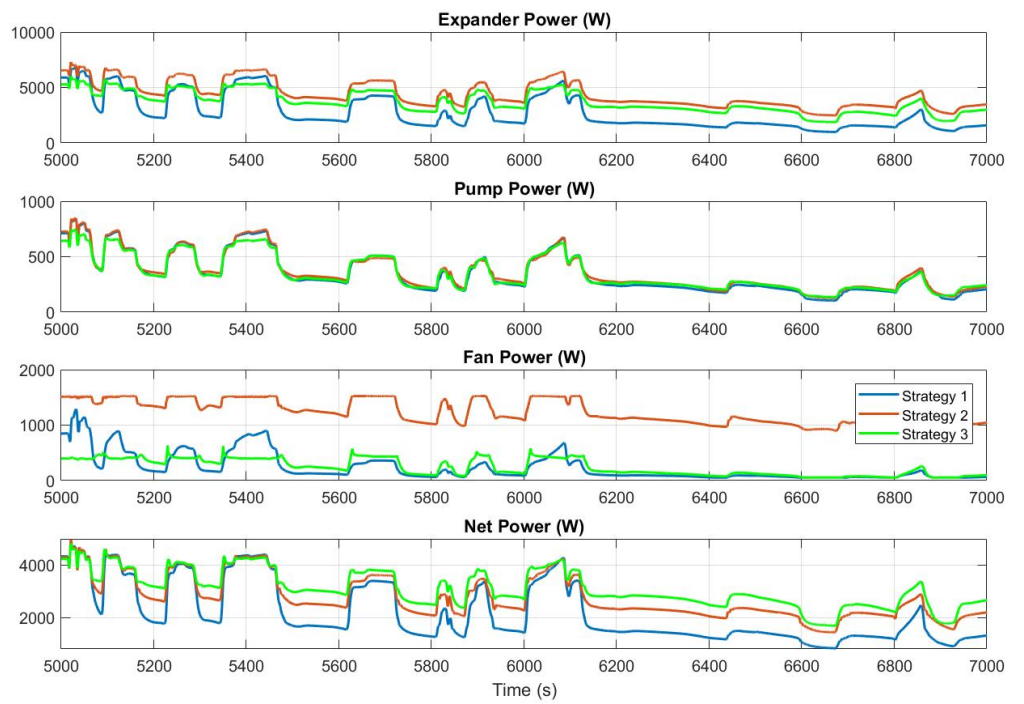

Figure 19: Comparison of the gross power produced and pump and fan power demands setting the air cooling temperature at $40^{\circ} \mathrm{C}$.

\section{Conclusion}

This work presented the complete modeling of a Rankine Cycle based waste heat recovery system for long-haul heavy-duty trucks. The proposed architecture recovers the energy from the exhaust gas and used ambient air as heat sink; this solution does not impact the operation of the cooling system of the vehicle, but in the same time it does not take advantage of any RAM air intake.

The main results can be summarized as follows:

- Evaporator and direct condenser models are validated according to experimental results and data suppliers.

- The manipulation of the condensation pressure using the current architecture and cyclopentane as working fluid is necessary, in order to track the lowest subcooling admitted in the current application and, in the same time, ensure high standard of performance. 
Figure 20: Comparison of the gross power produced and pump and fan power demands setting the air cooling temperature at $20^{\circ} \mathrm{C}$.

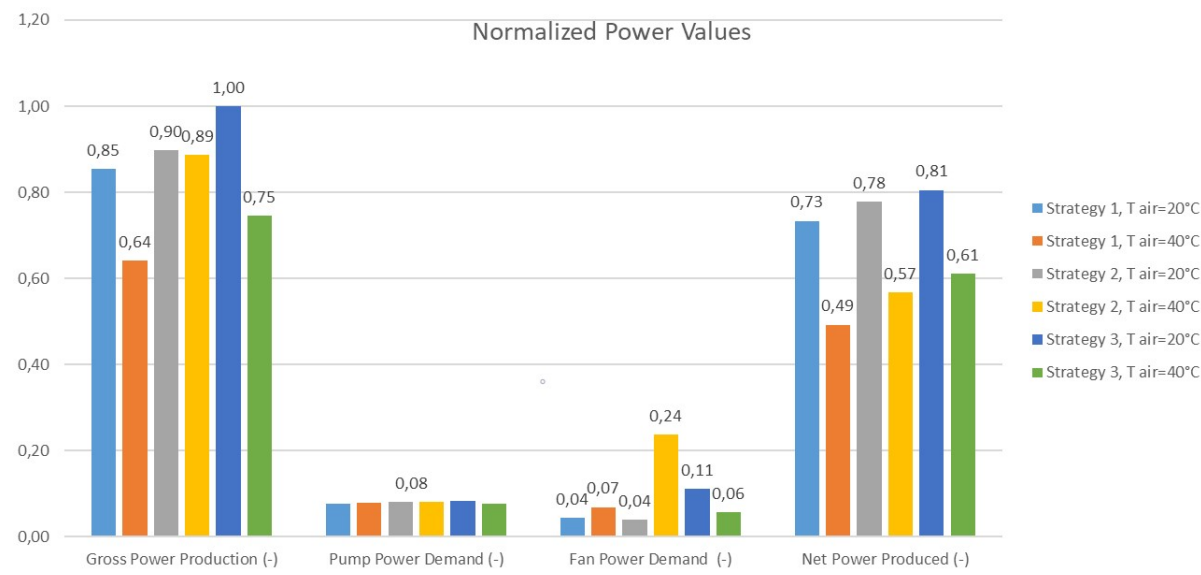

Figure 21: Comparison of the three strategies in terms of power produced and demand; the strategy 3 is able to increase the net power produced by the Rankine system, reducing the fan power demand when the air cooling temperature is $40^{\circ} \mathrm{C}$ and increasing the fan power demand when the air cooling temperature is $20^{\circ} \mathrm{C}$. Comparison of the gross power produced and pump and fan power demands setting the air cooling temperature at $20^{\circ} \mathrm{C}$. All the values are normalized with respect to the gross power in strategy 3 and air cooling temperature $20^{\circ} \mathrm{C}$. 
- The model-based optimization (strategy 3 ) improves the net power production of the system by 8 and $3 \%$ with respect to strategies 1 and 2 and air cooling temperature set at $20{ }^{\circ} \mathrm{C}$.

- The model-based optimization (strategy 3 ) improves the net power production of the system by 12 and $3 \%$ with respect to strategies 1 and 2 and air cooling temperature set at $40{ }^{\circ} \mathrm{C}$.

- In the case of the air cooling temperature $20^{\circ} \mathrm{C}$, the optimization (strategy 3 ) leads to an increase of the fan speed and a reduction of the condensation pressure with respect to strategies 1 and 2 .

- In the case of the air cooling temperature $40{ }^{\circ} \mathrm{C}$, the optimization (strategy 3 ) leads to an decrease of the fan speed and an increase of the condensation pressure with respect to strategies 1 and 2 .

\section{References}

Allain, M., Atherton, D., Gruden, I., Singh, S., and Sisken, K. (2012). Daimler ' s super truck program ; $50 \%$ brake thermal efficiency 2012 directions in engine-efficiency and emissions.

Aufderheide, B. and Bequette, B. W. (2003). Extension of dynamic matrix control to multiple models. Computers and Chemical Engineering, 27(8-9):10791096.

Chan Kang, H. and Jun, G. W. (2011). Heat transfer and flow resistance characteristics of Louver fin geometry for automobile applications. Journal of Heat Transfer, 133(10):101802(6pages).

Chang, Y. J. and Wang, C. C. (1997). A generalized heat transfer correlation for louver fin geometry. International Journal of Heat and Mass Transfer, $40(3): 533-544$.

Di Battista, D., Di Bartolomeo, M., Villante, C., and Cipollone, R. (2018). On the limiting factors of the waste heat recovery via ORC-based power units for on-the-road transportation sector. Energy Conversion and Management, 155:68-77.

Dickes, R. (2019). Charge-sensitive methods for the off-design performance characterization of organic Rankine cycle (ORC) power systems. PhD thesis, University of Liège, Belgium.

El Hajal, J., Thome, J. R., and Cavallini, A. (2003). Condensation in horizontal tubes, part 1: two-phase flow pattern map. International Journal of Heat and Mass Transfer, 46(18):3349-3363. 
Galuppo, F., Dufour, P., Nadri, M., Reiche, T., and Lemort, V. (2018a). Experiment design for waste heat recovery modeling in heavy duty trucks. IFACPapersOnLine, 51(31):726-731.

Galuppo, F., Reiche, T., Lemort, V., Dufour, P., Nadri, M., and Huin, X. (2018b). Waste heat recovery (WHR) assessment in complete truck simulation environment. In 2018 SIA POWERTRAIN conference, May 2018, Rouen, France.

Grelet, V. (2016). Rankine cycle based waste heat recovery system applied to heavy duty vehicles: topological optimization and model based control. PhD thesis, University de Lyon, France and University of Liège, Belgium.

Grelet, V., Dufour, P., Nadri, M., Reiche, T., and Lemort, V. (2015). Modeling and control of Rankine based waste heat recovery systems for heavy duty trucks. In IFAC-PapersOnLine, volume 48, pages 568-573.

Guillaume, L. and Lemort, V. (2019). Comparison of different ORC typologies for heavy-duty trucks by means of a thermo-economic optimization. Energy, 182:706-728.

Hountalas, D. T., Mavropoulos, G. C., Katsanos, C., and Knecht, W. (2012). Improvement of bottoming cycle efficiency and heat rejection for HD truck applications by utilization of EGR and CAC heat. Energy Conversion and Management, 53(1):19-32.

Incropera, F., Dewitt, D., Bergman, T., and Lavine, A. (1993). Fundamentals of heat and mass transfer. Number 1986.

Kandlikar, S. G. (2002). Fundamental issues related to flow boiling in minichannels and microchannels. Experimental Thermal and Fluid Science, 26(24):389-407.

Kanefsky, P., Nelson, V., and Ranger, M. (1999). A systems engineering approach to engine cooling design. SAE Technical Papers, Paper 1999-01-3780.

Karvountzis-Kontakiotis, A., Pesiridis, A., Zhao, H., Alshammari, F., Franchetti, B., Pesmazoglou, I., and Tocci, L. (2017). Effect of an ORC waste heat recovery system on diesel engine fuel economy for off-highway vehicles. SAE Technical Papers, 2017-01-0136.

Koeberlein, D. (2012). Cummins SuperTruck program relevance - Program objectives. Cummins.

Lopes, J., Douglas, R., McCullough, G., O'Shaughnessy, R., Hanna, A., Rouaud, C., and Seaman, R. (2012). Review of Rankine cycle systems components for hybrid engines waste heat recovery. SAE Technical Paper Series, 2012-01-1942. 
Lutz, R., Motisi, G., and Bruemmer, R. (2015). Device and method for recovering waste heat energy and a utility vehicle. United States Patent, DE102015016783A1.

Peralez, J. (2015). Recuperation d'énergie par cycle de Rankine à bord d'un véhicule : commande et gestion d'énergie. PhD thesis, University de Lyon, France.

Peralez, J., Tona, P., Lepreux, O., Sciarretta, A., Voise, L., Dufour, P., and Nadri, M. (2013). Improving the control performance of an organic rankine cycle system for waste heat recovery from a heavy-duty diesel engine using a model-based approach. Proceedings of the IEEE Conference on Decision and Control, pages 6830-6836.

Preißinger, M., Schwöbel, J. A. H., Klamt, A., and Brüggemann, D. (2017). Multi-criteria evaluation of several million working fluids for waste heat recovery by means of Organic Rankine Cycle in passenger cars and heavy-duty trucks. Applied Energy, 206:887-899.

Quoilin, Sylvain (2011). Sustainable energy conversion through the use of Organic Rankine Cycles for waste heat recovery and solar applications. PhD Thesis, University of Liège, Belgium.

Rivera, D., Morari, M., and Skogestad, S. (1986). Internal Model Control. 4. PID Controller Design. American Chemical Society, 25:252-265.

Rodriguez, F. (2018). The European Commission's Proposed CO2 Standards For Heavy-Duty Vehicles. IcCT.

Scaccabarozzi, R., Tavano, M., Invernizzi, C. M., and Martelli, E. (2018). Comparison of working fluids and cycle optimization for heat recovery ORCs from large internal combustion engines. Energy, 158:396-416.

Seitz, D., Gehring, O., Bunz, C., Brunschier, M., and Sawodny, O. (2016). Design of a nonlinear, dynamic feedforward part for the evaporator control of an Organic Rankine Cycle in heavy duty vehicles. IFAC-PapersOnLine, $49(11): 625-632$.

Shah, M. M. (1976). New correlation for heat transfer during boiling flow through pipes. ASHRAE Transactions, 2407:66-86.

Shah, M. M. (1979). A general correlation for heat transfer during film condensation inside pipes. International Journal of Heat and Mass Transfer, $22(4): 547-556$.

Skogestad, S. (2006). Tuning for Smooth PID Control with Acceptable Disturbance Rejection. Industrial \& Engineering Chemistry Research, 45(23):78177822 . 
Torregrosa, A., Galindo, J., Dolz, V., Royo-Pascual, L., Haller, R., and Melis, J. (2016). Dynamic tests and adaptive control of a bottoming organic Rankine cycle of IC engine using swash-plate expander. Energy Conversion and Management, 126:168-176.

Vaja, I. and Gambarotta, A. (2010). Internal Combustion Engine (ICE) bottoming with Organic Rankine Cycles (ORCs). Energy, 35(2):1084-1093.

Wang, T., Zhang, Y., Zhang, J., Shu, G., and Peng, Z. (2013). Analysis of recoverable exhaust energy from a light-duty gasoline engine. Applied Thermal Engineering, 53(2):414-419.

Winterton, R. H. S. (1998). Where did the Dittus and Boelter equation come from? International Journal of Heat and Mass Transfer, 41(4-5):809-810.

Yang, B., Yu, T., Shu, H., Zhang, X., Qu, K., and Jiang, L. (2018). Democratic joint operations algorithm for optimal power extraction of PMSG based wind energy conversion system. Energy Conversion and Management, 159:312-326.

Yang, B., Zhang, X., Yu, T., Shu, H., and Fang, Z. (2017). Grouped grey wolf optimizer for maximum power point tracking of doubly-fed induction generator based wind turbine. Energy Conversion and Management, 133:427443.

Zhao, R., Zhang, H., Song, S., Tian, Y., Yang, Y., and Liu, Y. (2018). Integrated simulation and control strategy of the diesel engine-organic Rankine cycle (ORC) combined system. Energy Conversion and Management, 156(100):639-654. 


\section{Organic Rankine Cycle based waste heat recovery modeling and control of the low pressure side using direct condensation and dedicated fans}

July 28,2020

\section{Introduction}

The recent European Union regulations for long-haul heavy-duty trucks, that set to $15 \%$ the reduction of $\mathrm{CO}_{2}$ emissions in 2025 with respect to the fleet baseline of 2019, pushed the automotive industry to adopt new effective to meet the new limits by decreasing the fuel consumption of the fleet (Rodriguez, 2018). The Organic Rankine Cycle (ORC) based waste heat recovery is considered one of the most promising technologies to reduce fuel consumption and increase the brake thermal efficiency of the vehicle (Wang et al., 2013); (Koeberlein, 2012); (Allain et al., 2012). The results of recent studies, supported by road cycle simulations and experimental campaigns, show an effective potential of the technology. (Zhao et al., 2018) claim an increase in thermal efficiency of $3.57 \%$ and a Break Specific Fuel Consumption (BSFC) reduction of $10.09 \mathrm{~g} / \mathrm{kWh}$ as a result of steady-state simulations, over different engine operating points, using GT-Suite and MATLAB/Simulink models, by recovering heat from exhaust gas. Extensive literature is available about constraints and limiting factors of the Rankine Cycle based waste heat recovery systems in long-haul heavy duty trucks: (Di Battista et al., 2018) investigated on the engine additional backpressure induced by the Rankine evaporator. (Karvountzis-Kontakiotis et al., 2017) studied the effects of the ORC on fuel economy of a heavy duty vehicle; the main focus of the analysis is a trade-off between the heat transfer area of the evaporator and the pressure drop that it imposes to the exhaust gas used as main heat source. The authors also identified the weight of the ORC system as one of the main limitations for the integration of the system in the vehicle. The final results show an optimal value when looking for a trade-off between exhaust back-pressure, ORC required net power and weight. (Hountalas et al., 2012) studied the problem of the rejection of excess heat of a ORC system, using exhaust gas flow as the main heat source. Adding the recuperation of the waste heat from the Exhaust Gas Recirculation flow (EGR) and a Charge Air Cooler $(\mathrm{CAC})$, the authors proved a further increase of the expander output power and in the same time a reduction of the thermal load in the cooling radiator, leading 
to the reduction of the fan power demand.

During the operation of a heavy duty truck in highway paths, external disturbances lead to a variation of the engine operating point and, consequently, to variable thermal power that can be recovered from the heat source. Therefore controllers are implemented in order to ensure at any time the suitable conditions of the working fluid (pressure, temperature, mass flow rate) in the system (and in particular at the inlet of the expansion machine and pump) and high standards of the system power production. (Grelet et al., 2015) compared the use of a non linear inverse model and a PI controller to track the set point of the temperature at the inlet of the expander; the inverse model leads to the best strategy. (Seitz et al., 2016) designed a feedforward controller, with online parameter adaptation, to control the temperature at the outlet of the evaporator; however according to the author the inverse model must be rechecked to increase the performance in highly transient situations. (Torregrosa et al., 2016) proposed an adaptive PID controller of the pump speed in a Rankine system fed by thermal power from a 2-liter gasoline engine; the adaptive gains are evaluated based on the working fluid temperature at the outlet of the evaporator and the estimation of the power released by the exhaust gas. A map based controller of the volumetric expander speed is also included. The controller is validated on test bench and, according to the authors, allows the control of the ORC in real driving conditions. Another example of feedforward controller designed to control the superheat (defined as the difference of the working fluid temperature and saturation temperature at the given pressure) at the inlet of the expander is presented by (Peralez et al., 2013); the authors used an inverse reduced model in the feedforward path and a gain-scheduling PID controller in the feedback path. Experimental results show a good performance of the controller, that allows to track the superheat set-point, set to the value of $40 \mathrm{~K}$. The same author in (Peralez, 2015) designed an energy monitoring algorithm addressed to the optimal control of a Rankine based waste heat recovery in a Diesel - electrical train; the condenser is cooled down by air and the condensation pressure is manipulated in high load transients in order to complete the condensation phase. The dynamic optimization shows an improvement of the net power produced that is higher with respect to static optimization strategies.

This last work that has been mentioned is a rare example of manipulation of condensation pressure in automotive waste heat recovery in literature, as most of the studies focus on the control of the working fluid conditions at the inlet of the expander to ensure high standards of power production of the system. In particular, direct condensation with air leads, in most of applications, to poor air mass flow rate at the inlet of the condenser. Therefore the increase of the condensation pressure is necessary to ensure the complete condensation of the working fluid. Additionally, in the applications consisting of a dedicated fan to supply the cooling air flow, the manipulation of the condensation pressure could be useful in terms of energy management, as the increase of the condensation pressure implies the reduction of the expander power of the system, but, in the same time, implies higher temperature difference between the working fluid and the air flow. Consequently a lower amount of air mass flow rate is needed to 
have the same working fluid condition at the outlet of the condenser; therefore the fan power demand is reduced as well. The reduction of the expander power production and the fan power demand could lead to an increase of the net power production of the system.

In this work, to design a model based control, a 1D finite volume model of the evaporator and direct condenser is firstly developed (both validated according to experimental results or data supplier), using MATLAB/Simulink. Furthermore, the complete model of the Rankine Cycle is proposed, as well as the model-based controllers. Particular attention is paid to the control of the subcooling of the working fluid at the inlet of the pump, by means of the dedicated fans speed and condensation pressure; additionally, a model-based optimization is run in order to find the best trade-off between the fans speed and the condensation pressure, ensuring the tracking of the subcooling and the maximization of the net power production of the Rankine system.

\section{Proposed Rankine architecture}

The Rankine Cycle architecture that is proposed in this work, presented in Fig. 1 , recovers heat from the exhaust gas flow and delivers electrical energy to the $48 \mathrm{~V}$ mild-hybrid drive-line. The pressure of the working fluid (in liquid state) is increased by a volumetric pump. The pre-heating, evaporation and superheating processes take place in the tailpipe heat exchanger. The working fluid is then expanded in the expander to produce useful work and the excess heat is rejected via the condenser, using ambient air as heat sink. This Rankine layout clarifies the possibility to manipulate the condensation (low) pressure in the system, via pressurized air stored in the dedicated air reservoir available in the vehicle; the control valve regulates the pressure of the air in the reservoir and, by consequence, the pressure of the working fluid. In the reservoir a membrane ensures the separation between the air and the working fluid, avoiding a drop in the performance and safety issues that appear in case of mixing. A similar system has been tested successfully and patented in order to ensure the desired condition of the working fluid at the inlet of the pump, avoiding its cavitation in all the operating points (Lutz et al., 2015); the main difference between the system presented here and the patented system is that in the latter an additional valve is installed between the reservoir and the Rankine line in order to have the possibility to disconnect the Rankine system and the reservoir. In order to improve the performance of the studied ORC, (Dickes, 2019) investigated on the sensitivity of the system to the charge of the working fluid in the system; the variation of the charge of working fluid is achieved by pressurizing an inert gas in a reservoir, connected to the Rankine line.

Fig. 2 clarifies the position of the Rankine system in the vehicle. The exhaust gas stream at the outlet of the Exhaust After Treatment System (EATS) flows in the Rankine system and cedes a portion of its thermal energy to the working 


\section{Nomenclature}

\begin{tabular}{|c|c|c|c|}
\hline \multicolumn{2}{|c|}{ Acronyms } & \multirow[t]{2}{*}{$c p$} & \multirow{2}{*}{$\begin{array}{l}\text { Specific Heat at Constant Pres- } \\
\text { sure }\left(\frac{\mathrm{J}}{\mathrm{kgK}}\right)\end{array}$} \\
\hline Bo & Boiling number & & \\
\hline \multirow{2}{*}{$B S F C$} & \multirow{2}{*}{$\begin{array}{l}\text { Break Specific Fuel Consump- } \\
\text { tion }\left(\frac{g}{k W h}\right)\end{array}$} & $D_{h}$ & Hydraulic diameter $(m)$ \\
\hline & & $h$ & Specific Enthalpy $\left(\frac{J}{k g}\right)$ \\
\hline$C A C$ & Charge Air Cooler & $K_{p}$ & Fan pressure coefficient \\
\hline \multirow[t]{2}{*}{$C F D$} & \multirow{2}{*}{$\begin{array}{l}\text { Computational Fluid Dynam- } \\
\text { ics }\end{array}$} & $K_{q}$ & Fan flow coefficient \\
\hline & & $K_{w}$ & Fan power coefficient \\
\hline Co & Convection number & $N$ & Rotational Speed (rpm) \\
\hline \multicolumn{2}{|c|}{$C O_{\text {ratio }}$ Cut-Off Ratio (-) } & $N u$ & Nusselt Number (-) \\
\hline$E G R$ & Exhaust Gas Recirculation & $\operatorname{Pr}$ & Prandtl Number (-) \\
\hline Err & Error (-) & $q$ & Vapor Quality (-) \\
\hline$F K$ & Frankfurt-Koblenz & Re & Reynolds Number (-) \\
\hline$F V$ & Finite Volume & $U$ & Specific Internal Energy $\left(\frac{J}{k g}\right)$ \\
\hline$I M C$ & Internal Model Control & $u$ & Model Input \\
\hline$M M P I$ & $\begin{array}{l}\text { Multi-Model proportional in- } \\
\text { tegral }\end{array}$ & $u_{c}$ & $\begin{array}{l}\text { Velocity in the minimum flow } \\
\text { area }(\mathrm{m} / \mathrm{s})\end{array}$ \\
\hline ORC & Organic Rankine Cycle & V & Volume $\left(m^{3}\right)$ \\
\hline$P I D$ & Proportional-Integral-Derivative & $V_{0}$ & Clearance Volume $\left(\mathrm{m}^{3}\right)$ \\
\hline$R A M$ & Air Intake & $w$ & Weight \\
\hline$S C$ & Subcooling $(K)$ & $x$ & State \\
\hline$S H$ & Superheat $(K)$ & $y$ & Model Output \\
\hline \multirow[t]{2}{*}{$S I M C$} & Skogestad Internal Model Con- & \multicolumn{2}{|c|}{ Subscripts } \\
\hline & trol & $c$ & Control \\
\hline$S P$ & Set-point & cond & Condenser \\
\hline & Working Fluid & cool & Coolant \\
\hline \multicolumn{2}{|c|}{ Greek letters } & $d$ & Derivative \\
\hline$\alpha$ & Heat Transfer Coefficient & $e q$ & Equivalent \\
\hline$\eta$ & $\begin{array}{l}\mathrm{kgm}^{2} \\
\text { Efficiency }(-)\end{array}$ & $e v$ & Evaporator \\
\hline \multirow[t]{3}{*}{$\psi$} & Ratio between two-phases and & $e x$ & Exit \\
\hline & single phase heat transfer coef- & $e x h$ & Exhaust gas \\
\hline & ficient & $\exp$ & Expander \\
\hline$\rho$ & Density $\left(\frac{\mathrm{kg}}{\mathrm{m}^{3}}\right)$ & expe & Experimental \\
\hline$\sigma$ & Standard Deviation & $g l$ & Global \\
\hline$\tau$ & Time Constant $(s)$ & $I$ & Integral \\
\hline$\theta$ & Delay $(s)$ & $p$ & Proportional \\
\hline$D_{h}$ & Transfer function & $P_{\text {red }}$ & Reduced Pressure (-) \\
\hline \multicolumn{2}{|c|}{ Latin letters } & sim & Simulated \\
\hline$\dot{m}$ & Mass Flow Rate $\left(\frac{\mathrm{kg}}{\mathrm{s}}\right)$ & $s p$ & Single phase \\
\hline$\dot{Q}$ & Thermal Power $(W)$ & su & Suction \\
\hline$\dot{W}$ & Mechanical Power $(W)$ & suit & Suitable \\
\hline C & Displacement $\left(m^{3}\right)$ & $V_{\text {cap }}$ & Volume Capacity $\left(m^{3}\right)$ \\
\hline
\end{tabular}




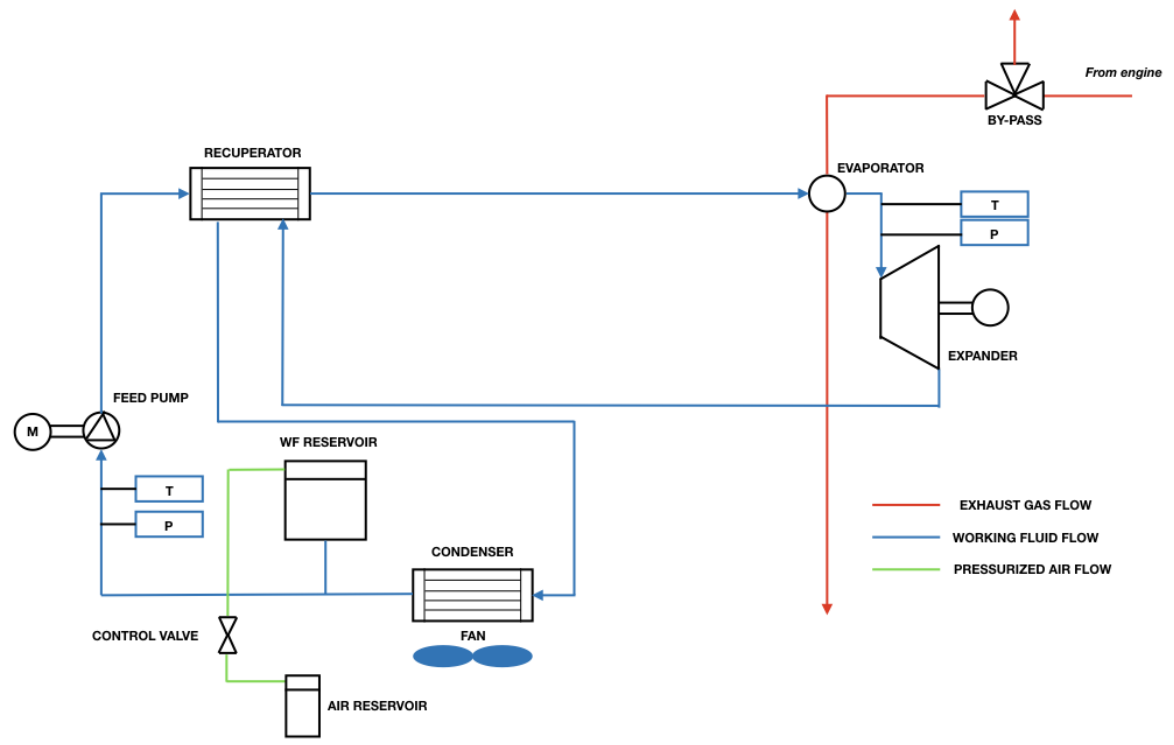

Figure 1: Rankine layout, recovering heat from exhaust gas, producing electrical power.

fluid in the evaporator. Additionally it can be noticed that the condenser and dedicated fans are placed on the side of the vehicle and the total cooling capacity is provided by the fan cooling airflow; consequently the removal of the excess heat from the condenser has no impact on the cooling system of the truck. The system produces electrical energy, therefore the expansion machine is coupled with a motor-generator electrical machine and it is mechanically disconnected from the drive-line. The working fluid is chosen in Sec. 2.2 following the analysis of the results of a simulation study where 4 different working fluids have been compared in terms of net power production of the system.

\subsection{Heat sources and sink}

Although several heat sources (such as engine coolant, EGR flow, Charge Air Cooler) are available on the vehicle for waste heat recovery applications, with different amount and variability of mass flow rate and temperature, in the proposed architecture the exhaust gas flow is used as the only heat source. The engine coolant is characterized by lower temperature (less than $100{ }^{\circ} \mathrm{C}$ ) and higher mass flow rate than the exhaust gas stream; the EGR flow is characterized by higher temperature and lower mass flow rate, as well as higher fluctuation of the available thermal power than the exhaust gas stream. Additionally 
Figure 2: Rankine system position in the truck (view from the top, not to scale).

(Grelet, 2016) observed that the heat source represented by the engine coolant flow is more interesting than the exhaust gas considering the first principle of thermodynamics, but results of a second principle of thermodynamic analysis show that the exhaust gas flow is the heat source that is characterized by the highest amount of exergy. This can be explained by noticing that the exhaust gas flow is at higher average temperature than the engine coolant flow.

In the current case study, the heat sink is represented by ambient air and no RAM Air Intake flow is supplied to the condenser, therefore the whole amount of air mass flow is provided by the electrically-driven fans. As already remarked, this architecture does not influence the cooling system of the truck, avoiding additional fan power demand of the cooling system (Galuppo et al., 2018b) because of the higher temperature of the air in the cooling package.

Moreover, the temperature of the cooling air, provided by the dedicated electricallydriven fans, at the inlet of the condenser has a strong impact on the overall performance of the system. Depending on the temperature of the cooling air, different strategies can be adopted to cool down the working fluid in the condenser, maximizing the net power production of the Rankine system. The strategies, that lead to a different handling of the condensation pressure and the rotating speed of the cooling fan, are presented and analyzed in Sec. 4.3.

\subsection{Working fluid selection}

The choice of the most suitable working fluid involves several aspects and performance is one of the major criteria; a working fluid should match well with 
the heat source, in order to reduce the exergy destruction and should be characterized by low heat of vaporization (Vaja and Gambarotta, 2010). Recently, (Preißinger et al., 2017) performed a computational chemical and thermodynamic selection among 72 millions of substances, to be used in an Organic Rankine Cycle recovering energy from internal combustion engine heat rejection; two different configurations of the ORC and three different cooling concepts were investigated. The multi-criteria evaluation considers thermodynamic aspects as well as regulations and safety issues and a trade-off occurs. Among the fluids with highest score, ethanol is present. In (Scaccabarozzi et al., 2018), the authors performed a working fluid selection and a cycle optimization based on thermodynamic and performance aspects. Among the organic fluids, cyclopentane is always considered as an optimal fluid.

Despite the numerous works about fluid selection, it is hard to recognize the best possible fluid to use in any waste heat recovery application for long-haul heavy-duty trucks (the architecture of the Rankine system strongly impacts the choice of the working fluids, (Guillaume and Lemort, 2019)). As for the Rankine system configuration that is presented in Fig. 1, the choice of the fluid is supported by an internal steady-state simulation work that considers the specific boundary conditions of the current architecture (heat source and sink) and the components that are used. In this work, four working fluids have been analyzed (cyclopentane, ethanol, Novec649 and R1233ZD) considering constant inputs, as the mass flow and temperature of the exhaust gas and the temperature of the air coolant flow. The size of the components is also considered as a constant input, because of packaging reasons.

On the other hand, specific parameters are changed because of the different nature of the working fluids. The lower heat of vaporization of Novec649 and R1233ZD leads to higher mass flow rate in the system. In the same time, the temperature and the density of both fluids in superheated conditions change very much as well with respect to cyclopentane and ethanol, affecting the operation of the expansion machine. One major change to be adopted in order to perform a fair comparison consists in the modification of the cut-off ratio of the volumetric expander (definition in Sec. 3.1.3), according to the temperature and the volumetric flow rate of the working fluid at the inlet of the expander. In order to take into account this feature of Novec649 and R1233ZD, the cutoff ratio of the expander is reduced as well as the set-point of the evaporation pressure; in this way it is possible to create the best operating conditions for the four fluids and then compare the different concepts as fairly as possible.

The performance analysis of the four working fluids is carried out in a specific operating point, $T_{e x h, s u, e v}=350^{\circ} \mathrm{C}$ and $\dot{m}_{e x h, s u, e v}=0.2 \mathrm{~kg} / \mathrm{s}$, found as the average of the exhaust mass flow rate and temperature provided by the 13-liter non-EGR engine driving a common highway road cycle and cooling air temperature $T_{\text {cool, su,cond }}=40{ }^{\circ} \mathrm{C}$; the performance is evaluated calculating the system net power produced $\dot{W}_{\text {net }}(1)$, that is obtained subtracting to the expander power produced $\dot{W}_{\text {exp }}$ the fan power $\dot{W}_{f a n}$ and pump power $\dot{W}_{\text {pump }}$ demand.

$$
\dot{W}_{n e t}=\dot{W}_{e x p}-\dot{W}_{f a n}-\dot{W}_{\text {pump }}
$$


The main variables results of the steady state simulations related to the four working fluids are listed in Tab. 1.

\begin{tabular}{cccccc} 
Fluid & $\rho_{\text {su,exp }}\left(\frac{\mathrm{kg}}{\mathrm{m}^{3}}\right)$ & $\dot{V}_{\text {su,exp }}\left(\frac{\mathrm{dm} \mathrm{m}^{3}}{\mathrm{~s}}\right)$ & $P_{\text {ev }}($ bar $)$ & $P_{\text {cond }}($ bar $)$ & NetPower $(k W)$ \\
\hline Cyclopentane & 61.2 & 1.410 & 25 & 3 & 3.76 \\
Ethanol & 35.5 & 1.135 & 25 & 2 & 3.69 \\
Novec649 & 235.1 & 1.895 & 16 & 3 & 2.26 \\
R1233ZD & 111.2 & 2.114 & 25 & 5 & 2.11 \\
\hline
\end{tabular}

Table 1: Main results of the simulation study basing on the different fluids.

The evaporation pressure set-point is 25 bar for ethanol, cyclopentane and R1233ZD, while the evaporation pressure of Novec649 is limited to 16 bar because of its lower critical pressure with respect to the other fluids; consequently, the expander power, as well as the net power produced by the system are reduced using Novec649. The condensation pressure that is set using the R1233ZD is higher than the values that are used for the other fluids because of the lowest normal boiling point of the R1233ZD among all the fluids that are currently considered; consequently the condensation pressure is raised in order to make feasible the removal of the excess heat from the condenser operating with the same cooling air temperature. The higher condensation pressure leads to a lower expander power produced, penalizing the global power balance of the system and reducing the net power produced.

Fig. 3 shows the different contributions of the net power produced (1); the reduced evaporation pressure of the Novec649 and the high condensation pressure of the R1233ZD lead to a lower expander power produced with respect to cyclopentane and ethanol and consequently to a lower net power produced.

Cyclopentane and ethanol are the best fluids for this specific architecture because their boiling points match better with the heat sink temperature and the design of the expander suits better with respect to the remaining fluids (according to the volumetric flow rate of the fluids at the inlet of the expander). However it can be noticed that the net power production of the system, using cyclopentane is higher, consequently cyclopentane is the selected working fluid for further analysis. 
Figure 3: Power demands and production of the Rankine system using the four fluids: the net performance of the Rankine system is evaluated subtracting the pump and fan power demand to the expander power produced.

\subsection{Actuators}

In order to deal with the disturbances induced by the road cycle, in terms of variation of mass flow and temperature of the heat source, controllers have to be implemented to adjust online specific important variables in the system. Indeed, as an example, a certain thermodynamic condition at the inlet of the expander and at the outlet of the condenser must be kept in order to avoid respectively liquid droplets in the expander and cavitation of the pump. In this process, the following five actuators are used as manipulated variables in different controllers:

- Feed pump speed, to control the thermodynamic conditions of the working fluid at the inlet of the expander

- Exhaust by-pass valve, that opens in case of over-temperature or overpressure of the working fluid

- Expander speed, to control the evaporation pressure

- Fan speed, to control the thermodynamic conditions of the working fluid at the outlet of the condenser

- Condensation pressure, to contribute to the control of the thermodynamic conditions of the working fluid at the outlet of the condenser, as well as to the improvement of the net power production of the system 


\section{Modeling}

Component models of the described Rankine architecture are developed and are implemented with the control algorithm in MATLAB/Simulink 2017. They are detailed in the following parts.

\subsection{Plant model}

The plant model is based on the interactions among the components of the Rankine and the thermodynamic state of the working fluid. The development of $1 \mathrm{D}$ models of the subsystems composing the plant model leads to the evaluation of physical relevant phenomena, as the thermal inertia in the heat exchangers, that are useful for the real assessment of the performance of the system.

This section shows the modeling approach of each component of the Rankine system and provides the validation of the evaporator and condenser models according to experimental results and data supplier; the plant that is presented in Fig. 9 uses cyclopentane as working fluid (that is selected as the most performing fluid for the current direct condensation architecture in Sec. 2.2) and pressure losses, as well as thermal losses are neglected in the current analysis.

\subsubsection{Pump model}

The pump model receives as input the pump speed from the controller and the pressure ratio, defined as the ratio between the evaporation pressure (supplied by the expander model, Sec. 3.1.3) and the condensation pressure that is determined by the dedicated controller.

The pressure at the outlet of the pump is calculated in the expander model, as the volumetric expander imposes the high pressure of the Rankine Cycle (assuming no pressure drops in the evaporator); the pressure at the inlet of the pump is a function of the mass flow rate (Sec. 4.3). As a function of the rotating speed $N_{\text {pump }}$, pressure ratio and displacement of the pump $C$, the model computes the mass flow rate of working fluid (2) and the pump power demand (3).

$$
\begin{gathered}
\dot{m}_{w f}=N_{\text {pump }} C \rho \\
\dot{W}_{\text {pump }}=\frac{\dot{m}_{w f}\left(h_{e x, i s}-h_{s u}\right)}{\eta_{g l, p u m p}}
\end{gathered}
$$

\subsubsection{Evaporator model}

The evaporator that is modeled and tested is a plate-fin heat exchanger, widely used in small-scale waste heat recovery applications (Lopes et al., 2012). Fig. 4 shows a frontal and side view of the evaporator as well as the inlet and outlet sections of the working fluid and exhaust gas; plates, where the working fluid

flows, are disposed in parallel with respect to the view from the top, therefore a counter-flow approach for modeling is fully justified. 
The model of the evaporator is a 1D finite volume (FV) model, where $N_{v o l}$ volumes are identified by discretizing the component along the longest dimension. In this application, the heat exchanger model is, as first approach, simulated as a standalone component, afterwards it is integrated into a complete Organic Rankine Cycle model and finally in a complete vehicle model, where cooling system, driver and all the mechanical components are modelled. Taking into account the frame of the work, the number of volumes $N_{v o l}$ is set to 10 , as a trade-off between accuracy and stability of the model and computational cost.

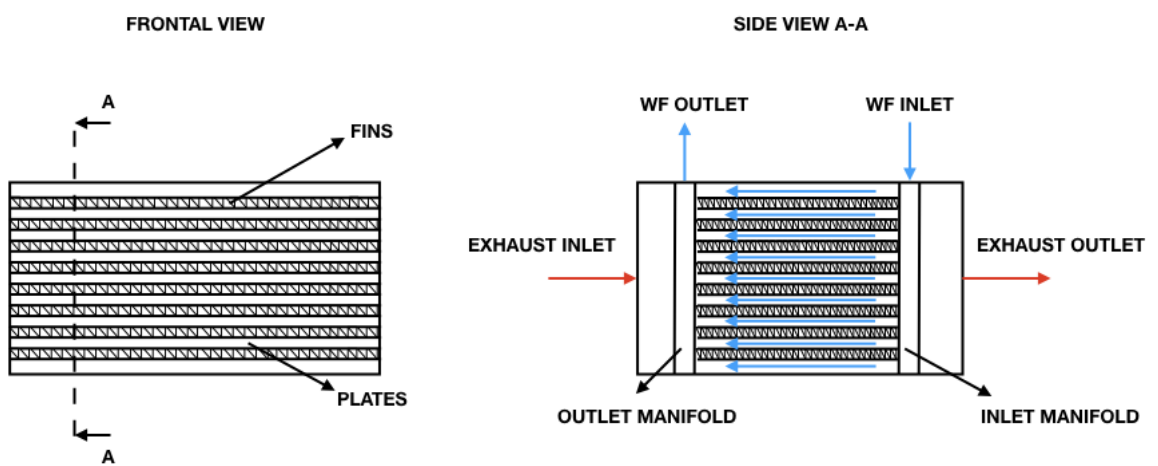

Figure 4: Frontal and side evaporator views; inlet and outlet of working fluid and exhaust flow as well as fins and plates are highlighted.

Fig. 5 shows that each volume is divided into three zones: the fluid side, the separation wall and the gas side. On the fluid and gas sides, mass and energy balance equations are applied in order to calculate the fluid state and the temperature of the exhaust gas at the outlet of each volume; in the separation wall the only energy balance equation is applied in order to calculate the average temperature of the wall in the specific volume. It can be noticed that the number of volumes is $N_{v o l}$ and the two nodes before and after the volume $i$ are named $i-1$ and $i$ respectively. In order to distinguish the volume variables from the node variables, the latter are denoted by a ' subscript. 


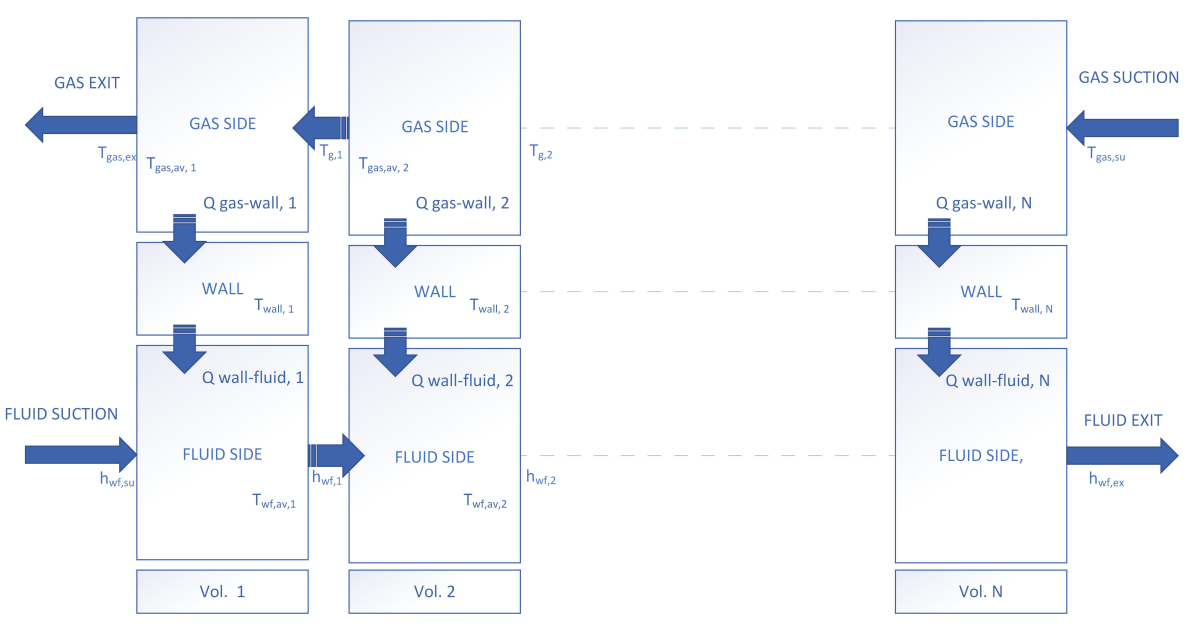

Figure 5: Discretization schema of the evaporator.

The discrete mass variation in time for each volume can be expressed by means of the differential of the enthalpy and pressure, as follows: (Quoilin, Sylvain, 2011):

$$
\frac{d M_{i}}{d t}=V \frac{\partial \rho}{\partial t}=V\left(\frac{\partial \rho}{\partial h} \frac{\partial h}{\partial t}+\frac{\partial \rho}{\partial p} \frac{\partial p}{\partial t}\right)=\dot{m}_{i}^{\prime}-\dot{m}_{i-1}^{\prime}
$$

The energy balance can be written as follows:

$$
\frac{d U_{i}}{d t}=\dot{m}_{i-1}^{\prime} h_{i-1}^{\prime}-m_{i}^{\prime} h_{i}^{\prime}+\dot{Q}_{i}+\dot{W}_{i}-p \frac{d V_{i}}{d t}
$$

Considering that no work is exchanged by the control volumes, using the definition of the internal energy $(U=H-p V)$ and the equation (4), the energy balance can be written as follow:

$$
\rho_{i} V_{i} \frac{\partial h_{i}}{\partial t}=\dot{m}_{i-1}^{\prime}\left(h_{i-1}^{\prime}-h_{i}\right)-\dot{m}_{i}^{\prime}\left(h_{i}^{\prime}-h_{i}\right)+\dot{Q}_{i}+V \frac{d p}{d t}
$$

Equ. (6) can be also written for the gas side considering that the enthalpy can be replaced by the product between the gas specific heat $c p$ and temperature $T$. The power balance equation applied to the wall is:

$$
\rho_{i} V_{i} c p \frac{\partial T_{i}}{\partial t}=\dot{m}_{i-1}^{\prime} c p\left(T_{i-1}^{\prime}-T_{i}\right)-\dot{m}_{i}^{\prime} c p\left(T_{i}^{\prime}-T_{i}\right)+\dot{Q}_{i}
$$

considering the specific heat $c p$ constant and the gas as incompressible fluid. The energy balance equation applied to the wall can be finally written as follows:

$$
M_{w} c p_{w} \frac{\partial T_{w, i}}{\partial t}=\dot{Q}_{g a s-w a l l, i}-\dot{Q}_{\text {wall-fluid }, i}
$$

In order to evaluate the heat transfer occurring between the exhaust gas and the fluid flow (via the internal wall of the heat exchanger) external and internal dimensions of the component are measured or calculated. In particular, the following geometrical data used in the evaluation of the heat transfer: 
- Heat transfer area for fluid and gas sides

- Flow section for fluid and gas

- Volume for fluid and gas sides

- Separation wall volume

The thermal power that is exchanged between the exhaust gas and the fluid can be calculated by (9):

$$
\dot{Q}_{t h}=A_{g l} U_{g l} \Delta T_{\text {suit }}
$$

$\Delta T_{\text {suit }}$ is a suitable temperature difference between exhaust gas and fluid (i.e. the mean logarithmic temperature difference) and the product $A_{g l} U_{g l}$ is the global heat transfer coefficient (Incropera et al., 1993). (9) can be written for each side of the heat exchanger by introducing the wall properties. Consequently the thermal power exchanged between the exhaust gas and the separation wall $\dot{Q}_{t h, \text { gas-wall }}$ and between the separation wall and the fluid $\dot{Q}_{\text {th,wall-fluid }}$ can be written respectively as in (10) and (11)

$$
\begin{gathered}
\dot{Q}_{\text {th,gas-wall }}=A_{\text {gas }} U_{\text {gas }} \Delta T_{\text {gas-wall }} \\
\dot{Q}_{\text {th,wall-fluid }}=A_{\text {fluid }} U_{\text {fluid }} \Delta T_{\text {wall-fluid }}
\end{gathered}
$$

The heat transfer coefficient $U$ should be determined for the gas and fluid. As reminded by (Quoilin, Sylvain, 2011), the gas heat transfer coefficient in singlephase flow is mainly dependent on the mass flow rate.

In this work, the heat transfer coefficient of the fluid is calculated taking into account the flow regime as well as the nature of the fluid; the Dittus-Boelter and the Shah correlations are used to calculate the Nusselt number (directly correlated to the heat transfer coefficient) respectively for single phase and twophase flow.

Dittus-Boelter correlation, according to turbulent flow in ducts (Winterton, 1998):

$$
N u_{s p}=0.023 R e_{D_{h}}^{0.8} \operatorname{Pr}^{0.4},
$$

where $R e_{D_{h}}$ is the Reynolds number calculated in the flow area fluid side and $\operatorname{Pr}$ is the Prandtl number. Then using Shah correlations ((Shah, 1976) for boiling flow (13) , (Shah, 1979) for condensing flow (14)), $N u$ is given by:

$$
N u=\left\{\begin{array}{l}
\psi N u_{s p} \\
N u_{s p}\left[(1-q)^{0.8}+\frac{3.8 q^{0.76}(1-q)^{0.04}}{P_{r e d}^{0.38}}\right]
\end{array}\right.
$$

where $\psi$ is a factor depending on the boiling number $B o$ and convection number Co defined in (Shah, 1976), $q$ is the quality of vapor and $P_{r e d}$ is the reduced pressure defined as the ratio of the actual fluid pressure to the critical pressure 
of the fluid.

Focusing on the evaporator, the experiments are realized in steady state condition in different engine operating points and consequently thermal power from 20 to $70 \mathrm{~kW}$. In each experiment the working fluid mass flow is adjusted in order to obtain the same superheat conditions at the outlet of the evaporator.

In the test bench the following variables can be measured:

- Mass flow rate of the working fluid by means of a Coriolis flow-meter at the outlet of the feed pump and mass flow rate of the exhaust gas by means of a Annubar flow-meter at the inlet of the evaporator

- Pressure on the fluid side by means of differential pressure sensors, at the inlet and outlet of the evaporator

- Temperature on the fluid side by means of thermocouples $\mathrm{T}$, one at the inlet and one at the outlet of the evaporator and on the gas side, three thermocouples $\mathrm{K}$ at the inlet of the evaporator and one at the outlet of the evaporator.

The thermal power exchanged between exhaust gas and working fluid has been plotted in Fig. 6. The error between the thermal power predicted by the model and measured from experiments, defined as in (15), is $0.51 \%$.

$$
E r r=100 \times\left\|\frac{\dot{Q}_{\text {expe }}-\dot{Q}_{\text {sim }}}{\dot{Q}_{\text {exp }}}\right\|
$$

Fig. 7 shows the prediction of the exhaust gas temperature at the outlet of the evaporator. In this case the absolute error of the prediction is $7.83 \mathrm{~K}$. Therefore, Fig. 6 and 7 show that the model is able to predict the performance of the evaporator.

\subsubsection{Expander model}

The considered expansion machine is a volumetric expander whose the following data are available:

- Clearance volume $V_{0}$ expressed in $m^{3}$

- The volume capacity $V_{c a p}$, expressed in $m^{3}$, that is the volume at the end of the expansion process

- The cut-off ratio $C O_{\text {ratio }}$, that is the fraction of the stroke that is involved in the admission process.

These data are useful to compute the volume at the end of the suction process, in other words the expander displacement, $V_{s}$, as shown in (16).

$$
V_{s}=V_{\text {cap }} C O_{\text {ratio }} .
$$




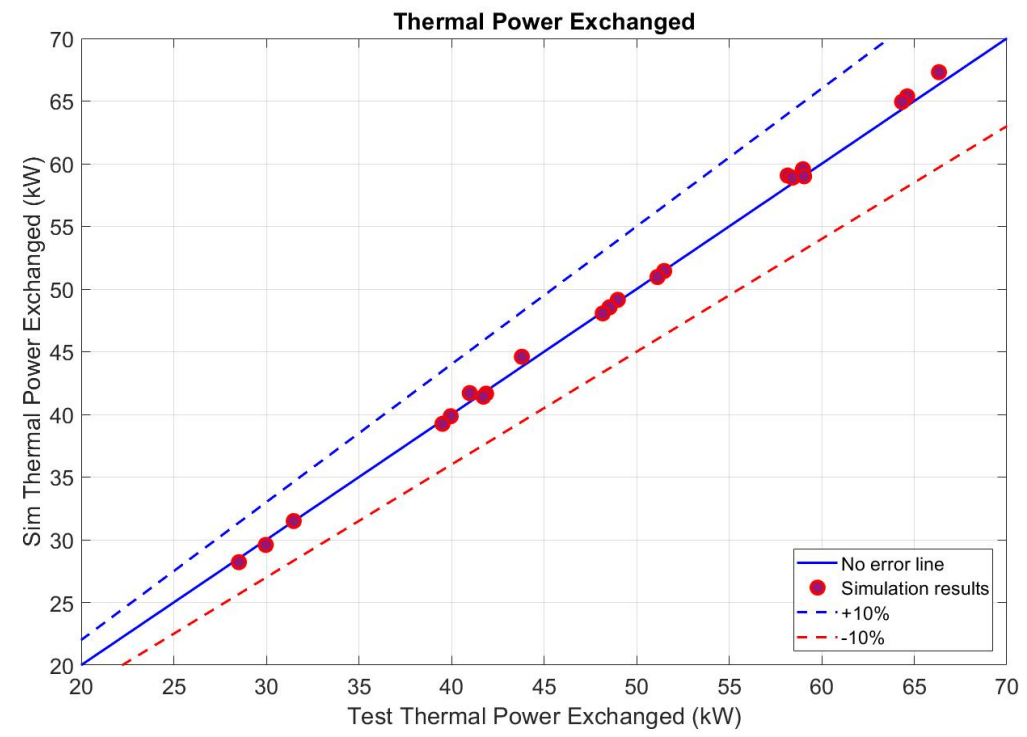

Figure 6: Comparison between predicted and measured thermal power exchanged in the evaporator.

Such an expander, rotating at variable speed, is responsible of the high pressure in the Rankine loop. The expander chambers accept in their volume a mass of working fluid that is function of the mass flow rate of the working fluid and its rotating speed. As a first approach, the density is calculated in the following time step $i+1$ as a function of the mass that is stored in the expander chambers in the time step $i$ for one revolution and the geometrical data of the machine :

$$
\rho(i+1)=\frac{\frac{\dot{m}_{w f}(i)}{N_{e x p}}(i)}{V_{\text {cap }} C O_{\text {ratio }}+V_{0}}
$$

where $i$ is the current time step.

The denominator of (17) represents the volume occupied by the working fluid at the end of the suction process, in other words when the supply valve closes. From density, calculated in (17) and temperature, calculated as the temperature at the outlet of the evaporator in the evaporator model, it is possible to obtain the pressure of the working fluid at the inlet of the expander. This information is also used by the pump model to consider the pressure ratio between inlet and outlet of the pump.

Once the state of the working fluid at the inlet of the expander is completely defined, it is possible to calculate, considering that the working fluid at the outlet of the expander is always in vapor state, the gross power production of the expander (18) taking advantage of the map of the total expander isentropic efficiency in Fig. (8) and the pressure at the outlet of the expansion machine: 


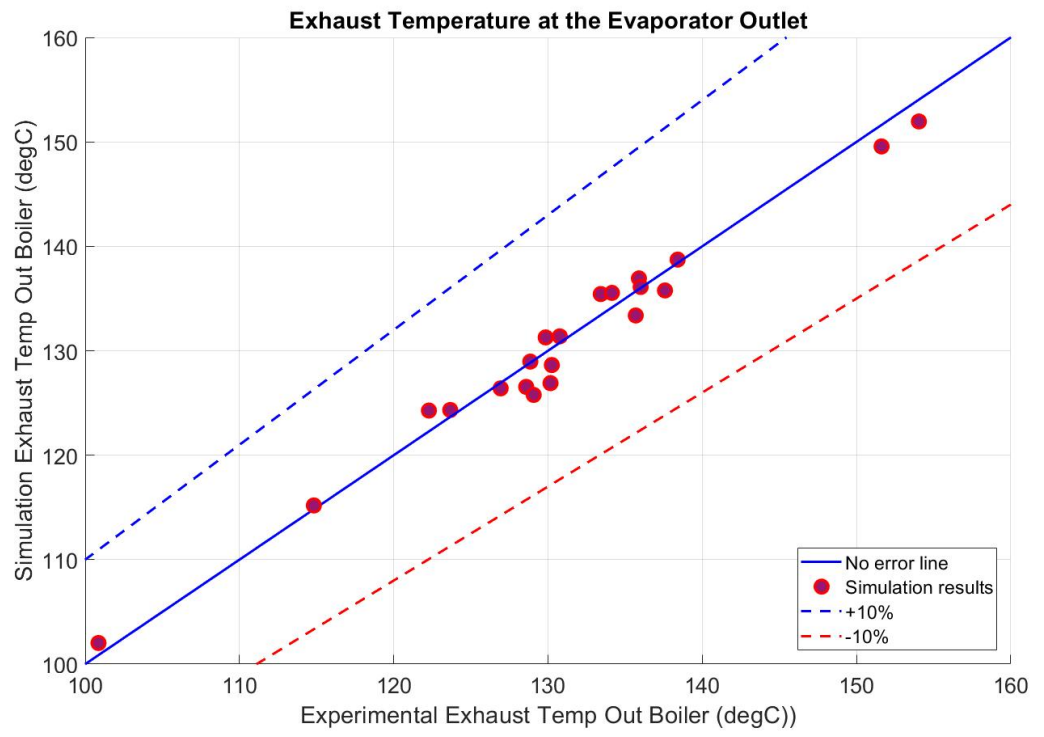

Figure 7: Comparison between the predicted and measured exhaust temperature at the outlet of the evaporator.

$$
\dot{W}_{g r o s s, \exp }=\dot{m}_{w f}\left(h_{s u, e x p}\left(T_{w f, s u, e x p}, p_{w f, s u, e x p}\right)-h_{e x, \exp }\left(T_{w f, \operatorname{ex}, \exp }, p_{w f, e x, \exp }\right)\right)
$$

\subsubsection{Direct Condenser and fan model}

The selected condenser is an aluminum heat exchanger made up of flat extruded tubes and of corrugated louvered fins. Assuming a perfect distribution of the cooling air on the surface of the condenser, it is possible to consider a cross-flow pattern as Fig. 9 shows.

The condenser model is obtained using a 1D finite volume (FV) discretization. Energy and mass balance conservation equations are applied to the gas side, fluid side and separation wall (eq. 4, 6, 7, 8.) The overall mass flow of cooling air is divided by the number of volumes adopted for the discretization and its outlet temperature is computed as the average of the outlet temperature of the cooling air from each volume.

In order to compute correctly the thermal power exchanged between the fluid and the wall, and between the wall and air flow, a geometrical analysis of the condenser is necessary. Geometrical data can be retrieved by calculations, once the fluid side and air side exchange areas are set (these data available from the supplier). In particular, the following data are retrieved or calculated: 


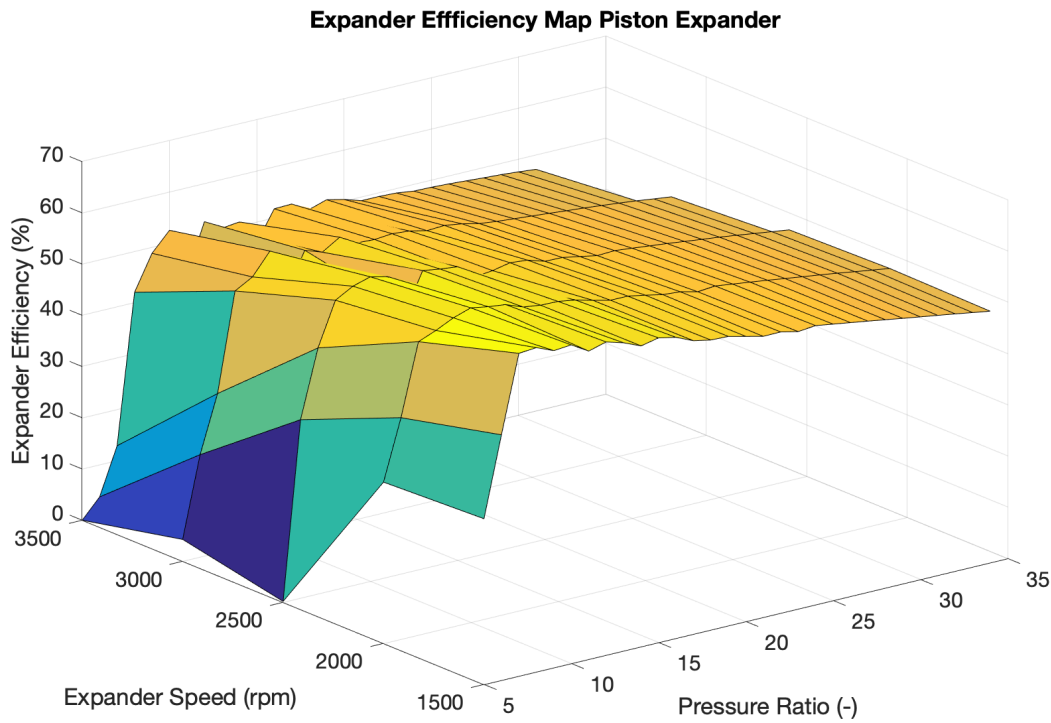

Figure 8: Total expander efficiency as a function of the pressure ratio and the expander speed.

- Number of tubes

- Fin density $\left(\frac{N_{f i n}}{d m}\right)$

- Heat transfer area for fluid and gas sides

- Flow section for fluid and gas

- Volume for fluid and gas sides

- Separation wall volume

Considering the fluid side, the fluid flows in channels that are obtained in the tubes; according to the classification of (Kandlikar, 2002), channels of the size between 0.2 and $3 \mathrm{~mm}$ are considered as mini-channels Here the mini channels have a rectangular section. Using this data and knowing the fluid side heat exchange area, it is possible to compute the fluid flow area and the number of mini channels per tube. These data are useful for the definition of the flow regime and calculation of the heat transfer coefficients in single phase and two-phase ((12), (14)). Regarding the air side, several other studies have been conducted in the last decades (Chang and Wang, 1997), (Chan Kang and Jun, 2011), (El Hajal et al., 2003). For this work, the correlation proposed by (Chan Kang and Jun, 2011) has been chosen because of the wide combination of different geometries of louvers and fins that have been investigated. The empirical correlations 
WF CONDENSER SUCTION

allow to compute the Colburn number $j$ and the friction factor $f$ (Fig. 10.a), that are useful to find respectively the heat transfer coefficient on air side $h_{a s}$ (Fig. 10.b) and the the pressure drop of the air through the condenser. In this work, we consider that the Colburn number $j$ and heat transfer coefficient $h$ are correlated as follow (Chan Kang and Jun, 2011):

$$
j=\frac{\eta_{f i n} h P r^{2 / 3}}{\rho u_{c} c p},
$$

where $\eta$ is the fin efficiency, $c p$ is the specific heat of the air at constant pressure and $u_{c}$ is the velocity of the air in the louver section (minimum flow section). The heat transfer coefficient and the air pressure drop as a function of the Reynolds number are shown in Fig. 10.b.

Fig. 10.a and 10.b show coherent results according to literature in terms of absolute values and variation with the Reynolds number.

Fan suppliers provide the fan curve, which expresses the static pressure $(\Delta P)$ variation through the fan as a function of the volumetric flow rate $\left(\mathrm{m}^{3} / h\right)$ at nominal speed. Curves at other speeds can be modeled thanks to the Fan Laws (20) (Kanefsky et al., 1999). Plotting in the same graph the fan curves at different fan speeds and the pressure drop curve characteristic of the condenser, it is possible to identify the intersections, hence the operating points of the system. The condenser model predicts the condenser pressure drop from data supplier with a relative error of $1 \%$ in the range of interest of volume flow rate (Fig. 11).

$$
\left\{\begin{array}{l}
\dot{Q}=K_{q} D^{3} N \\
\Delta P=K_{p} D^{2} N^{2} \rho \\
\dot{W}=K_{w} D^{5} N^{3} \rho
\end{array}\right.
$$




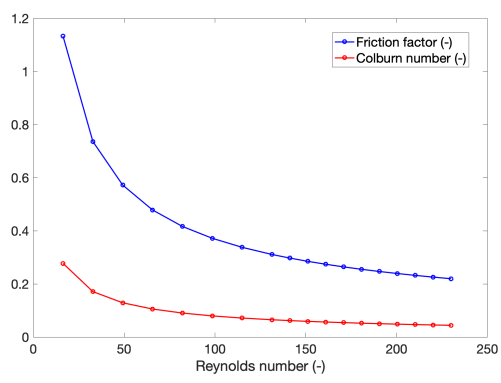

(a) $f-j$

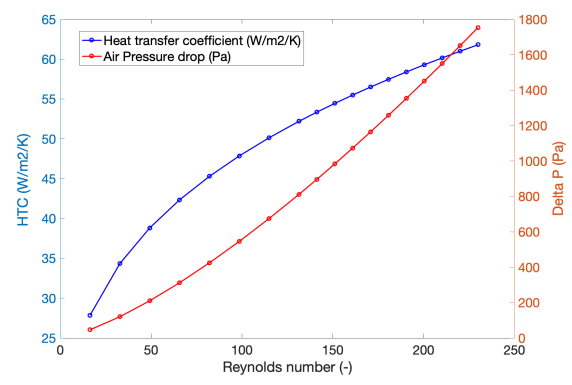

(b) $h-\Delta P$

Figure 10: (a) Friction factor and Colburn number as a function of the Reynolds number calculated in the minimum flow section (louver section). (b) Heat transfer coefficient and pressure drop as a function of the Reynolds number calculated in the minimum flow section (louver section).

where $K_{q}, K_{p}, K_{w}$ are the flow, pressure and power coefficients, $D$ is the fan diameter, $N$ is the fan speed.

\section{Base control strategy}

The main actuators of the proposed Rankine system have been already mentioned in Sec.2.3. In this section the control strategy that is adopted for each actuator is described.

The linear models that are adopted for control are Single Input Single Output (SISO) that can be written in the form:

$$
\begin{aligned}
& \dot{x}=f(x, y) \\
& y=g(x, u),
\end{aligned}
$$

where $x \in \mathcal{R}^{n}$ is the state, $u \in \mathcal{R}^{n_{u}}$ the input variable and $y \in \mathcal{R}^{n_{y}}$ is the output variable and $f$ and $g$ are two vector functions with appropriate dimension.

Considering the control of the thermodynamic conditions of the working fluid at the inlet of the expander, the variable $u$ is represented by the pump speed and the variable $y$ is represented by the specific variable that is necessary to keep close to a set-point by acting on the pump speed.

The same approach is not applicable, for the presented architecture and the purpose of control, for the control of the thermodynamic conditions at the outlet of the condenser; in this case, the considered system is treated as a Multiple Input Single Output (MISO), as the manipulated variables are the rotating fan speed and the condensation pressure. Sec.4.3 shows how the problem is treated in order to ensure good control performance and power production. 


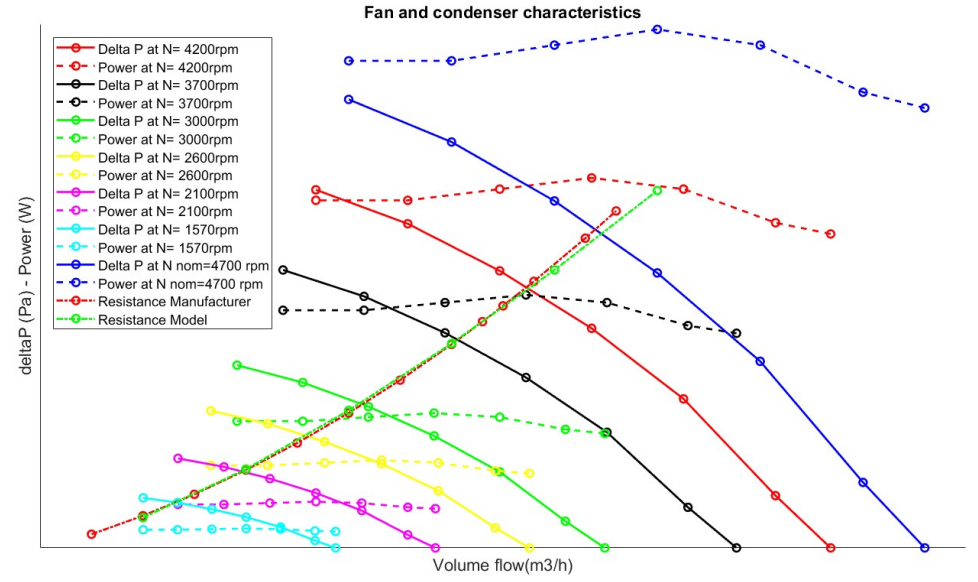

Figure 11: Fan static pressures and power demands at different fan speeds and condenser pressure drops. The condenser pressure drop is predicted (green resistance line) with an error of $1 \%$ with respect to the supplier data (red resistance line).

\subsection{Superheat control}

The control of the superheat $S H_{\text {su,exp }}$ is necessary to control the thermodynamic conditions of the working fluid at the inlet of the expander, ensuring performance and safe operation of the component.

$$
S H_{s u, e x p}=T_{s u, e x p}-T_{s a t}\left(P_{e v}\right) .
$$

The superheat must be kept at a positive value in order to ensure vapor supply to the expander. The set-point is tracked varying the pump speed, consequently the working fluid mass flow rate is changed.

In this work, a Multi Model PI controller is used, where the structure of the algorithm has been presented by (Grelet, 2016). The determination of the parameters of the PI control is usually a key aspect to ensure high performance of the controller; meta-heuristic approaches are available for such a goal, as the novel grouped grey world optimizer and democratic joint operation algorithm proposed in (Yang et al., 2017) and (Yang et al., 2018) and applied to a wind energy conversion system. In both cases, those strategies, according to the results, allow a larger amount of wind energy, lower tracking error and control costs with respect to other algorithms.

In this work, a step and response experimental campaign has been performed in different operating points chosen using the algorithm proposed in (Galuppo et al., 2018a). In general, it is possible to write a discrete nonlinear model in the form (24), for one operating point. 


$$
\left\{\begin{array}{l}
x(k+1)=f(x(k), u(k)) \\
y(k)=g(x(k), u(k))
\end{array}\right.
$$

with $y \in \mathcal{R}^{n_{y}}$ the measured outputs, $u \in \mathcal{R}^{n_{u}}$ the measured inputs. A set of local linear models can be written as (25)

$$
\left\{\begin{array}{l}
x_{i}(k+1)=f_{i}\left(x_{i}(k), u(k)\right) \\
y_{i}(k)=g_{i}\left(x_{i}(k), u(k)\right)
\end{array}\right.
$$

each tuned to approximate (24) around an operating point. To obtain a global model, these local models have to be combined. The chosen approach is to construct a global model by linearly interpolating between the local models:

$$
\hat{y}(k)=\sum_{i=1}^{N} w_{i}(k) y_{i}(k)
$$

Here, the weights $w_{i}$ provide a time-varying adaptation and they are calculated according to Bayesian estimators as in (Aufderheide and Bequette, 2003). As shown in (Galuppo et al., 2018a), the relationship between pump actuator and superheat at evaporator outlet can be modeled locally by a low order linear system around an equilibrium point; a first order plus time delay model (FOPTD) is used (27)

$$
\frac{y_{u}(s)}{u(s)}=\frac{G_{u}}{\left(1+\tau_{u} s\right)} e^{-L_{u} s}
$$

The Bayesian estimator identifies a single set of FOPTD parameters that are composed of an equivalent static gain $G_{e q}$, time constant $\tau_{e q}$ and delay $\theta_{e q}$ and computed as in (28).

$$
\left\{\begin{array}{l}
G_{e q}=\sum_{i=1}^{N} w_{i, k} G_{i} \\
\tau_{e q}=\sum_{i=1}^{N} w_{i, k} \tau_{i} \\
\theta_{e q}=\sum_{i=1}^{N} w_{i, k} \theta_{i}
\end{array}\right.
$$

where $N$ is the total number of FOPTD models (37 in the current application). In Tab. 2, the equivalent mean values of the FOPTD time varying parameters over a complete road cycle are shown, as well as their standard deviations.

Table 2: FOPTD parameters, statistical analysis.

\begin{tabular}{ccccccc} 
Weighting scheme & $\bar{G}$ & $\bar{\tau}$ & $\bar{\theta}$ & $\sigma(G)$ & $\sigma(\tau)$ & $\sigma(\theta)$ \\
\hline Bayesian & -0.37 & 9.10 & 0.54 & $2.3 \mathrm{e}-3$ & $3.6 \mathrm{e}-2$ & $3.9 \mathrm{e}-4$ \\
\hline
\end{tabular}

For each time step, a PID controller is tuned using the equivalent FOPTD model, applying the SIMC approach proposed by (Skogestad, 2006), where one 
additional tuning parameter $\tau_{c}$ is required to govern the desired closed-loop time response (29).

$$
\left\{\begin{array}{l}
K_{p}=\frac{1}{G_{e q}} \frac{\tau_{e q}}{\tau_{c} \theta_{e q}} \\
T_{I}=\min \left(\tau_{e q}, 4\left(\tau_{c}+\theta_{e q}\right)\right) \\
T_{d}=0
\end{array}\right.
$$

Fig. 12 shows the effect of the change of operating point of the engine on the mass flow rate of working fluid and, consequently on pressure and temperature at the inlet of the expansion machine; the controller of the superheat at the inlet of the expander reacts quickly and keep the actual value of superheat very close to the set-point.
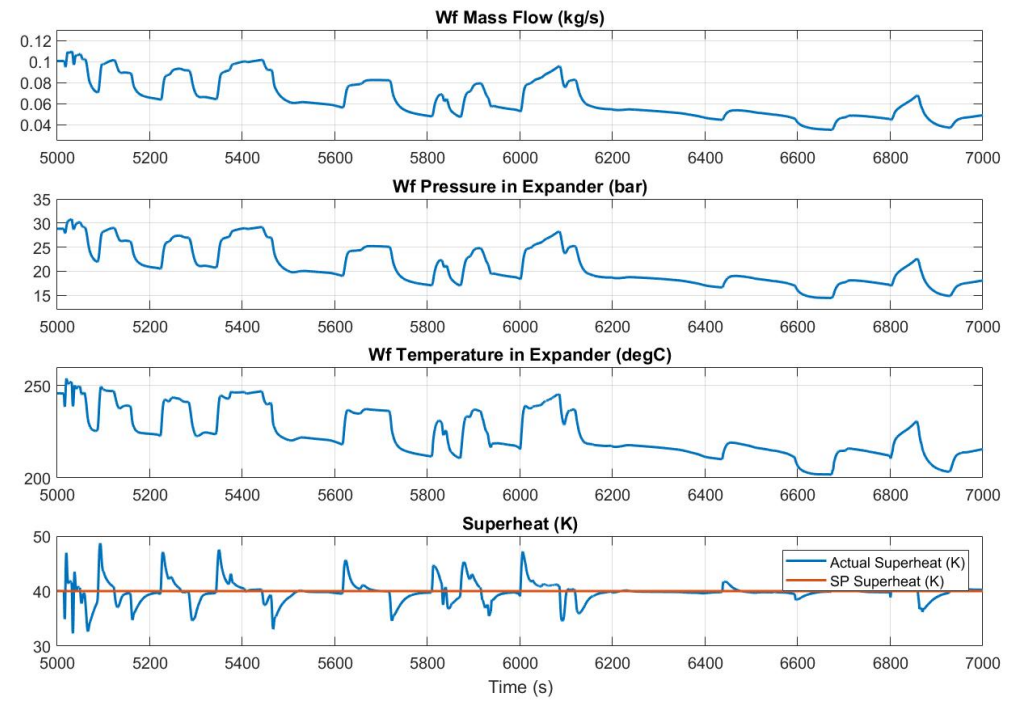

Figure 12: Superheat, depending on temperature and pressure, control acting on pump speed and consequently on the mass flow rate of the working fluid.

\subsection{Expander speed and exhaust by-pass control}

The exhaust by-pass valve is a safety component that reduces the thermal power input to the Rankine system in case of over-temperature or over-pressure detected in the working fluid. The control of the exhaust by-pass valve is mapbased and by-pass opens as soon as the maximum temperature of the working fluid reaches $240^{\circ} \mathrm{C}$. Fig. 14 shows how the exhaust by-pass is fully closed in the phases that are characterized by the working fluid maximum temperature below $240{ }^{\circ} \mathrm{C}$ and the progressive opening of the by-pass as soon as the working 
fluid temperature is larger than $240{ }^{\circ} \mathrm{C}$.

The expander speed influences the high pressure loop of the Rankine system (17) and the tracking of an optimal set-point leads to the operation of the expansion machine within the points that are characterized by highest efficiency values (8); the expander speed varies between 1000 and $3500 \mathrm{rpm}$, the exhaust bypass value varies from 0 , by-pass completely opened, to 100 , by-pass completely closed). The controller is a PI (Proportional-Integral controller) that varies the expander speed to track the evaporation pressure set-point. The controller is tuned using the IMC technique (Rivera et al., 1986) and the computation of the gain and time constant is based on step and response campaign on the expander model. The tracking results are shown in Fig 13; the evaporation pressure setpoint varies according to the working fluid mass flow and the expander speed regulation ensures the tracking of the set-point.
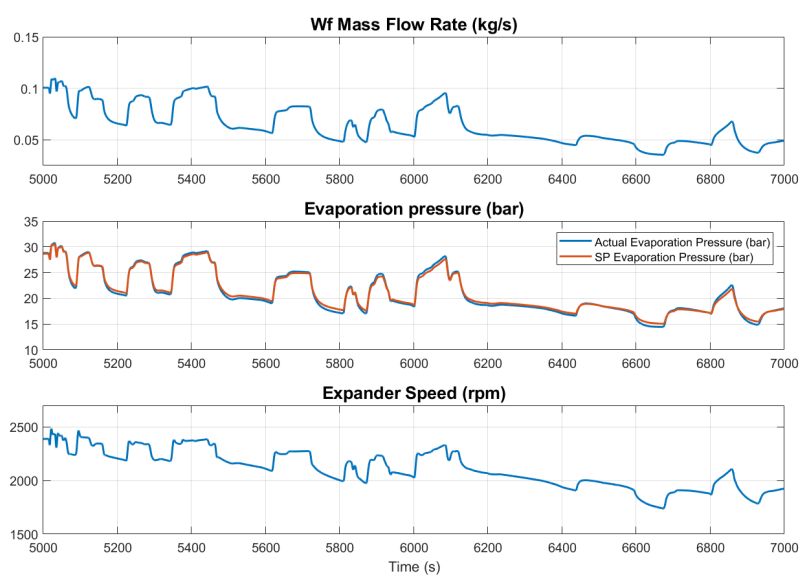

Figure 13: Evaporation pressure control; the evaporator pressure set-point is computed for each time step as a function of the working fluid mass flow rate.

\subsection{Subcooling control}

The subcooling is an useful variable to establish the phase of the fluid at the outlet of the condenser (30).

$$
S C_{e x, \text { cond }}=T_{\text {sat }}\left(P_{\text {cond }}\right)-T_{\text {ex }, \text { cond }} .
$$

The choice of set-point of the subcooling at the outlet of the condenser is, at a first sight, straightforward. It is clear that, a higher subcooling value leads to higher energy demand of the cooling actuators, with a negative impact on the energy balance of the whole Rankine system. In the same time, a higher subcooling strongly impacts on the efficiency of the thermodynamic cycle, by 
Figure 14: Exhaust by-pass control depending on the maximum working fluid temperature admitted in the Rankine system.

reducing it. Therefore, the main interest is to keep the subcooling particularly low, in order to reduce the impact on the energy balance and efficiency. Unfortunately, in real experiments, two main problems arise when reducing the subcooling at the outlet of the condenser (inlet of the pump):

- When the subcooling is particularly low and the working fluid is very close to the saturation conditions, local phenomena of condensation, with formations of bubbles can appear. This situation is particularly dangerous for the correct operation of the pump, that requires a liquid fluid at the inlet section.

- The use of complicated controllers is forbidden in automotive applications. Therefore, the actual value of the subcooling deviates from the set-point in highly transient conditions and choosing a too low value of subcooling would increase the risk of having a two-phase fluid at the inlet of the pump.

Considering the necessity to reduce the subcooling and, in the same time, ensure a positive actual value in all the possible conditions, a subcooling set-point $S C_{S P}=9 K$ is chosen and a controller is designed.

The Bayesian estimators and the SIMC technique (presented in Sec. 4.1) have been used to determine the parameters of the PID controllers of the subcooling at the outlet of the condenser (a step and response campaign on the condenser model has been performed). However the fan speed can reach a maximum value at high loads, consequently the air flow provided to the condenser is not enough to reach the complete condensation of the working fluid.

In order to face the high loads and to ensure a subcooled liquid supply to the pump, the condensation pressure has to be raised. This leads to the fact that 
the mean temperature difference between the cooling air and the working fluid is higher; consequently a lower air flow rate to the condenser is necessary to ensure the subcooling set-point at the inlet of the pump and, in the same time, the gross power production of the expander reduces consistently (more details in Sec. 5).

In this work, three different strategies for the control of the subcooling at the outlet of the condenser are presented:

1. PID controller acting on the fan speed and constant condensation pressure

2. PID controller acting on the fan speed, computing the desired condensation pressure setting a constant pressure ratio $P R$ between the inlet and outlet of the expansion machine

3. PID controller acting on the fan speed and an optimized strategy for the condensation pressure taking into account the temperature of the air flow at the inlet of the condenser. The controller scheme in Fig. 15 shows the optimization block, that has as output the optimal condensation pressure $P_{\text {cond }} ; G_{c, S C}(s)$ and $G_{p}(s)$ are the subcooling controller and the plant transfer functions. The vector $x_{p}$ is the vector of states, that is actively used in the computation of the optimal condensation pressure.

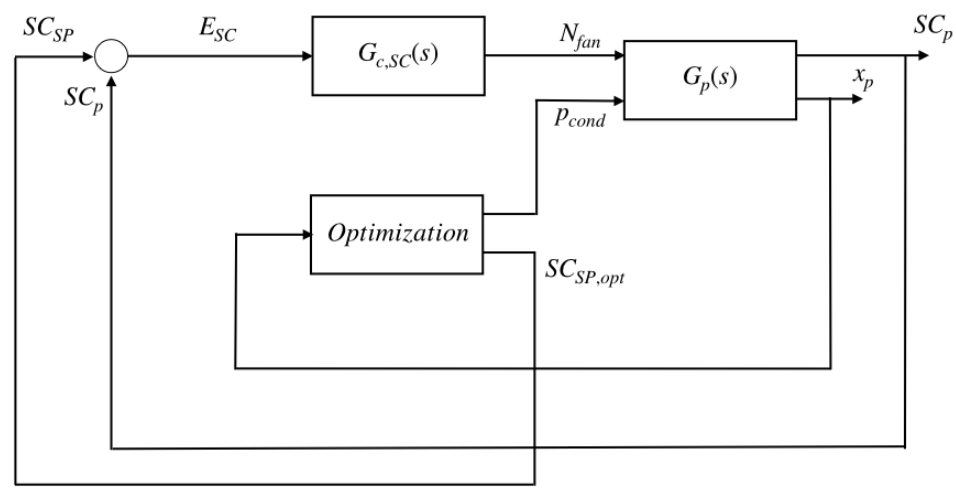

Figure 15: Optimal control strategy of the subcooling.

The same approach adopted in Sec. 4.1 to tune the PID controller of the subcooling at the inlet of the pump has been applied.

The condensation pressure can be modified by pressurizing the low pressure side of the Rankine system using the air storage at 7 bar that is available in the vehicle; an increase of the condensation pressure determines an increase of the subcooling (30) with faster dynamics than the fan speed. In the case of strategy 2 , the desired condensation pressure is calculated on-line considering the evaporation pressure and a fixed pressure ratio, that has been identified with the value of $P R=9$, according to the efficiency table of the current expander (Fig. $8)$. This solution is adopted to ensure the tracking of the subcooling at the inlet 
of the pump and, in the same, working with high values of expander efficiency. In the case of strategy 3 , the condensation pressure value to adopt is varied according to a model based optimization, that ensures the tracking of the subcooling set-point and improves the performance of the system (1) with respect to the strategy 1 and 2. A simplified analytical model has been developed, in order to compute the net power produced as a function of few variables that will be further available as measurements in the following experimental campaign. These known variables are listed hereafter and the complete equation of the net power produced as a quadratic form with respect to the fan speed $N_{f a n}$ and condensation pressure $p_{\text {cond }}$ is presented in (31):

- Pressure and temperature at the inlet of the expander

- Pressure and temperature at the outlet of the condenser

- Pump, expander and fan speed

$$
\dot{W}_{\text {net }}=A_{1} N_{\text {fan }}^{2}+A_{2} p_{\text {cond }}^{2}+B_{1} N_{\text {fan }}+B_{2} p_{\text {cond }}+C .
$$

where the coefficients $A_{1}, A_{2}, B_{i}, B_{2}$ and $C$ are depending on the plant state vector $x_{p}$, consequently they are variable in time.

The analytical model predicts the net power output as a function of the fan speed and condensation pressure and a trade-off between the two variables can be found (in other words, a trade-off between the fan power demand and the expander power production); therefore strategy 3 represents a solution that maximizes the net power, taking into account the temperature of the air at the inlet of the condenser (results in Sec. 5).

The comparison of the three strategies in terms of subcooling control is shown in Fig. 16, considering the ambient cooling air set at $40{ }^{\circ} \mathrm{C}$ at the inlet of the condenser and in Fig. 17, considering the ambient cooling air set at $20^{\circ} \mathrm{C}$. The subcooling set-point is well tracked in most of the road cycle phases, except adopting the strategy 1 , that, in particular during the phases characterized by low thermal load in the condenser and ambient cooling air set at $20^{\circ} \mathrm{C}$, has not the property to adapt (reduce in this case) the condensation pressure when the fan speed saturated to its lowest value; consequently the actual value of the subcooling is higher than the set-point. As for the strategies 2 and 3 , it is possible to notice that a different trade-off between condensation pressure and fan speed can be found ensuring the tracking of the same subcooling set-point. As for ambient cooling air set at $40{ }^{\circ} \mathrm{C}$, the strategy 3 leads to a global increase of the condensation pressure and a reduction of the fan speed, as a result of the fact that the high temperature of the cooling air at the inlet of the condenser. This result is physically logical, as for higher temperature of the air at the inlet of the condenser, the thermal exchange in the condenser is less performing and it is more convenient, from an energetic point of view, to pressurize the condensing side of the system, reducing in the same time the expander power produced and the fan power demand and eventually increasing the net power produced. 

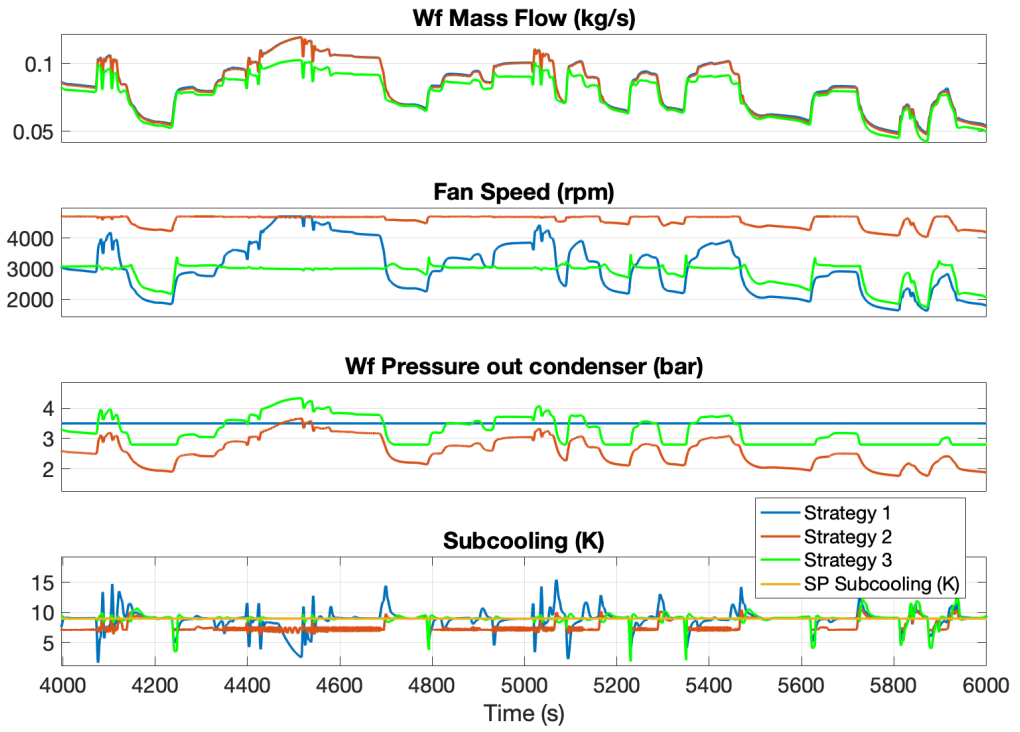

Figure 16: Comparison of the three strategies for subcooling control setting the air cooling temperature at $40^{\circ} \mathrm{C}$.

On the other hand, as for ambient cooling air set at $20^{\circ} \mathrm{C}$, the strategy 3 leads to an increase of the fan speed and a reduction of the condensation pressure with respect to the strategy 2 (Fig. 17), as it is more favorable to increase the air flow rate to the condenser when cooling air temperature is lower. The results in terms of net power produced by the Rankine system are shown in Sec. 5 .

\section{Road cycle results}

Road cycle simulations, using cyclopentane as working fluid, in a highly transient environment are necessary to estimate the potential of the Rankine technology in long-haul heavy-duty trucks. The engine is a 13-liter non-EGR and the road cycle, Frankfurt-Koblenz lately called FK, is characterized by the average thermal power of $50 \mathrm{~kW}$, with important variability of the heat source in terms of temperature and mass flow of the exhaust gas, due to braking phases over the 150 minutes of the cycle duration, as it is shown in Fig. 18.

For the three strategies previously presented and air cooling temperature set at $40{ }^{\circ} \mathrm{C}$ and $20{ }^{\circ} \mathrm{C}$ respectively, Fig. 19 and 20 show the net and expander power produced and the pump and fan power demands; the graphs confirm that the strategy 3 is able to improve the net power produced by the strategy 1 and 2, respecting the constraint represented by the subcooling set-point (Fig. 16 and 17). In order to compare the different strategies along the complete road cycle, 
Figure 17: Comparison of the three strategies for subcooling control setting the air cooling temperature at $20^{\circ} \mathrm{C}$.
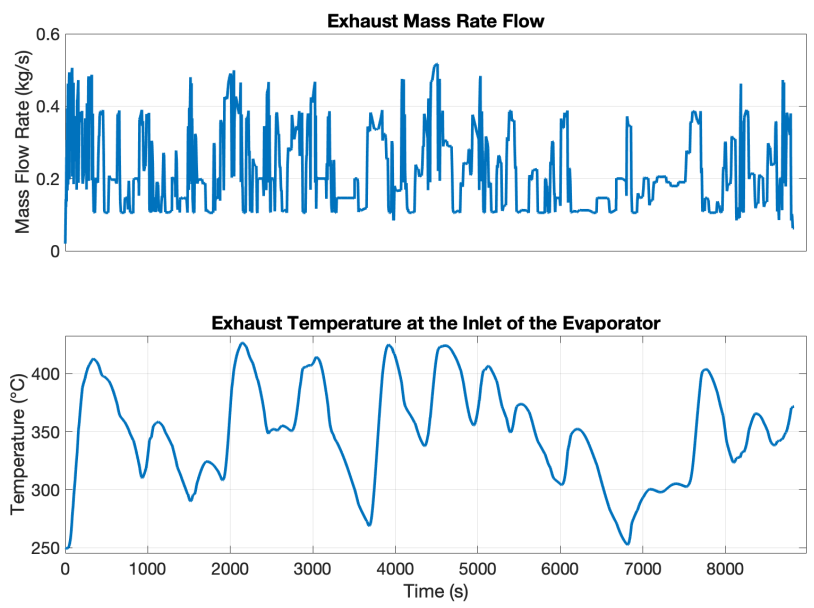

Figure 18: Exhaust mass flow rate and temperature at the inlet of the Rankine evaporator along the whole FK road cycle.

mean values are shown, normalizing each value with respect to the highest value of the expander gross power produced (Fig. 21); the graph confirms that the strategy 3 is able to improve the net power produced by the strategy 1 and 2, 
setting the air cooling temperature at 20 and $40{ }^{\circ} \mathrm{C}$. In particular, as for air cooling temperature set to $20{ }^{\circ} \mathrm{C}$, the net power is improved by 8 and $3 \%$ with respect to the strategies 1 and 2; as for air cooling temperature set to $40{ }^{\circ} \mathrm{C}$, the net power is improved by 12 and $3 \%$ with respect to the strategies 1 and 2 .
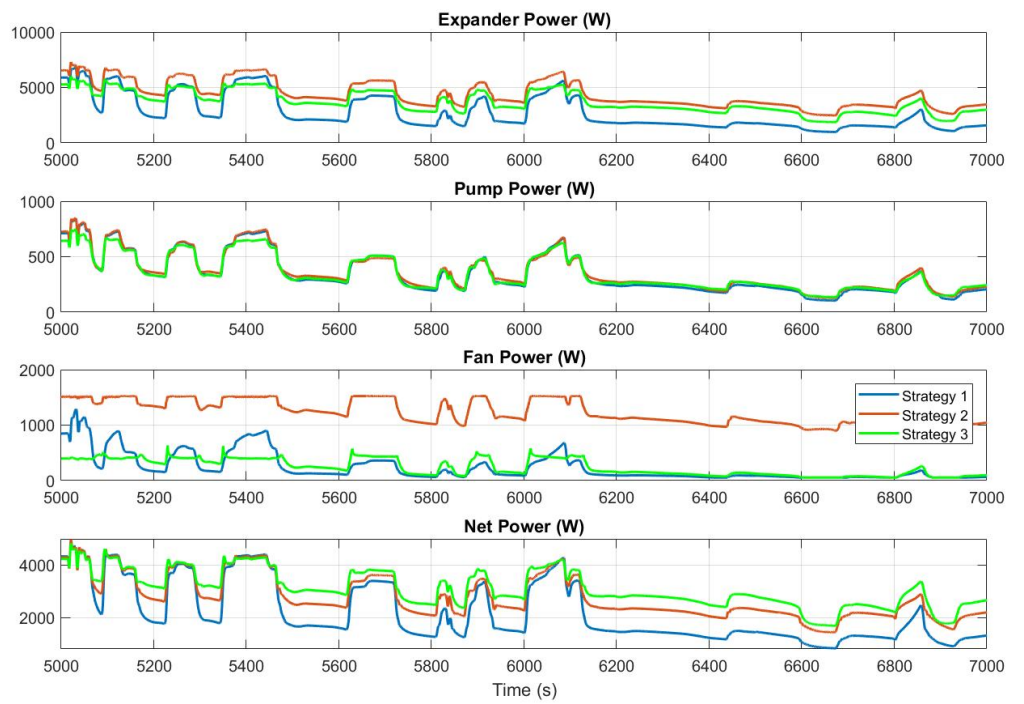

Figure 19: Comparison of the gross power produced and pump and fan power demands setting the air cooling temperature at $40^{\circ} \mathrm{C}$.

\section{Conclusion}

This work presented the complete modeling of a Rankine Cycle based waste heat recovery system for long-haul heavy-duty trucks. The proposed architecture recovers the energy from the exhaust gas and used ambient air as heat sink; this solution does not impact the operation of the cooling system of the vehicle, but in the same time it does not take advantage of any RAM air intake.

The main results can be summarized as follows:

- Evaporator and direct condenser models are validated according to experimental results and data suppliers.

- The manipulation of the condensation pressure using the current architecture and cyclopentane as working fluid is necessary, in order to track the lowest subcooling admitted in the current application and, in the same time, ensure high standard of performance. 
Figure 20: Comparison of the gross power produced and pump and fan power demands setting the air cooling temperature at $20^{\circ} \mathrm{C}$.

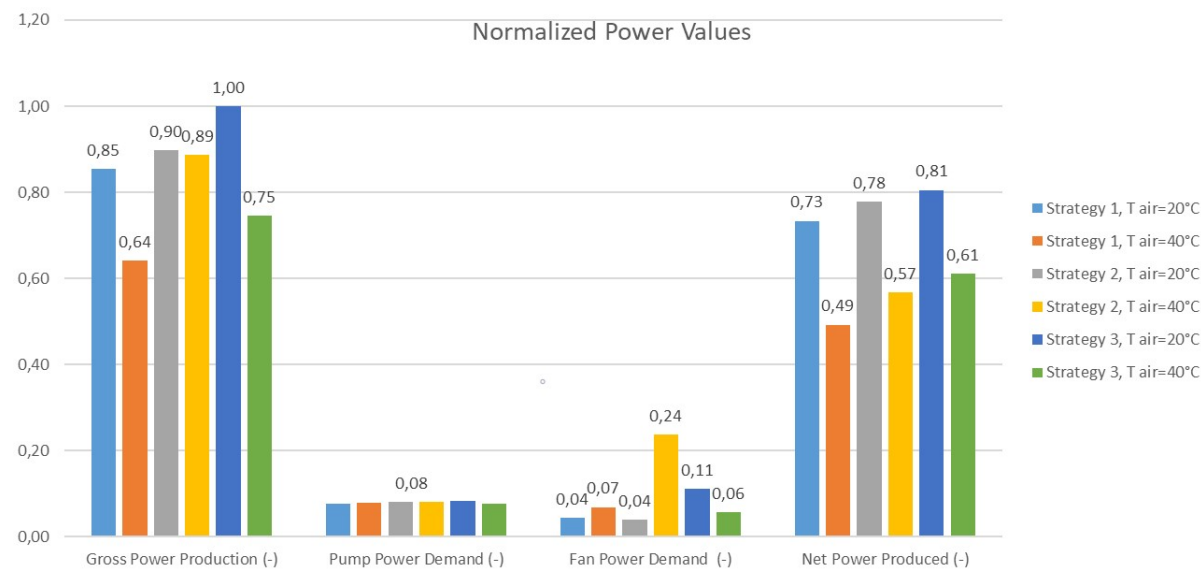

Figure 21: Comparison of the three strategies in terms of power produced and demand; the strategy 3 is able to increase the net power produced by the Rankine system, reducing the fan power demand when the air cooling temperature is $40^{\circ} \mathrm{C}$ and increasing the fan power demand when the air cooling temperature is $20^{\circ} \mathrm{C}$. Comparison of the gross power produced and pump and fan power demands setting the air cooling temperature at $20^{\circ} \mathrm{C}$. All the values are normalized with respect to the gross power in strategy 3 and air cooling temperature $20^{\circ} \mathrm{C}$. 
- The model-based optimization (strategy 3 ) improves the net power production of the system by 8 and $3 \%$ with respect to strategies 1 and 2 and air cooling temperature set at $20{ }^{\circ} \mathrm{C}$.

- The model-based optimization (strategy 3 ) improves the net power production of the system by 12 and $3 \%$ with respect to strategies 1 and 2 and air cooling temperature set at $40{ }^{\circ} \mathrm{C}$.

- In the case of the air cooling temperature $20^{\circ} \mathrm{C}$, the optimization (strategy 3 ) leads to an increase of the fan speed and a reduction of the condensation pressure with respect to strategies 1 and 2 .

- In the case of the air cooling temperature $40{ }^{\circ} \mathrm{C}$, the optimization (strategy 3 ) leads to an decrease of the fan speed and an increase of the condensation pressure with respect to strategies 1 and 2 .

\section{References}

Allain, M., Atherton, D., Gruden, I., Singh, S., and Sisken, K. (2012). Daimler ' s super truck program ; $50 \%$ brake thermal efficiency 2012 directions in engine-efficiency and emissions.

Aufderheide, B. and Bequette, B. W. (2003). Extension of dynamic matrix control to multiple models. Computers and Chemical Engineering, 27(8-9):10791096.

Chan Kang, H. and Jun, G. W. (2011). Heat transfer and flow resistance characteristics of Louver fin geometry for automobile applications. Journal of Heat Transfer, 133(10):101802(6pages).

Chang, Y. J. and Wang, C. C. (1997). A generalized heat transfer correlation for louver fin geometry. International Journal of Heat and Mass Transfer, $40(3): 533-544$.

Di Battista, D., Di Bartolomeo, M., Villante, C., and Cipollone, R. (2018). On the limiting factors of the waste heat recovery via ORC-based power units for on-the-road transportation sector. Energy Conversion and Management, 155:68-77.

Dickes, R. (2019). Charge-sensitive methods for the off-design performance characterization of organic Rankine cycle (ORC) power systems. PhD thesis, University of Liège, Belgium.

El Hajal, J., Thome, J. R., and Cavallini, A. (2003). Condensation in horizontal tubes, part 1: two-phase flow pattern map. International Journal of Heat and Mass Transfer, 46(18):3349-3363. 
Galuppo, F., Dufour, P., Nadri, M., Reiche, T., and Lemort, V. (2018a). Experiment design for waste heat recovery modeling in heavy duty trucks. IFACPapersOnLine, 51(31):726-731.

Galuppo, F., Reiche, T., Lemort, V., Dufour, P., Nadri, M., and Huin, X. (2018b). Waste heat recovery (WHR) assessment in complete truck simulation environment. In 2018 SIA POWERTRAIN conference, May 2018, Rouen, France.

Grelet, V. (2016). Rankine cycle based waste heat recovery system applied to heavy duty vehicles: topological optimization and model based control. PhD thesis, University de Lyon, France and University of Liège, Belgium.

Grelet, V., Dufour, P., Nadri, M., Reiche, T., and Lemort, V. (2015). Modeling and control of Rankine based waste heat recovery systems for heavy duty trucks. In IFAC-PapersOnLine, volume 48, pages 568-573.

Guillaume, L. and Lemort, V. (2019). Comparison of different ORC typologies for heavy-duty trucks by means of a thermo-economic optimization. Energy, 182:706-728.

Hountalas, D. T., Mavropoulos, G. C., Katsanos, C., and Knecht, W. (2012). Improvement of bottoming cycle efficiency and heat rejection for HD truck applications by utilization of EGR and CAC heat. Energy Conversion and Management, 53(1):19-32.

Incropera, F., Dewitt, D., Bergman, T., and Lavine, A. (1993). Fundamentals of heat and mass transfer. Number 1986.

Kandlikar, S. G. (2002). Fundamental issues related to flow boiling in minichannels and microchannels. Experimental Thermal and Fluid Science, 26(24):389-407.

Kanefsky, P., Nelson, V., and Ranger, M. (1999). A systems engineering approach to engine cooling design. SAE Technical Papers, Paper 1999-01-3780.

Karvountzis-Kontakiotis, A., Pesiridis, A., Zhao, H., Alshammari, F., Franchetti, B., Pesmazoglou, I., and Tocci, L. (2017). Effect of an ORC waste heat recovery system on diesel engine fuel economy for off-highway vehicles. SAE Technical Papers, 2017-01-0136.

Koeberlein, D. (2012). Cummins SuperTruck program relevance - Program objectives. Cummins.

Lopes, J., Douglas, R., McCullough, G., O'Shaughnessy, R., Hanna, A., Rouaud, C., and Seaman, R. (2012). Review of Rankine cycle systems components for hybrid engines waste heat recovery. SAE Technical Paper Series, 2012-01-1942. 
Lutz, R., Motisi, G., and Bruemmer, R. (2015). Device and method for recovering waste heat energy and a utility vehicle. United States Patent, DE102015016783A1.

Peralez, J. (2015). Recuperation d'énergie par cycle de Rankine à bord d'un véhicule : commande et gestion d'énergie. PhD thesis, University de Lyon, France.

Peralez, J., Tona, P., Lepreux, O., Sciarretta, A., Voise, L., Dufour, P., and Nadri, M. (2013). Improving the control performance of an organic rankine cycle system for waste heat recovery from a heavy-duty diesel engine using a model-based approach. Proceedings of the IEEE Conference on Decision and Control, pages 6830-6836.

Preißinger, M., Schwöbel, J. A. H., Klamt, A., and Brüggemann, D. (2017). Multi-criteria evaluation of several million working fluids for waste heat recovery by means of Organic Rankine Cycle in passenger cars and heavy-duty trucks. Applied Energy, 206:887-899.

Quoilin, Sylvain (2011). Sustainable energy conversion through the use of Organic Rankine Cycles for waste heat recovery and solar applications. PhD Thesis, University of Liège, Belgium.

Rivera, D., Morari, M., and Skogestad, S. (1986). Internal Model Control. 4. PID Controller Design. American Chemical Society, 25:252-265.

Rodriguez, F. (2018). The European Commission's Proposed CO2 Standards For Heavy-Duty Vehicles. IcCT.

Scaccabarozzi, R., Tavano, M., Invernizzi, C. M., and Martelli, E. (2018). Comparison of working fluids and cycle optimization for heat recovery ORCs from large internal combustion engines. Energy, 158:396-416.

Seitz, D., Gehring, O., Bunz, C., Brunschier, M., and Sawodny, O. (2016). Design of a nonlinear, dynamic feedforward part for the evaporator control of an Organic Rankine Cycle in heavy duty vehicles. IFAC-PapersOnLine, $49(11): 625-632$.

Shah, M. M. (1976). New correlation for heat transfer during boiling flow through pipes. ASHRAE Transactions, 2407:66-86.

Shah, M. M. (1979). A general correlation for heat transfer during film condensation inside pipes. International Journal of Heat and Mass Transfer, $22(4): 547-556$.

Skogestad, S. (2006). Tuning for Smooth PID Control with Acceptable Disturbance Rejection. Industrial \& Engineering Chemistry Research, 45(23):78177822 . 
Torregrosa, A., Galindo, J., Dolz, V., Royo-Pascual, L., Haller, R., and Melis, J. (2016). Dynamic tests and adaptive control of a bottoming organic Rankine cycle of IC engine using swash-plate expander. Energy Conversion and Management, 126:168-176.

Vaja, I. and Gambarotta, A. (2010). Internal Combustion Engine (ICE) bottoming with Organic Rankine Cycles (ORCs). Energy, 35(2):1084-1093.

Wang, T., Zhang, Y., Zhang, J., Shu, G., and Peng, Z. (2013). Analysis of recoverable exhaust energy from a light-duty gasoline engine. Applied Thermal Engineering, 53(2):414-419.

Winterton, R. H. S. (1998). Where did the Dittus and Boelter equation come from? International Journal of Heat and Mass Transfer, 41(4-5):809-810.

Yang, B., Yu, T., Shu, H., Zhang, X., Qu, K., and Jiang, L. (2018). Democratic joint operations algorithm for optimal power extraction of PMSG based wind energy conversion system. Energy Conversion and Management, 159:312-326.

Yang, B., Zhang, X., Yu, T., Shu, H., and Fang, Z. (2017). Grouped grey wolf optimizer for maximum power point tracking of doubly-fed induction generator based wind turbine. Energy Conversion and Management, 133:427443.

Zhao, R., Zhang, H., Song, S., Tian, Y., Yang, Y., and Liu, Y. (2018). Integrated simulation and control strategy of the diesel engine-organic Rankine cycle (ORC) combined system. Energy Conversion and Management, 156(100):639-654. 
Click here to access/download main.tex

\section{LaTeX Source Files} main.tex 